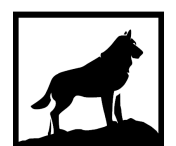

Michigan

Technological

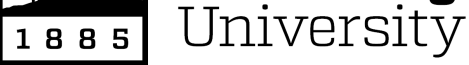

Michigan Technological University

Digital Commons @ Michigan Tech

CHARACTERIZING THE SPATIAL AND TEMPORAL ASPECTS OF SUBSTRATES, CHANNEL MORPHOLOGY, AND LARGE WOOD IN FORESTED STREAMS IN THE WESTERN UPPER PENINSULA, MICHIGAN.

Brian M. Danhoff

Michigan Technological University, bmdanhof@mtu.edu

Copyright 2020 Brian M. Danhoff

Recommended Citation Danhoff, Brian M., "CHARACTERIZING THE SPATIAL AND TEMPORAL ASPECTS OF SUBSTRATES, CHANNEL MORPHOLOGY, AND LARGE WOOD IN FORESTED STREAMS IN THE WESTERN UPPER PENINSULA, MICHIGAN.", Open Access Dissertation, Michigan Technological University, 2020. https://doi.org/10.37099/mtu.dc.etdr/1033 


\title{
CHARACTERIZING THE SPATIAL AND TEMPORAL ASPECTS OF SUBSTRATES, CHANNEL MORPHOLOGY, AND LARGE WOOD IN FORESTED STREAMS IN THE WESTERN UPPER PENINSULA, MICHIGAN.
}

By

Brian M. Danhoff

\begin{abstract}
A DISSERTATION
Submitted in partial fulfillment of the requirements for the degree of DOCTOR OF PHILOSOPHY

In Biological Sciences
\end{abstract}

MICHIGAN TECHNOLOGICAL UNIVERSITY

2020

(C) 2020 Brian M. Danhoff 
This dissertation has been approved in partial fulfillment of the requirements for the Degree of DOCTOR OF PHILOSOPHY in Biological Sciences.

Department of Biological Sciences

\author{
Thesis Advisor: Dr. Casey J Huckins \\ Committee Member: $\quad$ Dr. Amy M. Marcarelli \\ Committee Member: $\quad$ Dr. Joseph W. Wagenbrenner \\ Committee Member: $\quad$ Dr. Troy G. Zorn \\ Department Chair: Dr. Chandrashekhar P. Joshi
}




\section{Table of Contents}

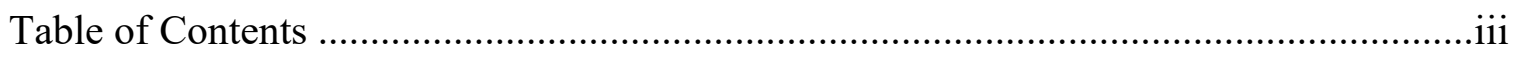

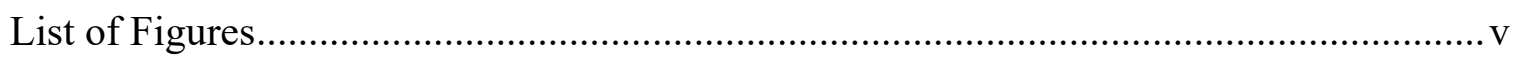

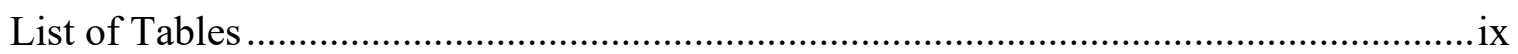

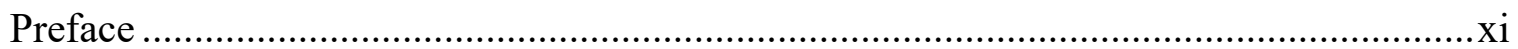

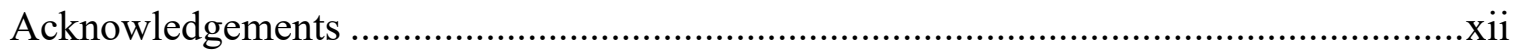

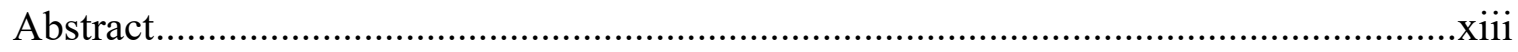

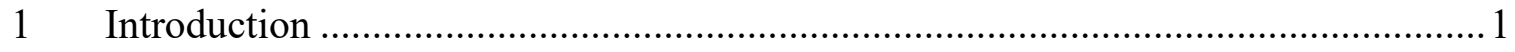

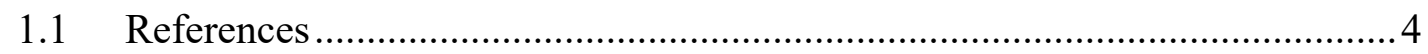

2 Modeling submerged fluvial substrates with Structure from Motion

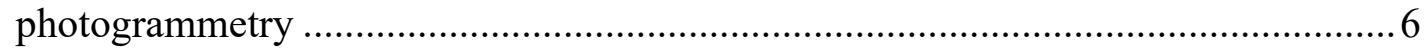

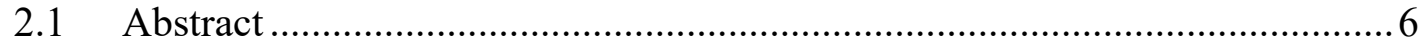

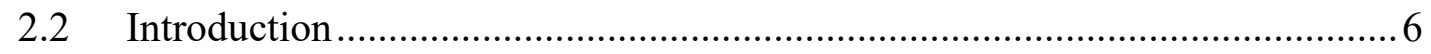

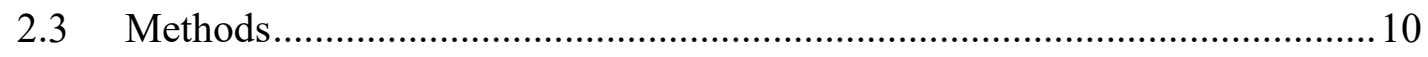

2.3.1 Laboratory Streambed ........................................................... 10

2.3.2 Image Acquisition \& Analysis ................................................... 11

2.3.3 SfM Change Detection \& Precision Analysis: ............................... 13

2.3.4 Assessment of Natural Streambed:............................................... 14

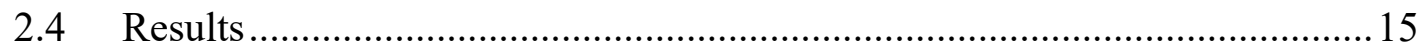

2.4.1 Laboratory Streambed .......................................................... 15

2.4.2 Natural Streambed ................................................................. 17

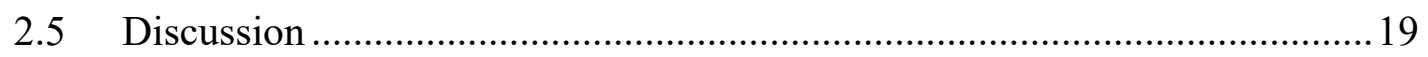

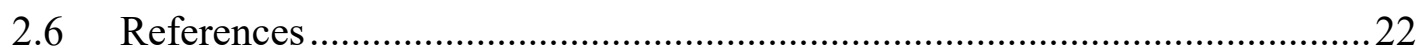

3 Temporal dynamics of large wood, stream channel morphology, and substrates in a selectively logged watershed of the western Upper Peninsula, Michigan. .............29

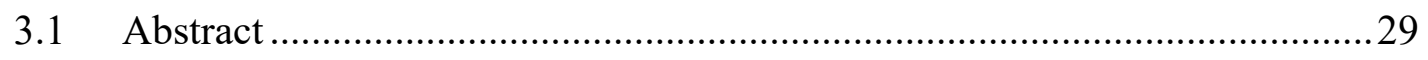

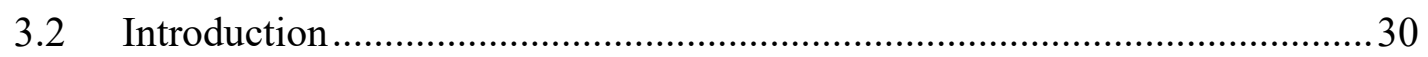

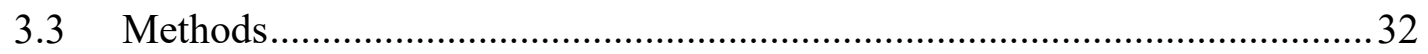

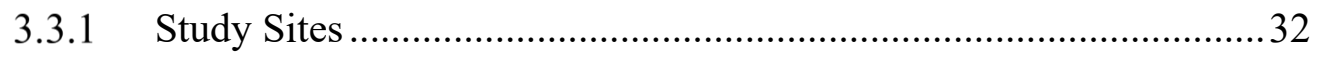

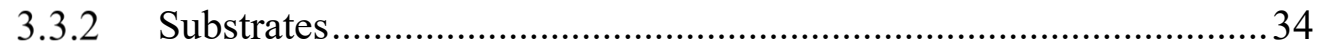

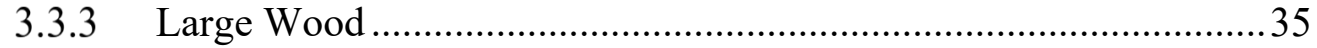

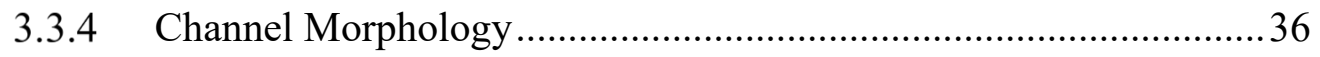

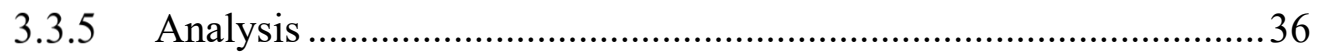

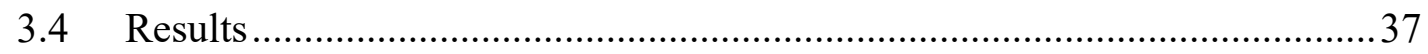




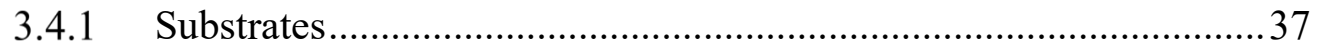

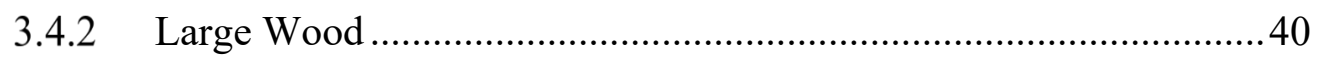

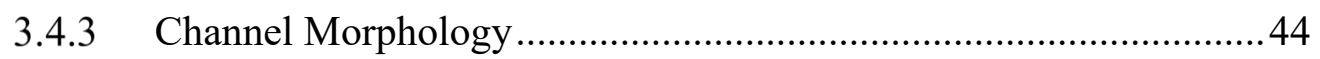

3.4.4 Differences Between Sampling Periods ............................................. 45

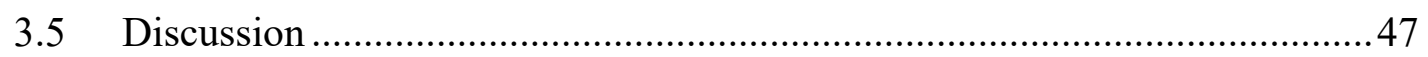

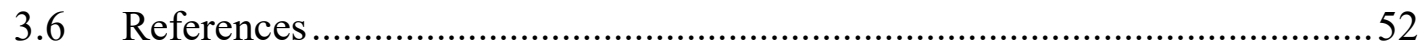

4 Associations between large wood and streambed complexity in headwater streams

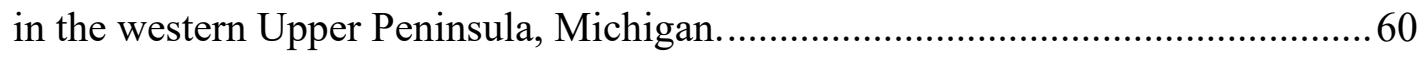

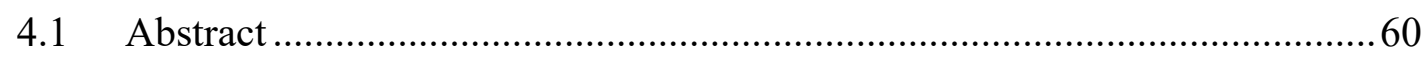

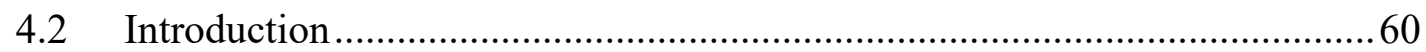

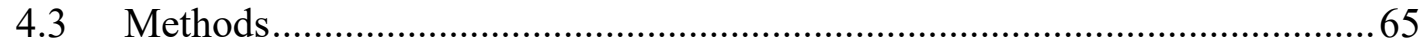

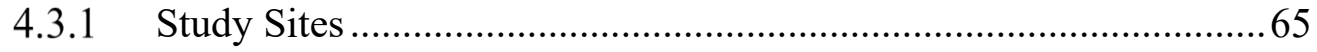

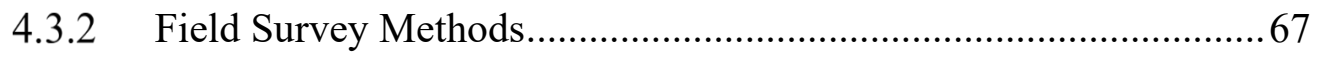

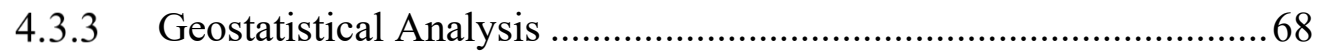

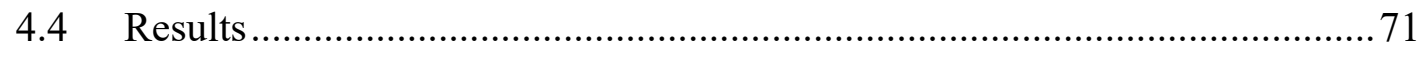

4.4.1 Large Woody Material and Substrates ............................................ 71

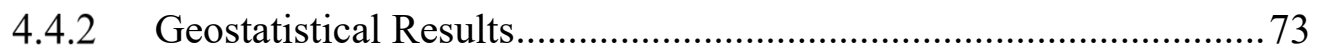

4.4.3 Non-metric Multidimensional Scaling Results ................................. 80

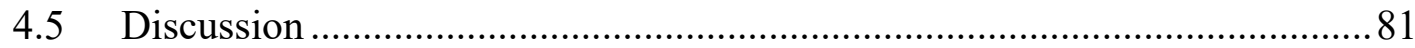

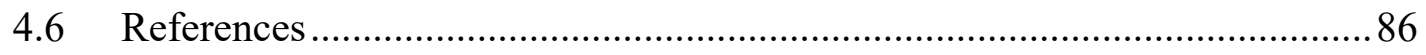




\section{List of Figures}

Figure 2.1. Dense point clouds of the $1 \mathrm{~m}^{2}$ artificial streambed with no sand (A, C) and $75 \%$ sand added (B, D). Images represent overhead (A, B) and oblique angles (C, D) of models. The black square in (A) depicts the $0.61 \mathrm{~m}^{2}$ plot after the original model was clipped to reduce edge effects.

Figure 2.2. Regression models for percentiles of substrate diameters from measured pebble count data (y-axis) and modeled substrate roughness from SfM derived DEMs (x-axis) of artificial streambeds with varying amounts of fines added. Points represents percentiles, from 0-95th, in 5\% increments. Solid and dotted lines represent the best fit and 95\% confidence intervals, respectively. Arrows point to the median (D50) from pebble count and roughness.

Figure 2.3. Regression model for the substrate size D84 measured from a pebble count of each artificial streambed configuration, and the predicted D84 from regression models between percentiles of roughness and pebble count diameter.

Figure 2.4. SfM derived point cloud for the $\sim 5 \mathrm{~m} 2$ area of Pilgrim River, MI streambed.

Rebar with flagging represent ground control and check point locations and are the perimeter for the $\sim 2 \mathrm{~m} 2$ region analyzed. Inset image used to develop the model and white arrow pointing to the same substrate particle in the model as in the image.

Figure 2.5. Regression model for measured substrate diameter and modeled substrate roughness from SfM derived DEM of the natural Pilgrim River streambed. Each point represents a percentile, from $0-95$ th, in 5\%. Solid and dotted lines represent the best fit and 95\% confidence intervals, respectively. The D50 is indicated by the arrow.

Figure 3.1 Map of study sites in Otter River Watershed, Michigan. Circles are the downstream boundary of each site. BEC $=$ Beaver Creek, BTC $=$ Bart Creek, NBR $=$ North Branch Bear Creek, OSR $=$ Otter Siding Road, THM $=$ Thirteen Mile Creek, WBS $=$ West Branch Sante Creek. Dark gray shaded areas represent 
the catchment area for each site. Light gray shaded area is the Otter River Watershed.

Figure 3.2. Large wood volume $\left(\mathrm{m}^{3} \mathrm{~m}^{-2}\right)$ from Burgess (2008) sampling (black bars) and our sampling (gray bars) of Otter River Watershed, MI sites.

Figure 3.3. Large wood abundance from Burgess (2008) sampling (black bars) and our sampling (gray bars) of Otter River Watershed, MI sites.

Figure 3.4 How large wood volume (A) and abundance (B) changed in relation to time since most recent logging occurred adjacent or within the catchment of Otter River Watershed, MI sites.

Figure 3.5. Mean \pm standard deviation for large woody material diameters from Burgess (2008) sampling (black bars) and our sampling (gray bars) of Otter River Watershed, MI sites. Asterisks indicates significant change $(\mathrm{p}<0.05)$ .43

Figure 3.6. Box plots for large woody material diameters in six tributaries of the Otter River Watershed, MI based on surveys in (A) Burgess (2008) and (B) 2017. Box boundaries and middle line represent $25^{\text {th }}, 50^{\text {th }}$, and $75^{\text {th }}$ percentiles, respectively. Whiskers are the $10^{\text {th }}$ and $90^{\text {th }}$ percentile, and points are individual outliers

Figure 3.7. Mean \pm standard deviation for channel width and depth from Burgess (2008) data (black bars) and our sampling (gray bars) of Otter River Watershed, MI sites. Asterisks indicates significant change in channel width or depth $(\mathrm{p}<0.05)$.

Figure 3.8. Coefficient of variation for (A) channel depth and (B) channel width, along with (C) channel width:depth ratios from 2001 (Burgess 2008) and 2017. Black lines connect sites over time and illustrate changes that have occurred between sampling periods.

Figure 3.9. Non-metric multidimensional scaling (NMDS) illustrating temporal dynamics of physical channel features of tributaries in the Otter River Watershed from 2001 (black circles) to 2015/2017 (white circles). Variables used in the ordination included: Coefficients of Variation (CV) of channel width and depth, width:depth 
ratio, D16, D50, and D84 from pebble counts, and volume of large instream wood.

Figure 4.1. Theoretical variogram showing sill, range, and nugget effect.

Figure 4.2. Map of study sites in Otter River Watershed, Michigan. Circles are the downstream boundary of each site. $\mathrm{BEC}=$ Beaver Creek, BTC $=$ Bart Creek, NBR $=$ North Branch Bear Creek, OSR $=$ Otter Siding Road, THM = Thirteen Mile Creek, WBS $=$ West Branch Sante Creek. Dark gray shaded areas represent the catchment area for each site. Light gray shaded area is the Otter River Watershed.

Figure 4.3. Area standardized volume of large woody material in Otter River Watershed sites. Black portion of bars represent volume of individual logs while gray portions represent log jam volume. OSR contained a beaver dam in the lower part of the study reach, which is why the majority of large wood in this site was classified as a jam. This site also had much additional smaller (diameter $>0.1 \mathrm{~m}$ ) wood that was not quantified.

Figure 4.4. Streamwise variograms for Otter River Watershed sites derived from channel bed morphology data from total station surveys. The y-axis represents semivariance values while the $\mathrm{x}$-axis is the lag distance between measurements in the streamwise (i.e. longitudinal) direction. The black points in each graph represent the empirical variogram while the black line represents the model variogram. Nugget effects (i.e. a value $>0$ at zero lag distance) were observed in Otter Siding Road (OSR) and Bart Creek (BTC).

Figure 4.5. Normal (across stream) variograms for Otter River Watershed sites derived from channel morphology data from total station surveys. The y-axis represents semivariance values while the $\mathrm{x}$-axis is the lag distance between measurements in the normal or across the channel (i.e. bank to bank) direction. The black points in each graph represent the empirical variogram while the black line represents the model variogram. A nugget effects (i.e. a value $>0$ at zero lag distance) was observed in Bart Creek (BTC). 
Figure 4.6. Variogram maps for Otter River Watershed sites illustrate how variogram values change as the lag distance increases in the streamwise (S) and normal (n) or across stream directions. Colors represent semivariance, with the cooler colors (e.g. blue) in the center represent low semivariance while the warmer colors (e.g. red) are higher variogram values and the highest values representing the sills for each site.

Figure 4.7. Total sill, integral range and dispersion variance for the one-dimensional streamwise and across stream directions, and the full two-dimensional anisotropic variogram for each study site in the Otter River Watershed. The total sill represents the overall variance observed in the data, while the integral range represents the change in topography. Finally, dispersion variance represents the spatial heterogeneity within a defined area (e.g. the 1 stream width $x 8$ stream width area of the variogram maps in Figure 4.6).

Figure 4.8. Non-metric multidimensional scaling (NMDS) of substrate heterogeneity $\left(\mathrm{D}_{84} / \mathrm{D}_{50}\right)$, channel slope, catchment area, and average width/depth ratio for the six Otter River Watershed sites.

Figure 4.9: Topographic survey data and variogram maps for Bart Creek (BTC) and West Branch Sante (WBS) sites in the Otter River Watershed, MI. Longitudinal change in elevation is shown in $\mathrm{A}$ and $\mathrm{B}$, while residuals from detrended elevation data are shown in $\mathrm{C}$ and $\mathrm{D}$. These residuals were used in the variogram analysis to produce the variogram maps (E, F). Based on variograms, Bart Creek was a low heterogeneity site (E) while West Branch Sante was a high heterogeneity site (F). 


\section{List of Tables}

Table 2.1. Streambed conditions (fine sediments added) in artificial streambeds, and the Pilgrim River natural streambed. Dense cloud points derived from SfM model developed from the number of Images. GCP (ground control points) and CP (check points) are locations with known coordinates measured via total station. Their errors represent the difference in their actual and SfM estimated location and used as the $\mathrm{M} 3 \mathrm{C} 2$ registration error. Mean precisions estimates derived from bundle adjustments (random error added to each point and variance is characterized) and presented for each model. D50 and D84 reported from pebble count measurements and predicted from SfM roughness/pebble count percentile regression models.

Table 3.1 Past logging of Otter River Watershed sites. Years since adjacent logging data from Burgess (2008). Available catchment logging data provided by Mi-DNR. . 33

Table 3.2. Characteristics for Otter River Watershed sites from 2001 (upper, from Burgess 2008) and present-day sampling (lower). Channel Width, depth, and percent fine substrates are all mean \pm standard deviation. Sixteenth (D16), Median (D50) and 84th percentile substrate diameters (D84) were derived from Wolman pebble counts (Wolman 1954). Percent fine substrate was calculated from bulk sediment samples (see Hames et al. 1996).

Table 3.3. Otter River Watershed study site metrics of complexity from 2001 (upper, from Burgess 2008) and present-day sampling (lower). Substrate heterogeneity and gradation coefficient are derived from pebble count data. CV (coefficient of variation) for width and depth, and width:depth ratio are all from survey data....39

Table 3.4 Summary of large wood characteristics in forested rivers from studies throughout North America and this study. ** Minimum size $0.3 \mathrm{~m}$ diameter, $3.0 \mathrm{~m}$ length. .50

Table 4.1. Otter River Watershed tributary site characteristics. Channel widths and depths were measured in 2015/2017 and are reported as mean \pm standard deviation. .....67 
Table 4.2. Substrate and large wood in Otter River Water sites.

Table 4.3. Total sill $\left(\sigma^{2}\right)$ and range (channel widths) from streamwise (S) and cross channel (n) model variograms of Otter River Watershed tributaries. Variogram data derived from channel morphology survey using a total station. 


\section{Preface}

All chapters in this dissertation were a collaboration with Dr. Casey Huckins. I led the collection and analysis of all data and am the primary author. Dr. Casey Huckins contributed to the acquiring of funding, study design, data analysis, and manuscript writing. Chapter 2 was published in the journal River Research and Applications. Chapter 3 will be submitted for publication in River Research and Applications or The Journal of Great Lakes Research. Chapter 4 will be submitted for publication in the journal Geomorphology or Water Resources Research. 


\section{Acknowledgements}

This research, and my time as a graduate student would not have been possible without the financial, logistical, and infrastructural support of Michigan Technological University’s Department of Biological Sciences, Great Lakes Research Center, Ecosystem System Science Center, Center for Water and Society, Graduate School, and the Michigan Science Teaching and Assessment Reform (Mi-STAR) program. Additionally, the Fred Waara Chapter of Trout Unlimited, Greater Lake Superior Foundation, National Science Foundation GK-12 Watershed program, and the NASA Michigan Space Grant Consortium.

I would like to recognize my committee members for their support throughout my research. Thank you to my advisor, Casey Huckins, for your guidance, wisdom, and patience throughout this journey. I am grateful to Amy Marcarelli for the thoughtful conversations, feedback, and mentoring. I would also like to thank Joe Wagenbrenner and Troy Zorn, for their invaluable comments and discussions that have improved my research and the way I think as a scientist.

I appreciate all the help with data collection, manuscript and presentation review, and friendship from all past and present members of the Huckins-Marcarelli (Huckarelli) group as well graduate students from the Department of Biological Sciences. I also am so thankful to all of our wonderful friends who have supported me and provided opportunities to take a break from work to recharge.

Finally, I thank my family for their love and encouragement. You all have believed in me even when I struggled to do so. Angela, words cannot describe how much I appreciate everything you have done to help me get to this point. 


\section{Abstract}

The relationships between wood and streambed substrates, among other abiotic components, are complex and an important part of the arrangement and dynamics of habitat in forested stream ecosystems. The objective of this research was to expand how we approach the study of the physical components of forested streams by considering the methods used to quantify these features, particularly substrates. Additionally, we assessed the temporal change over 14 years for streambed substrates, channel morphology, and large wood in a selectively-logged watershed. Our final objective was to understand if a relationship exists between the complexity of streambed morphology derived from variograms, and volume of instream large wood in forested streams. Our results suggest that Structure from Motion photogrammetry is a suitable complement or alternative to pebble counts for quantifying submerged streambed substrate composition as well as temporal changes in streambed morphology at small spatial scales (chapter 2). We determined the volume and abundance of large wood decreased within streams located in selectively logged catchments over the 14 years, but that the stability in streambed substrates and channel morphology did not appear relate to the amount of wood present (chapter 3). Finally, we found that in these tributaries of the Otter River, channel complexity metrics developed from variograms were not related to the volume of large wood present in stream channels (chapter 4). We hypothesize that may be due to the relatively low volume of wood compared to western US streams in addition to wood being too small relative to the local channel and larger landscape features, and that other underlying factors may be driving morphological complexity in these stream channels. Together, this research demonstrates that the association between large wood and channel complexity may not apply to all forested streams, and highlights some of the complexity in understanding the spatial and temporal relationships in forested streams, as well as presents an innovative approach to quantifying and monitoring streambed substrates and morphology. 


\section{Introduction}

The relationships among instream wood, streambed substrates, and channel morphology are complex and critical to the structure, habitat, and dynamics of forested river ecosystems. Due in part to this complexity, there are questions to be addressed regarding how the interactions among these components form and influence instream habitat for biota, and how they should be measured. This is in part because watershed disturbances have altered the natural processes in rivers in the United States and elsewhere (EPA 2002, EPA 2007) leading to embedding of coarse substrates (Stednick and Kern 1994), reductions of instream large wood (Montgomery et al. 2003), and reduced channel stability (Bilby 1984). These impacts have been attributed to activities including forest management and urbanization/development (e.g. road construction) (Chamberlin et al. 1991, Malmqvist and Rundle 2002) and have implications for fluvial biota.

This dissertation seeks to advance our understanding of the spatial and temporal relationships between large wood, channel morphology, and substrate composition in forested streams of the upper Great Lakes and improve our approach to quantifying these features. A large body of research focused on large wood in fluvial systems has been conducted in the western United States, including the Pacific Northwest and Alaska (Wohl 2017). Relatively little research on this topic has been done in the upper Great Lakes region so comparatively less is known about wood and substrate related conditions and dynamics in other parts of the country including the upper Great Lakes region (Cordova et al. 2007). A goal of this dissertation is to support successful management and restoration of forested streams in this region by expanding our understanding of the past and present conditions as well as what relationships may occur between the physical components of these streams. For the important task of quantifying streambed substrates and channel morphology, we apply innovative approaches in order to better understand what physical conditions exist in these streams.

A major limitation of understanding the dynamics and mechanisms of any system is the ability to efficiently and accurately measure it. In chapter 2, we sought to expand the 
ways that streambeds and streambed substrates are measured by using a modeling technique called Structure from Motion (SfM) photogrammetry. With SfM photogrammetry we created three-dimensional point clouds (Westoby 2012) of submerged substrates. These models were then used to characterize channel morphology and the surface roughness of the streambed (Heritage and Milan 2009). To ensure that this method would be comparable to standard commonly used techniques, we developed regression models to relate percentiles of surface roughness derived from SfM photogrammetry to substrate size percentiles from the widely used pebble counts. We found that roughness derived from SfM photogrammetry was a good predictor of pebble count percentiles for streambeds with low abundances of fine sediments such as sand $\left(\mathrm{r}^{2}\right.$ $>0.95)$, particularly for frequently reported metrics such as the $84^{\text {th }}$ percentile $\left(\mathrm{D}_{84}\right)$. This means that SfM models derived from submerged images may be a useful quantitative tool comparable to pebble counts. We also determined that SfM photogrammetry point cloud models can accurately quantify changes in channel morphology at small spatial scales (e.g. 1-2 $\mathrm{m}^{2}$ ), meaning that the use of SfM photogrammetry to survey and quantify temporal changes in submerged streambed morphology following, for example, disturbance or restoration, may be appropriate.

Along with substrates, large wood is important in streams by influencing their morphology and habitat for biota. However, many studies span relatively short periods and data is spare for the longer term dynamics of wood in forested rivers. In the next study (chapter 3), we sought to characterize how large woody material, streambed substrates, and channel morphology changed in six streams in a selectively logged watershed in the western Upper Peninsula, Michigan since they were surveyed in 2001 following the most recent harvest (Burgess 2008). We expected that sites with a higher volume of large wood would have the most stable (i.e. similar) substrates and channel morphology, and that sites with less large woody material would be less similar between the two sampling periods. Despite decreases in large wood volume and abundance among most of the sites, stability in substrate characteristics and channel morphology do not appear to relate to the amount of wood present in these sites within this time frame and in 
the conditions resulting from this active forest management. Additionally, the low volume of wood in these streams may be linked to the active forest management strategy that selectively harvests larger trees. Although we expected to see differences between sites, it may be that there is not enough wood in these sites to detect between this 14-year period.

Large wood is associated with greater geomorphic complexity in forested streams and its historical removal has resulted in numerous disturbances, and is often added in attempts to enhance complexity and increase habitat for biota. However, the way that complexity is quantified may not represent the way that it is structured (e.g. discrete vs continuum) and some have called for different approaches for considering this important component of streams. In the final study (chapter 4), we surveyed large wood and channel morphology in six forested streams of the western Upper Peninsula, Michigan and then used variograms to describe the spatial structure in channel morphology of the streams (Legleiter 2014a). The goal of this study was to determine if a relationship exists between instream large wood volume and the complexity of channel morphology (i.e. variability in topography) as derived from the variograms. Based on extensive literature showing association between large woody material and the structure and composition of local scale habitat features such as riffles, pools and runs (Montgomery et al. 2003), we predicted a strong association with channel complexity. Metrics of channel complexity from the variogram analysis did not appear to show a trend with the volume of large wood present in the channel. This may be due to the small size and low abundance of large wood as well as other underlying landscape and environmental factors driving morphological complexity in these streams.

Complexity is an important part of fluvial systems. Not only are complex streams more resilient and resistant to disturbance (Pearson et al. 1992), but they often support greater biodiversity (e.g. Beisel et al. 2000). Complexity in streams can come in many forms and although this and associated terms (e.g., heterogeneity) are found throughout each of the chapters in this dissertation, it is important to distinguish the differences between them. 
In chapter 2, substrate roughness is a metric of the complexity in small-scale topography of the streambed. In chapter 3, stream complexity is considered at a larger spatial scale and takes the form of variogram metrics from the topographic data. Finally, in chapter 4, complexity is considered in regard to channel morphology in the form of coefficient of variation of channel width and depth. We also consider complexity of substrate characteristics such as the heterogeneity in substrate diameters, and the gradation coefficient, which measures the spread in substrate diameters.

Together, these three studies expand how we approach the study of the abiotic components of fluvial systems, especially small headwater streams draining mixed hardwood forests (chapter 2), as well as our understanding of what physical conditions exist temporally (chapter 3) and spatially (chapter 4) in the upper Great Lakes region. The results from this research are useful by expanding the ways that substrates and streambed morphology are measured using SfM photogrammetry and variograms. Additionally, our data for the physical conditions present in these tributaries of the Otter River watershed indicate that the current relationship between large wood and channel morphology does not appear to support the what has been found in other parts of North America, as well as provide data for what conditions may be representative of streams in this selectively logged Upper Great Lakes watershed. Together this understanding will support future management and restoration by providing a reference for what physical conditions exist as well as appropriate techniques for quantifying these features.

\subsection{References}

Beisel, J., P. Usseglio-Polatera, and J. Moreteau. 2000. The spatial heterogeneity of a river bottom: a key factor determining macroinvertebrate communities. Hydrobiologia 422/423: 163-171.

Bilby, R. E. 1984. Removal of woody debris may affect stream channel stability. Journal of Forestry 82(10):609-613.

Burgess, A. F. 2008. Macroinvertebrate communities, organic matter, and physical habitat conditions across headwater streams of the Otter River, in Michigan's upper 
peninsula. Michigan Technological University. Houghton, MI.

Chamberlin, T. W., R. D. Harr, and F. H. Everest. 1991 Timber harvesting, silviculture, and watershed processes. American Fisheries Society Special Publication 19: 181205.

Cordova, J. M., E. J. Rosi-Marshall, A. M. Yamamuro, and G. A. Lamberti. 2007. Quantity, controls and function of large woody debris in midwestern USA streams. River Research and Applications. 23: 21-33.

EPA. 2002. National water quality inventory: 2000 report. EPA-841-R-02-001.

EPA. 2007. National management measures to control nonpoint source pollution from hydromodification. EPA 841-B-07-002:

Heritage, G. L., and D. J. Milan. 2009. Terrestrial Laser Scanning of grain roughness in a gravel-bed river. Geomorphology 113:4-11.

Legleiter, C. J. 2014a. A geostatistical framework for quantifying the reach-scale spatial structure of river morphology: 1. Variogram models, related metrics, and relation to channel form. Geomorphology 205(4): 65-84.

Malmqvist, B. and S. Rundle. 2002. Threats to the running water ecosystems of the world. Environmental Conservation 29(2): 134-153.

Montgomery, D. R., B. D. Collins, J. M. Buffington, and T. B. Abbe. 2003. Geomorphic effects of wood in rivers. American Fisheries Society Symposium 37: 1-27.

Pearsons, T. N., H. Li, and G. A. Lamberti. 1992. Influence of habitat complexity on resistance to flooding and resilience of stream fish assemblages. Transactions of the American Fisheries Society 121: 427-436.

Stednick, J. D., and T. J. Kern. 1994. Risk assessment for salmon from water quality changes following timber harvest. Environmental Monitoring and Assessment 32: 227-238.

Westoby, M. J., J. Brasington, N. F. Glasser, M. J. Hambrey, and J. M. Reynolds. 2012. "Structure-From-Motion" photogrammetry: A low-cost, effective tool for geoscience applications. Geomorphology 179:300-314.

Wohl, E. 2017. Bridging the gaps: An overview of wood across time and space in diverse rivers. Geomorphology 279: 3-26. 


\section{$2 \quad$ Modeling submerged fluvial substrates with Structure from Motion photogrammetry}

\subsection{Abstract}

Natural sediment regimes of fluvial systems are variable and important to the biological and physical structure of rivers, yet watershed degradation has led to increased fine sediments entering and aggrading in rivers. As a result, quantifying substrate composition is important for targeting and monitoring restoration. Conventional methods for assessing substrate composition (e.g. pebble counts) can be time consuming and biased. We examined the use of the photogrammetric technique, Structure-from-Motion (SfM), as an alternative method by measuring streambed roughness. We expanded its application to submerged substrates in an artificial streambed to assess if roughness could predict pebble count substrate size percentiles across a range of manipulated levels of fine sediment aggradation. We then assessed the use of SfM in a free-flowing river streambed. Results from the artificial streambed with coarse substrates ( $\leq 31 \%$ added fine sediment) revealed repeated SfM models of the same streambed had a high degree of similarity (mean difference $=1 \mathrm{~mm}$ ) and a strong relationship between SfM derived roughness and pebble counts $\left(\mathrm{r}^{2}>0.95\right)$. This relationship was weaker $\left(\mathrm{r}^{2}<0.66\right)$ and violated regression variance assumptions when substrates had up to $47 \%$ (55.7 kg) fines added, possibly due to SfM characterizing details not captured by pebble counts. In the natural streambed there was a strong relationship between percentiles from the SfM model roughness and pebble count diameter $\left(\mathrm{r}^{2}=0.96\right)$. Structure-from-Motion appears to be an efficient and appropriate alternative to direct substrate measurements across a broad range of streambed substrate compositions and thus a useful tool to model streambed morphology.

\subsection{Introduction}

Substrate composition is a critical feature of rivers that varies spatially, driven by factors including the influence of gradient on sediment aggradation and transport relative to 
particle size and discharge (Church 2002), tributary connections as sources of sediments (Benda et al. 2004), landscape position (Frissel et al. 1986), and land-use (Walling 1999). This variability is also expressed temporally, for example, in the form of greater sediment transport during high discharge and greater rates of aggradation during low flow (Allen \& Castillo 2007). The condition and variation of streambed substrates is important because substrate composition and dynamics are strongly linked to biological and physical structures of rivers (Wohl et al. 2015). Anthropogenic watershed erosion and aggradation of sand in rivers, especially those with historically coarse substrates, has ecological and economic consequences (e.g., decreased recreational fisheries) for recipient aquatic and adjacent terrestrial communities (Wood \& Armitage 1997). Activities such as agriculture, forest management, road construction and use, etc. (Waters 1995) can disturb natural sediment dynamics by increasing sediment inputs to fluvial systems and resulting in turbidity and aggradation of fine particles, which is a major pollutant to rivers (EPA 2017). Furthermore, excess sediment can reduce the ability of a river to move water (i.e. channel capacity), thus increasing flooding potential (Raven et al. 2009).

Modifications to substrate composition, including increased fine sediment (i.e., fines) can influence the occupation and fitness of organisms in rivers (May et al. 2009) such as benthic primary producers (Molinos \& Donohue 2009), invertebrates (Angradi 1999, Jones et al. 2012b), and fish (Cover et al. 2008, Kemp et al. 2011). Substrate size distribution within a stream can determine the spatial distribution of organism such as benthic algae attached to coarse rocks or macrophytes prospering in fines (Jones et al. 2012a), and can influence primary production and respiration (Marcarelli et al. 2015), and organic matter retention (Hoover et al. 2006) that fuel food webs. While some invertebrates tolerate a broad range of substrate sizes, (e.g., some dipteran larvae), others such as clinging stoneflies favor a narrow range of conditions (Williams \& Mundie 1978). Fine particles tend to favor burrowing taxa (e.g. oligochaetes), while larger particles are important for taxa that feed from stable substrates (Hershey et al. 2010). Sediment size is also important for salmonid spawning (Kondolf \& Wolman 1993), early development of eggs and larvae in interstitial spaces between rocks where they are protected from predation and elevated streamflow (Kemp et al. 2011), and 
juvenile growth (Suttle et al. 2004). Additionally, coarse substrates alter small scale water currents (Robert 2011), which some fish use to reduce energy expenditure while maintaining channel position (Liao 2007). The importance of a natural sediment regime and substrate size characteristics in a habitat, signify the importance of accurately and efficiently quantifying status and changes to streambed habitat for management (May et al. 2009, Wohl et al. 2015).

Currently, a variety of survey techniques with often unique biases are used to assess streambed substrates and there is a need for improved efficiency and effectiveness. Some methods for evaluating substrates include pebble counts (Wolman 1954), bulk percent fine $(<2 \mathrm{~mm}$ ) analysis (Hames et al. 1996), and visual classification (Bjornn 1977). Pebble counts, in particular, are widely used to estimate size frequency distributions and percentiles of substrate diameters, most commonly the $50^{\text {th }}$ and $84^{\text {th }}$ percentiles $\left(\mathrm{D}_{50}\right.$ and $\mathrm{D}_{84}$, respectively) (Marcus et al. 1995, Daniels \& McCusker 2010). These data are often used as an estimate for streambed roughness (Wohl et al. 1996), as was intended when the method was developed (Wolman 1954). Streambed roughness is a measure of small-scale topographic change that affects water turbulence (Robert 2011), making it an important component to the spatial structure of stream ecosystems (Biggs et al. 2005) and the interactions between biota (Fausch 2014). However, pebble count percentiles (e.g. $\mathrm{D}_{50}$ ) may be inadequate for estimating roughness because they do not account for the effects of imbrication (i.e. water aligning substrates in a downstream direction) on roughness (Entwistle \& Fuller 2009). Under this scenario, imbricated substrates are less rough than a pebble count might indicate. In addition, inadequate sample size (Daniels \& McCusker 2010), variability between samples, and smaller particles being underrepresented are additional pebble count limitations (Hey \& Thorne 1983, Marcus et al. 1995).

A contemporary metric for roughness is the standard deviation of elevation (Pearson et al. 2017) because it may be better at estimating flow resistance than substrate diameter (Aberle \& Smart 2003). Modern techniques (e.g. Terrestrial Laser Scanning (TLS)). have been used to model streambed topography and quantify roughness. By measuring surface elevation, improvements to the data can result from measuring only the portions of 
individual particles interacting with the water column (Heritage \& Milan 2009); however TLS can be cost prohibitive and has limited ability to penetrate water (Smith et al. 2012).

An alternative technique to measure topography, and thus roughness, is Structure from Motion photogrammetry (hereafter SfM), which produces three dimensional models of objects from overlapping images (Westoby 2012). Matching locations in each image are identified to construct a point cloud of data representing the object. A major advantage of SfM over TLS is that it requires only a digital camera and SfM software (e.g. Agisoft Photoscan), however, referencing SfM models still involves additional equipment (e.g. total station or GPS). SfM has been used in terrestrial ecosystems to measure landscape changes (Lucieer et al. 2014), while underwater images have been used to characterizing habitat, bathymetry, and the structural complexity of coral reefs in marine environments (Carrivick \& Smith 2019). In rivers, SfM primarily has been applied to exposed streambed and floodplain regions, often collected via unmanned aerial vehicles (UAV) and used to create surface models of topography (Fonstad et al. 2013, Javernick et al. 2014), and characterize substrates (Woodget \& Austrums 2017). There has been progress using through-water images and SfM to extract elevation data of submerged streambeds (Woodget et al. 2015, Dietrich 2017) but there are some sampling limitations to consider (e.g. shallow $(\leq 0.7 \mathrm{~m})$ ), clear, and calm water, with a correction factor applied to account for refraction; Woodget et al. 2015). Despite the extensive progress in using SfM for sampling rivers, we are unaware of previous attempts to combine underwater imaging and SfM in fluvial ecosystems.

Here we incorporated images acquired underwater (i.e. no images were captured across the air/water interface) to expand SfM's application for surveying and characterizing submerged streambed habitat and substrates. We evaluated if SfM derived streambed roughness models can predict substrate percentiles $\left(\mathrm{D}_{50}\right.$ and $\left.\mathrm{D}_{84}\right)$. If suitable, $\mathrm{SfM}$ could be used to supplement pebble counts for repeated assessments such as monitoring restoration responses. Additionally, we evaluated the dynamic relationship between surface roughness and pebble count percentiles by simulating a streambed altered with 
increasing fine sediment aggradation in an artificial streambed. Finally, we applied underwater SfM to a natural streambed in a free-flowing river.

\subsection{Methods}

\subsubsection{Laboratory Streambed}

We used SfM derived roughness to estimate substrate diameters in an artificial streambed simulated in a $1500 \mathrm{~L}$ ( $\sim 1.83 \mathrm{~m}$ diameter) tank filled with water. We then incrementally increased the fines to evaluate how fine sediment aggradation affects SfM's ability to generate these estimates. Eight equally spaced points inside the tank outlining the perimeter of a $1 \mathrm{~m}^{2}$ area were marked and measured (x, y, z) using a total station. These served as ground control points $(\mathrm{n}=4)$ to establish a local coordinate system, and check points $(\mathrm{n}=4)$ where the known coordinates are compared to the models estimated locations to assess SfM point cloud accuracy. The streambed was made using bulk samples collected from the Salmon Trout River, Marquette County, Michigan where pebble count $\mathrm{D}_{50}$ and $\mathrm{D}_{84}$ were 0.5 and $45 \mathrm{~mm}$, respectively. Substrates were dried $\left(100^{\circ} \mathrm{C}\right.$ for $24 \mathrm{hrs}$.), sieved (<0.063, 0.063-0.125, 0.125-0.25, 0.25-0.5, 0.5-1, 1-2, 2-4, 4$16,16-64$, and $>64 \mathrm{~mm}$ ) and weighed as size-categories. From these, 535 coarse substrates ( $>2 \mathrm{~mm}$ diameter) were selected, individually weighed $(0.01 \mathrm{~g})$, and their intermediate axis diameters were measured (nearest $1 \mathrm{~mm}$ ) before being placed within the $1 \mathrm{~m}^{2}$ area of the tank. Diameters for this initial (no fines) streambed ranged from 11-231 $\mathrm{mm}$ and the total mass was $\sim 62 \mathrm{~kg}$. A range of sediment distributions were then created by iteratively adding $9.3 \mathrm{~kg}$ of particles $<2 \mathrm{~mm}$ ( $15 \%$ of the initial course streambed's weight) from the bulk sample, dispersed over the streambed to simulate sediment aggradation. Six additions were done until the streambed contained $55.7 \mathrm{~kg}$ of fines $(90 \%$ of the initial streambed weight). By the second addition of fines $(18.6 \mathrm{~kg})$ the median substrate size was sand $(\leq 2 \mathrm{~mm})$ and by the fifth addition $(46.4 \mathrm{~kg})$ the course substrates were fully embedded. After each addition a pebble count was conducted by measuring the intermediate axis of 100 randomly selected particles. From these data, percentiles were calculated from $0-95^{\text {th }}$, in $5 \%$ increments. Any fines encountered during the pebble 
count were assigned a diameter of $0.5 \mathrm{~mm}$ because $\sim 66 \%$ of the sieved fines were 0.25 $0.5 \mathrm{~mm}$.

\subsubsection{Image Acquisition \& Analysis}

For each streambed condition SfM was used to create a point cloud from overlapping images (all acquired underwater) using a 20.2-megapixel Sony RX100 camera (1” sensor, $24 \mathrm{~mm}$ equivalent focal length). Images should overlap by $\geq 60 \%$ to ensure adequate coverage (James \& Robson 2012) and be taken from oblique angles to minimize model distortion (e.g. doming, James \& Robson 2014). All images were captured in a similar manner: using the same focal length $(24 \mathrm{~mm})$, from overhead and multiple oblique angles, and spaced for at least 60\% overlap. Point clouds were developed using Agisoft Photoscan Professional (Agisoft 2018). After removing blurry images, the remaining (Table 2.1) were imported into Photoscan, aligned using the medium accuracy setting, while automated camera alignment optimization was run to correct potential model distortion such as doming (Agisoft 2018). During this phase outlier points were manually identified and removed. Dense point clouds were developed using medium accuracy with mild depth filtering to ensure key features were retained, and ground control and check point coordinates were entered. Finally, digital elevation models (DEM) were produced from the dense point clouds, with spatial resolutions ranging from 0.3-0.5 $\mathrm{mm}$ (Table 2.1) and exported from Photoscan. 
Table 2.1. Streambed conditions (fine sediments added) in artificial streambeds, and the Pilgrim River natural streambed. Dense cloud points derived from SfM model developed from the number of Images. GCP (ground control points) and CP (check points) are locations with known coordinates measured via total station. Their errors represent the difference in their actual and SfM estimated location and used as the M3C2 registration error. Mean precisions estimates derived from bundle adjustments (random error added to each point and variance is characterized) and presented for each model. D50 and D84 reported from pebble count measurements and predicted from SfM roughness/pebble count percentile regression models.

\begin{tabular}{|c|c|c|c|c|c|}
\hline Streambed & $\begin{array}{l}\text { Percent } \\
\text { Fines }\end{array}$ & $\begin{array}{l}\text { Images } \\
\text { Used for } \\
\text { Model }\end{array}$ & $\begin{array}{l}\text { Dense Cloud } \\
\text { Points }\left(\times 10^{6}\right)\end{array}$ & $\begin{array}{c}\text { DEM } \\
\text { Resolution } \\
(\mathrm{mm})\end{array}$ & $\begin{array}{l}\text { GCP/ } \\
\text { CP } \\
\text { Points }\end{array}$ \\
\hline 1a-Lab: $0 \mathrm{~kg}$ Fines & 0 & 53 & 17.06 & 0.5 & $4 / 4$ \\
\hline 1b-Lab: 0 kg Fines ${ }^{+}$ & 0 & 86 & 5.24 & 0.3 & $4 / 4$ \\
\hline 2-Lab: $9.3 \mathrm{~kg}$ Fines & 13.0 & 88 & 8.05 & 0.4 & $4 / 4$ \\
\hline 3-Lab: $18.6 \mathrm{~kg}$ Fines & 23.1 & 134 & 7.38 & 0.5 & $4 / 4$ \\
\hline 4-Lab: 27.9 kg Fines & 31.0 & 139 & 8.69 & 0.4 & $4 / 4$ \\
\hline 5-Lab: $37.2 \mathrm{~kg}$ Fines & 37.5 & 82 & 7.89 & 0.4 & $4 / 4$ \\
\hline 6-Lab: 46.4 kg Fines & 42.9 & 120 & 7.87 & 0.5 & $4 / 4$ \\
\hline 7a-Lab: $55.7 \mathrm{~kg}$ Fines & 47.4 & 123 & 8.65 & 0.4 & $4 / 4$ \\
\hline 7b-Lab: 55.7 kg Fines ${ }^{+}$ & 47.4 & 78 & 8.28 & 0.4 & $4 / 4$ \\
\hline 8-Natural: Pilgrim River & - & 294 & 23.81 & 0.5 & $2 / 2$ \\
\hline Streambed & $\begin{array}{l}\mathrm{GCP} / \mathrm{CP} \\
\text { Error }(\mathrm{mm})\end{array}$ & $\begin{array}{l}\text { Mean Point } \\
\text { Precision } \\
(\mathrm{mm})\end{array}$ & $\begin{array}{l}\text { Pebble Count } \\
\mathrm{D}_{50} / \mathrm{D}_{84}(\mathrm{~mm})\end{array}$ & $\begin{array}{c}\text { Estimated } \\
\mathrm{D}_{50} / \mathrm{D}_{84} \\
(\mathrm{~mm})\end{array}$ & \\
\hline 1a-Lab: $0 \mathrm{~kg}$ Fines & $4 / 4$ & 3 & $40 / 72$ & $41 / 77$ & \\
\hline 1b-Lab: 0 kg Fines ${ }^{+}$ & $5 / 3$ & 3 & $40 / 72$ & $38 / 70$ & \\
\hline 2-Lab: $9.3 \mathrm{~kg}$ Fines & $5 / 4$ & 4 & $37 / 63$ & $39 / 73$ & \\
\hline 3-Lab: 18.6 kg Fines & $5 / 4$ & 3 & $* 0.5 / 54$ & $17 / 50$ & \\
\hline 4-Lab: 27.9 kg Fines & $5 / 5$ & 3 & $* 0.5 / 48$ & $14 / 45$ & \\
\hline 5-Lab: 37.2 kg Fines & $6 / 4$ & 3 & $* 0.5 / 19$ & $5 / 22$ & \\
\hline 6-Lab: 46.4 kg Fines & $5 / 4$ & 3 & $* 0.5 / * 0.5$ & $2 / 7$ & \\
\hline 7a-Lab: $55.7 \mathrm{~kg}$ Fines & $4 / 4$ & 3 & $* 0.5 / * 0.5$ & $1 / 1$ & \\
\hline 7b-Lab: $55.7 \mathrm{~kg} \mathrm{Fines}^{+}$ & $5 / 4$ & 3 & $* 0.5 / * 0.5$ & $1 / 1$ & \\
\hline 8-Natural: Pilgrim River & $5 / 9$ & 1 & $33 / 57$ & $34 / 60$ & \\
\hline
\end{tabular}


Some fines slumped beyond the $1 \mathrm{~m}^{2}$ plot boundary resulting in relatively less sand along the edges (see Fig. 2.1 B and D). To avoid bias in the form of reduced embeddedness and exaggerated roughness, the DEMs were clipped to a $0.61 \mathrm{~m}^{2}$ square in Arcmap 10 (see e.g., Fig. 2.1A). Following Heritage \& Milan (2009), twice the standard deviation of elevation (i.e. roughness) within a moving window was calculated for the DEM. The window was set equal to the radius of the largest observable substrate (range: 15-75 $\mathrm{mm}$ ) and moved in $50 \mathrm{~mm}$ increments (Heritage \& Milan 2009) using the Focal Statistic and Resample tools in Arcmap 10. The individual roughness values were then used to quantify percentiles of roughness $\left(0-95^{\text {th }}, 5 \%\right.$ increment). Finally, we assessed if SfM derived roughness could predict pebble count data under different streambed conditions (i.e. increasing aggradation) using linear regression. For the six streambed configurations, substrate diameter percentiles were regressed against percentiles of surface roughness using SigmaPlot 13.0 (Systat Software, Inc.)
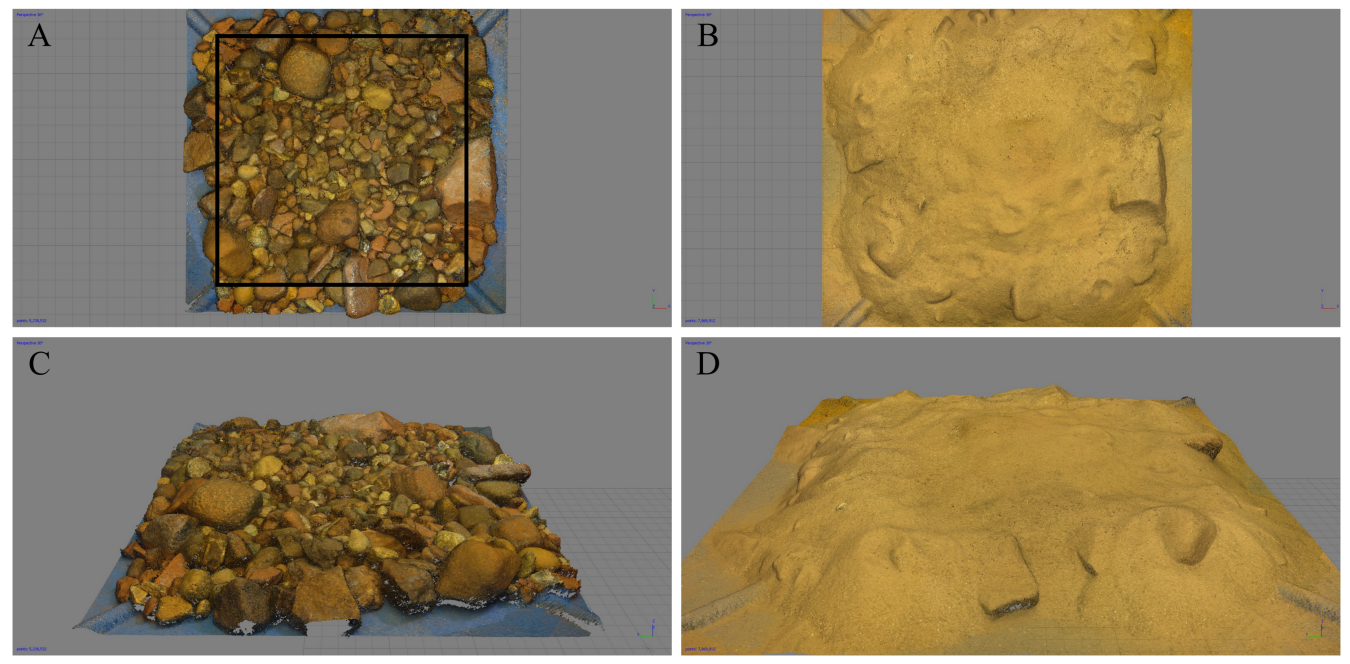

Figure 2.1. Dense point clouds of the $1 \mathrm{~m}^{2}$ artificial streambed with no sand (A, C) and $75 \%$ sand added (B, D). Images represent overhead (A, B) and oblique angles (C, D) of models. The black square in (A) depicts the $0.61 \mathrm{~m}^{2}$ plot after the original model was clipped to reduce edge effects.

\subsubsection{SfM Change Detection \& Precision Analysis:}

To test the repeatability and accuracy of SfM models we collected two image sets for each streambed configuration from 0 and $55.7 \mathrm{~kg}$ added fines to identify point cloud 
differences that may have resulted from insufficient image coverage or model errors. We applied the Multiscale Model to Model Cloud Comparison (M3C2) approach (Lague et al. 2013), previously used to detect temporal landscape changes from SfM derived terrestrial data (Esposito et al. 2017). The M3C2 compares models based on individual point orientation relative to a normal surface, which is more robust than subtracting DEMs (Lague et al. 2013). To calculate confidence intervals, the M3C2 accounts for registration errors, which combine ground control and check point errors (Table 2.1) and are attributed to differences between their actual and calculated locations in the model. Finally, survey precision was evaluated for each of the streambeds following the methods outlined by James et al. (2017) resulting in error estimates that stabilized after fewer than 4000 iterations (see Table 2.1).

\subsubsection{Assessment of Natural Streambed:}

Following the artificial streambed assessment, we evaluated these methods in the Pilgrim River, Houghton County, Michigan, which drains $\sim 63 \mathrm{~km}^{2}$ of mostly forested landscape in Michigan's western Upper Peninsula. A reach was selected with a streambed of coarse and fine substrates, and a water depth of $\sim 0.5 \mathrm{~m}$. We sampled during baseflow, relatively clear water, and overcast conditions to maximize image clarity and minimize shadows, both of which can introduce error into point clouds. Four pieces of rebar were anchored into the streambed, referenced by placing a prism pole on them and sighting with a total station to establish a $\sim 2 \mathrm{~m}^{2}$ plot, and designated as ground control $(\mathrm{n}=2)$ and check points $(\mathrm{n}=2)$. Within the plot, a pebble count was done for 125 substrates to balance sampling time and reducing errors associated with smaller sample sizes (Hey \& Thorne 1983) and 294 overlapping underwater images from overhead and oblique angles were taken of the streambed. After photo alignment and optimization (see Image Acquisition and Analysis) a dense point cloud was constructed (medium accuracy), ground control and check point coordinates were entered, and the model was exported as a $0.5 \mathrm{~mm}$ resolution DEM from Photoscan. Following the artificial streambed methodology, roughness was quantified using a $100 \mathrm{~mm}$ window (radius of largest substrate) moved at a $50 \mathrm{~mm}$ interval (Heritage \& Milan 2009). Percentiles (0-95 $5^{\text {th }}, 5 \%$ increment) of these roughness values 
were extracted from the DEM while substrate diameters were estimated from the pebble count. Linear regression was used to develop a model to predict percentiles of substrate diameter from surface roughness.

\subsection{Results}

\subsubsection{Laboratory Streambed}

Across the iterative sand additions we achieved a large range in substrate size

distributions in the lab streambed with pebble count $\mathrm{D}_{50}$ measurements ranging from 0.5 $40 \mathrm{~mm}$, and $\mathrm{D}_{84}$ measurements from 0.5-72 $\mathrm{mm}$ (Table 2.1). The number of images collected for each trial ranged from 53-139 and the resultant SfM point cloud models contained 7->17 million points (Table 2.1) that were highly resolved with low error (e.g. Table 2.1, Figure 2.1) and mean point precisions that ranged from 3-4 mm (Table 2.1). In general, the point clouds had continuous coverage, however, there were locations with larger gaps between adjacent points. This primarily occurred for streambeds with low sand abundance (e.g. $\leq 18.6 \mathrm{~kg}$ added sand) and is likely due to inadequate image coverage of the interstitial spaces.

We found strong associations between percentiles of measured pebble count diameter and SfM modeled streambed roughness (adjusted R-squared range: 0.81-0.96, all p<0.001) for streambeds up to $27.9 \mathrm{~kg}$ added sand (Figure 2.2). However, these relationships for streambeds with 37.2-55.7 kg added sand were weaker (adjusted R-squared range: 0.19$0.65, \mathrm{p}<0.001-0.005)$ and violated the regression assumption that data have an equal variance. Based on regression models for each artificial streambed, pebble count $\mathrm{D}_{50}$ estimated from the SfM models ranged from 0.6-41 mm and $\mathrm{D}_{84}$ ranged from 1-77 mm (Table 2.1). The estimated $\mathrm{D}_{84}$ values were strongly related to values measured from the pebble counts for each artificial streambed configuration (adjusted R-squared $=0.97$, $\mathrm{p}<0.001$; Figure 2.3). 

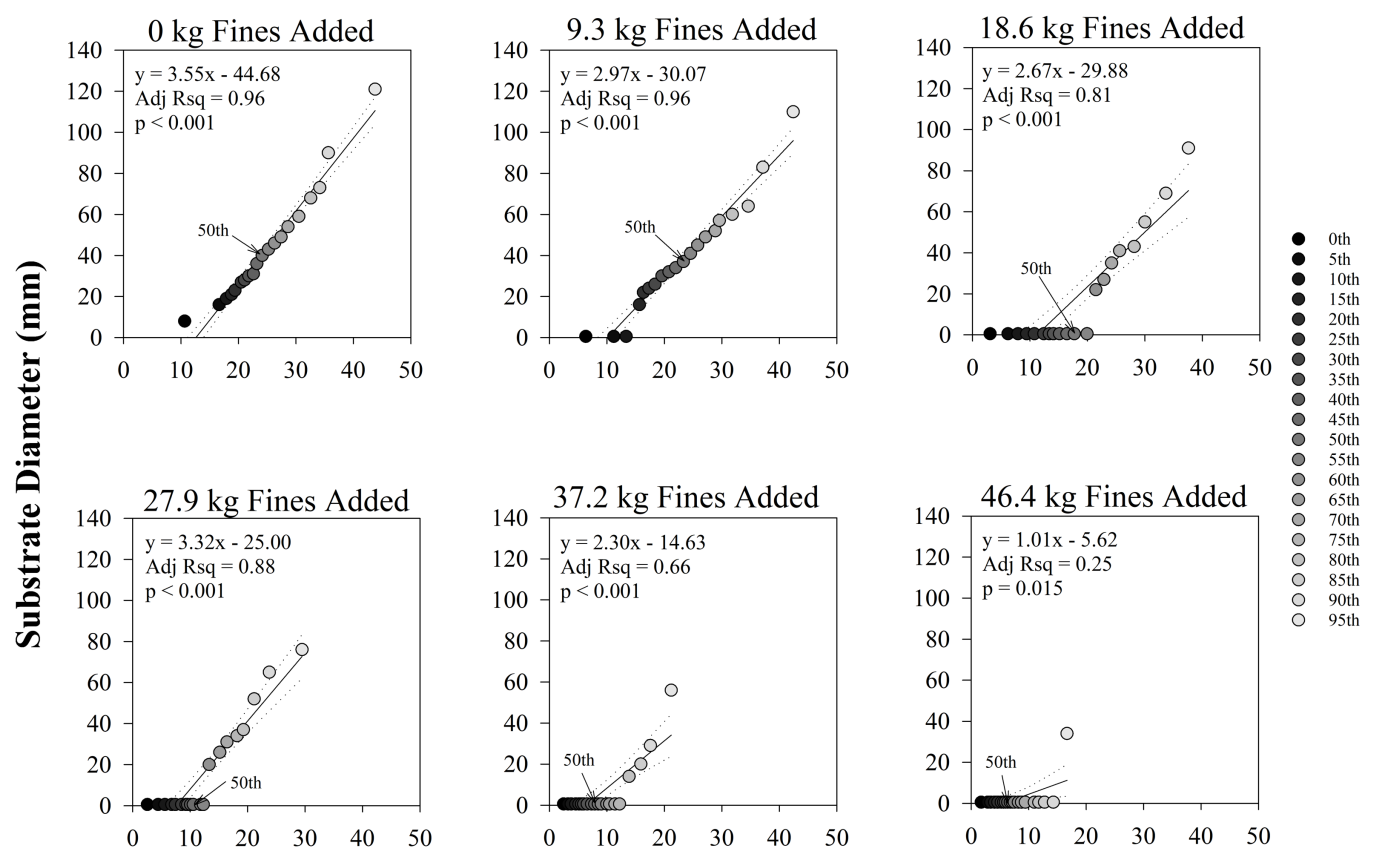

\section{Substrate Surface Roughness (mm)}

Figure 2.2. Regression models for percentiles of substrate diameters from measured pebble count data (y-axis) and modeled substrate roughness from SfM derived DEMs (xaxis) of artificial streambeds with varying amounts of fines added. Points represents percentiles, from 0-95th, in 5\% increments. Solid and dotted lines represent the best fit and $95 \%$ confidence intervals, respectively. Arrows point to the median (D50) from pebble count and roughness. 


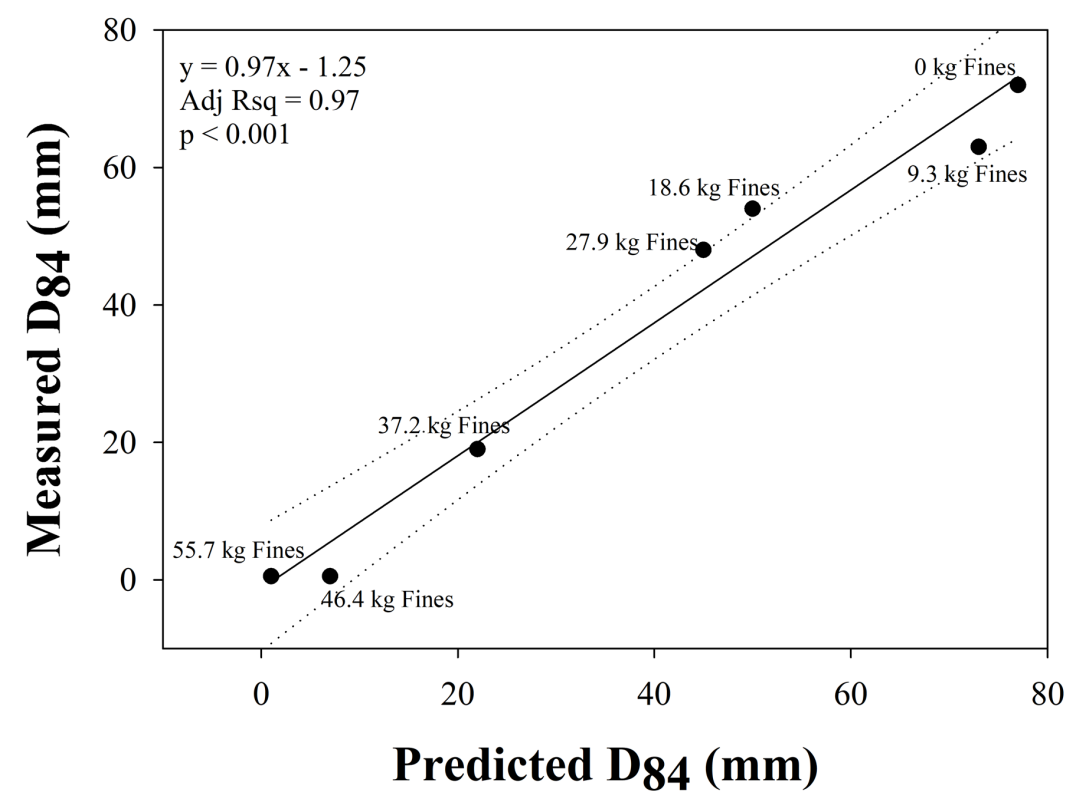

Figure 2.3. Regression model for the substrate size D84 measured from a pebble count of each artificial streambed configuration, and the predicted D84 from regression models between percentiles of roughness and pebble count diameter.

Mean $( \pm \mathrm{SD})$ and maximum differences between point clouds from the resampled streambed with no fines was $1.0 \pm 2.8 \mathrm{~mm}$, and $51.3 \mathrm{~mm}$, respectively, with the areas of greatest disparity generally occurring in the interstitial spaces between the substrates. However, results from the $\mathrm{M} 3 \mathrm{C} 2$ tool indicated $<1 \%$ of points were significantly different between the models. When comparing the original and resampled $55.7 \mathrm{~kg}$ added sand streambed, mean $( \pm \mathrm{SD})$ and maximum differences between point cloud were $0.8 \pm 0.7 \mathrm{~mm}$ and $1.2 \mathrm{~mm}$, respectively, and no significant difference between the models were indicated from the $\mathrm{M} 3 \mathrm{C} 2$ tool.

\subsubsection{Natural Streambed}

Substrates measured during the pebble count ranged from 1-200 mm, the $\mathrm{D}_{50}$ and $\mathrm{D}_{84}$ within the $\sim 2 \mathrm{~m}^{2}$ natural streambed were 33 and $57 \mathrm{~mm}$, respectively (Table 2.1 ), and the point cloud had $\sim 24$ million points with a mean precision of $1 \mathrm{~mm}$ (Table 2.1; Figure 2.4). Similar to those for the artificial streambeds, the model was nearly continuous with few locations where insufficient image overlap caused point cloud gaps (Figure 2.4). The regression model indicated a strong association between percentiles from pebble count 
diameters and surface roughness (adjusted R-squared $=0.96, \mathrm{p}<0.001$; Figure 2.5). Based on the regression model, estimated $\mathrm{D}_{50}$ and $\mathrm{D}_{84}$ were 34 and $61 \mathrm{~mm}$, respectively (Table 2.1).

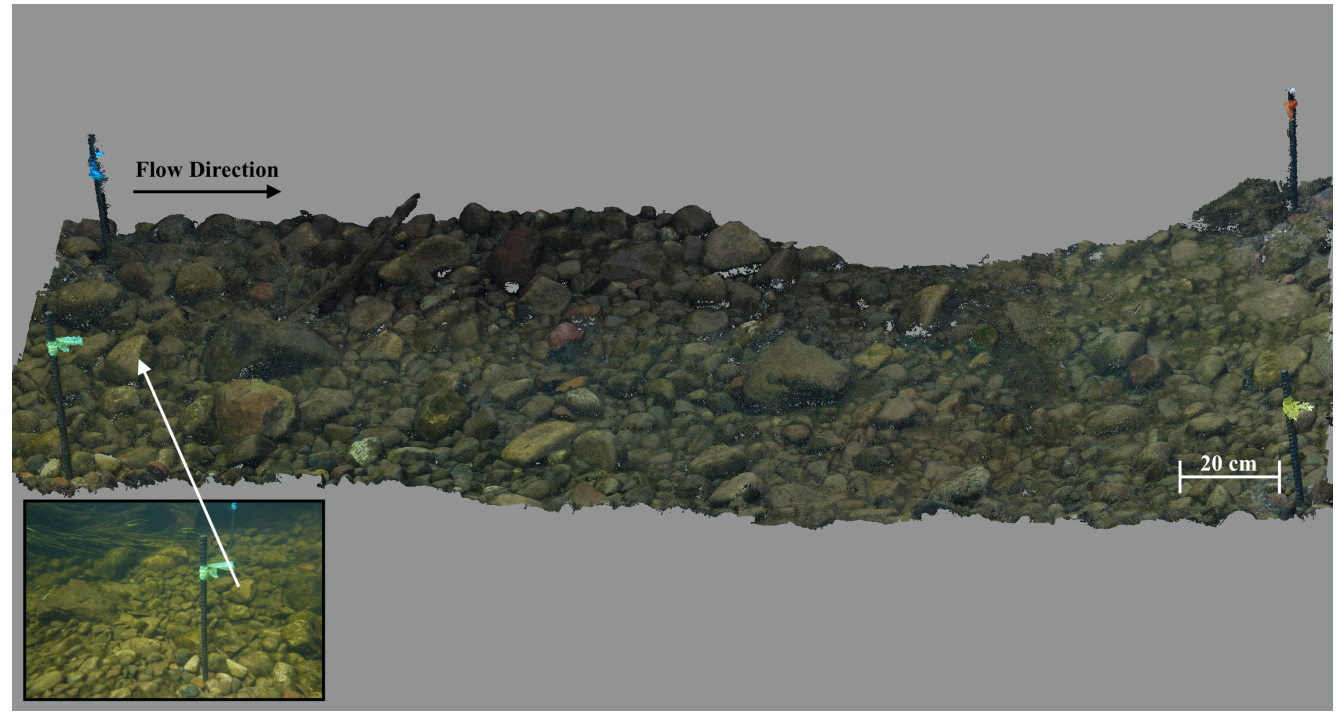

Figure 2.4. SfM derived point cloud for the $\sim 5 \mathrm{~m} 2$ area of Pilgrim River, MI streambed. Rebar with flagging represent ground control and check point locations and are the perimeter for the $\sim 2 \mathrm{~m} 2$ region analyzed. Inset image used to develop the model and white arrow pointing to the same substrate particle in the model as in the image. 


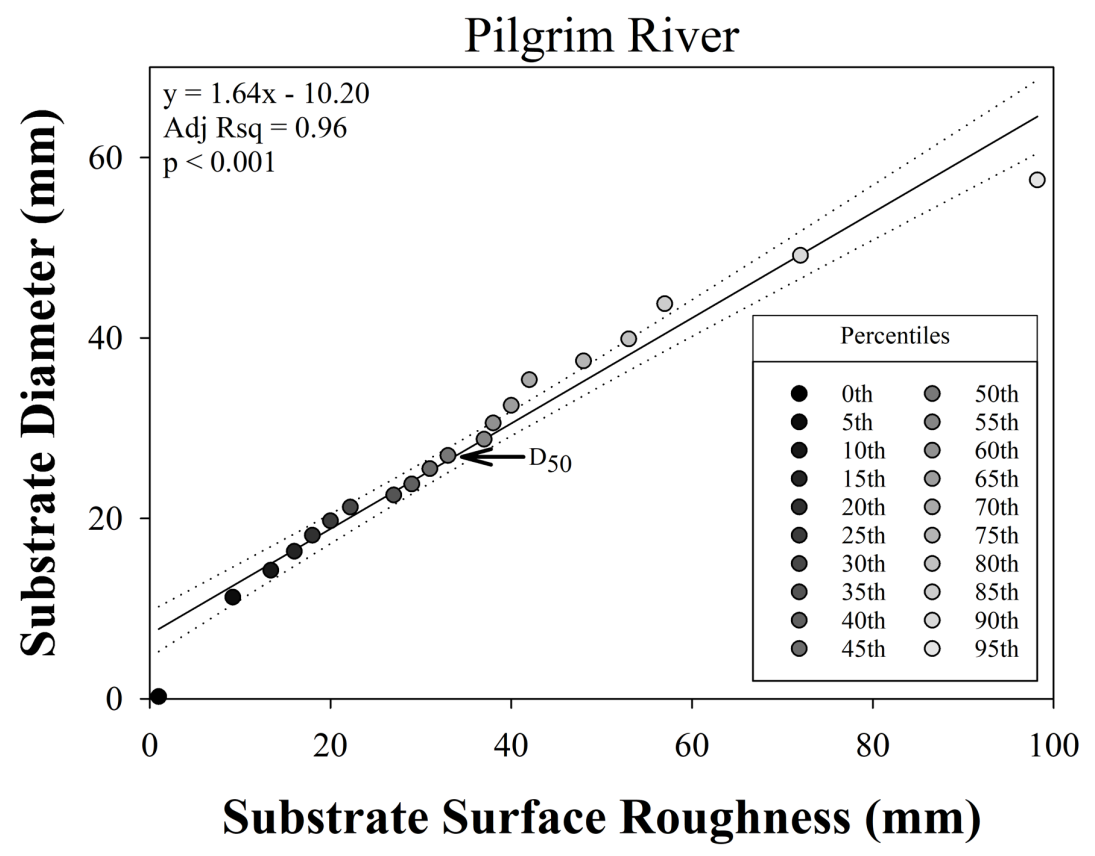

Figure 2.5. Regression model for measured substrate diameter and modeled substrate roughness from SfM derived DEM of the natural Pilgrim River streambed. Each point represents a percentile, from 0-95th, in 5\%. Solid and dotted lines represent the best fit and $95 \%$ confidence intervals, respectively. The D50 is indicated by the arrow.

\subsection{Discussion}

We have shown that SfM and underwater imagery can be used to develop high-resolution (0.3-0.5 mm) models of submerged streambeds with a high degree of precision (Table 2.1) comparable to other studies (e.g. $20 \mathrm{~mm}$; Woodget et al. 2015, James et al. 2017). These models accurately estimate pebble count diameter percentiles and quantify morphological changes at small spatial scales. Our results indicate SfM estimated roughness is comparable to and reportable in commonly used metrics (e.g. $\mathrm{D}_{50}, \mathrm{D}_{84}$ ), and may be useful as a quantitative tool comparable to pebble counts. This builds upon previous SfM work characterizing fluvial substrates (Woodget \& Austrums 2017) by expanding its use to underwater images and may be an appropriate alternative when extensive canopy and/or bank vegetation prevent through-water aerial or remote imaging. As previously shown (see Carrivick \& Smith 2019) this may be especially useful for 
repeatedly sampled submerged habitat, where pebble counts or other assessments are unsuitable, or for collecting local high-resolution data.

In our manipulated streambeds in the lab, we found a clear relationship between $\mathrm{D}_{84}$ from pebble counts and those predicted from regression models (Figure 2.3). Coupling this with the high-precision we achieved (Table 2.1) highlights the potential use of these methods for accurately characterizing temporal changes in substrate sizes within submerged streambeds. A benefit SfM is that substrates are spatially referenced and sampled with finer resolution than possible using direct measurements (e.g. pebble count). However, there are limitations to predicting pebble count diameters from roughness for streambeds with abundant fines (Figure 2.2), likely due to the pebble count's difficulty characterizing smaller $(>2 \mathrm{~mm}$ ) substrates (Hey and Thorne 1983). This results in smaller pebble count percentile being identical (e.g. $0.5 \mathrm{~mm}$ ), while equivalent roughness percentiles increase (Figure 2.2). In addition, SfM derived roughness of poorly sorted streambeds may underrepresent smaller particles, inaccurately predicting substrate diameter percentiles (Pearson et al. 2017). Although a strong linear relationship was found between the measured and estimated $\mathrm{D}_{84}$ for each artificial streambed (Figures 2.2 and 2.3), regression models may be river and/or site specific, as these relationships vary substantially across studies (Pearson et al. 2017). It is important to note that pebble counts are generally performed at coarser scales (e.g. 1-2 measurements $/ \mathrm{m}^{2}$ ) than done in this study ( $\geq 100$ particles in $1 \mathrm{~m}^{2}$ ) and others relating roughness to substrate diameter (Heritage \& Milan 2009, Pearson et al. 2017). For regression models to be highly predictive, initial site assessment may require higher resolution pebble counts, but the effect of pebble count density on this relationship was not assessed. Despite these limitations, SfM avoids the biases of bulk sampling by only evaluating the substrate surface, and thus relevant to organisms that interact with and physical dynamics that operate at this sediment/water interface. When using these techniques to relate roughness to substrate percentiles in sandy and/or poorly sorted streambeds care should be taken when evaluating results. 
Substantial progress has been made using high-resolution topographic surveys such as TLS and SfM, and while both approaches produce comparable models (James \& Robson 2012, Hamshaw et al. 2018), SfM has the advantage of using lower-cost (Castillo et al. 2012) and more portable equipment (Smith et al. 2016). Prosdocimi et al. (2015) highlighted the low-cost aspect of SfM by characterizing bank erosion and deposition along an agricultural stream using a DSLR and smartphone camera. When coupled with unmanned aerial platforms, larger scale assessments can be performed (Woodget \& Austrums 2017), such as quantifying scour and deposition for exposed regions of river channels (Marteau et al. 2017). Along with measuring stream morphology, coupling SfM with other assessments may provide new insights, such as quantifying fish habitat suitability by combining SfM and hydrodynamic models (Tamminga et al. 2015).

Like other remote sensing techniques, environmental limitations exist, including water depth and clarity, surface turbulence, and floating particulate matter that are difficult to sample or can introduce model errors (Woodget et al. 2015, Dietrich 2017). In addition to a maximum water depth that can be sampled (e.g. Woodget et al. 2015), there is likely a minimum depth at which achieving $\geq 60 \%$ image overlap of underwater images becomes unrealistic. Therefore, proper planning is important for developing complete and accurate models. This study was performed on small spatial scales as a proof of concept and should be directly applicable for sampling individual habitats (e.g. $\leq 10 \mathrm{~m}^{2}$ ). To apply these methods beyond this scale (e.g. reach scale) would require careful site planning to ensure all relevant habitat can be imaged, additional ground control and check points, and a more intense sampling effort, which has not yet been evaluated.

Anthropogenic impacts have resulted in significant changes to fluvial sediment supply (Owens et al. 2005). Therefore, accurately characterizing substrates is important for restoration and understanding environmental conditions essential for biota. Coupling low cost digital cameras with SfM means small scale $\left(\leq 10 \mathrm{~m}^{2}\right)$ remote sensing is an accessible option for stream monitoring, and substantial progress has been made modeling exposed streambeds, as well as using through-water images to quantify submerged topography. 
We have shown that models derived from underwater images can accurately predict pebble count percentiles for streambeds with a low abundance of fine sediment. Throughwater images allow for larger portions (i.e. submerged) of rivers to be sampled using SfM at larger scales. Our study indicates that underwater images are useful at small scales with high-resolution and where through-water imaging is not feasible, thus broadening the types of rivers, situations, and problems to which SfM can be applied. In addition to using underwater SfM to predict pebble count percentiles, the high-resolution and precision achievable with this technology suggests it may be useful in measuring and monitoring underwater topography such as for longer term or repeated assessments of the effects of restoration on streambed substrates. Based on the results of this study and others, the ability to rapidly collect high-resolution data that accurately and efficiently characterizes streambed substrate condition along with its increased use for assessing ecosystems (Carrivick \& Smith 2019) warrants the continued application and refinement of SfM for sampling submerged stream habitat.

\subsection{References}

Aberle, J., and G. M. Smart. 2003. The influence of roughness on flow resistance on steep slopes. Journal of Hydraulic Research 41(3)259-269.

Agisoft. 2018. Agisoft photoscan user manual: Professional edition, version 1.4.

Allen, J. D., M. M. Castillo. 2007. Stream ecology: structure and function of running water, 2nd edition. Springer, New York.

Angradi, T. R. 1999. Fine sediment and macroinvertebrate assemblages in Appalachian streams: A field experiment with biomonitoring applications. Journal of the North American Benthological Society 18(1):49-66

Bain, M. B., and N. J. Stevenson, editors. 1999. Aquatic habitat assessment: common methods. American Fisheries Society, Bethesda, Maryland.

Benda, L., K. Andras, D. Miller, P. Bigelow. 2004. Confluence effects in rivers: interactions of basin scale, network geometry, and disturbance regimes. Water Resources Research 40:W05402.

Biggs, B. J. F., V. I. Nikora, and T. H. Snelder. 2005. Linking scales of flow variability to 
lotic ecosystem structure and function. River Research and Application 21:283-298. Bjornn, T. C., M. A. Brusven, M. P. Molnau, J. H. Milligan, R.A. Klamt, E. Chacho, and C. Schaye. 1977. Transport of granitic sediment in streams and its effects on insects and fish. Bulletin 17. College of Forestry, Wildlife and range Sciences. University of Idaho, Moscow, ID, USA.

Brasington, J., D. Vericat, and I. Rychkov. 2012. Modeling river bed morphology, roughness, and surface sedimentology using high resolution terrestrial laser scanning. Water Resources Research 48, W11519.

Castillo, C., R. Perez, M. James, J. N. Quinton, E. V. Taguas, J. A. Gomez. 2012. Comparing the accuracy of several field methods for measuring gully erosion. Soil \& Water Management \& Conservation 76:1319-1322.

Carrivick, J. L. and M. W. Smith. 2019. Fluvial and aquatic applications of Structure from Motion photogrammetry and unmanned aerial vehicle/drone technology. WIREs Water 2019;6:e1328.

Church, M. 2002. Geomorphic thresholds in riverine landscapes. Freshwater Biology 47:541-557.

Cover, M. R., C. L. May, W. E. Dietrich, and V. H. Resh. 2008. Quantitative linkages among sediment supply, streambed fine sediment, and benthic macroinvertebrates in Norther California streams. Journal of the North American Benthological Society. 27:135-149.

Daniels, M. D., and M. H. McCusker. 2010. Operator bias characterizing stream substrates using Wolman pebble counts with a standard measurement template. Geomorphology 115:194-198.

Dietrich, J. T. 2017. Bathymetric Structure-from-Motion: extracting shallow stream bathymetry from multi-view stereo photogrammetry. Earth Surface Processes and Landforms 42:355-364.

Entwistle, N. S., and I. C. Fuller. 2009. Terrestrial laser scanning to derive surface grain size facies character of gravel bars. Laser Scanning for the Environmental Sciences 7:102-114.

EPA. 2017. National Water Quality Inventory: Report to Congress. EPA 841-R-16-011 
Esposito, G. G. Mastrorocco, R. Salvini, M. Oliveti, P. Starita. 2017. Application of UAV photogrammetry for the multi-temporal estimation of surface extent and volumetric excavation in the Sa Pigada Bianca open-pit mine, Sardinia, Italy. Environmental Earth Sciences 76:203.

Fausch, K. D. 2014. A historical perspective on drift foraging models for stream salmonids. Environmental Biology of Fishes 97:453-464.

Fonstad, M. A., J. T. Dietrich, B. C. Courville, J. L. Jensen, and P. E. Carbonneau. 2013. Topographic structure from motion: a new development in photogrammetric measurement. Earth Surface Processes and Landforms 38(4):421-430.

Hames, D. S., B. Conrad, A. Pleus, D. Smith. 1996. Field comparison of the McNeil sampler with three shovel-based methods used to sample spawning substrate composition in small streams. Northwest Indian Fisheries Commission Report TFWAM-9-96-005.

Hamshaw, S. D., T. Bryce, D. M. Rizzo, J. O’Neil-Dunne, J. Frolik, M. M. Dewoolkar. 2018. Quantifying streambank movement and topography using unmanned aircraft system photogrammetry with comparison to terrestrial laser scanning. River Research and Application 33: 1354-1367.

Hershey, A. E., G. A. Lamberti, D. T. Chaloner, and R. M. Northington. 2010. Aquatic insect ecology. In J. H. Thorp and A. P. Covich (Eds.), Ecology and classification of North American freshwater invertebrates 3rd edition (pp.659-694). Academic Press, San Diego, California.

Hey, R. D., and C. R. Thorne. 1983. Accuracy of surface samples from gravel bed material. Journal of Hydrologic Engineering 109:842-851.

Heritage, G. L., and D. J. Milan. 2009. Terrestrial Laser Scanning of grain roughness in a gravel-bed river. Geomorphology 113:4-11.

Hodge, R., J. Brasington, K. Richards. 2009. In situ characterization of grain-scale fluvial morphology using terrestrial laser scanning. Earth Surface Processes and Landforms 34:954-968.

Hoover, T. M., J. S. Richardson, and N. Yonemitsu. 2006. Flow-substrate interactions create and mediate leaf litter resource patches in streams. Freshwater Biology 
51:435-447.

James, M. R., and S. Robson. 2012. Straightforward reconstruction of 3D surfaces and topography with a camera: Accuracy and geoscience application. Journal of Geophysical Research 117:1-17.

James, M. R., and S. Robson. 2014. Mitigating systematic error in topographic models derived from UAV and ground-based image networks. Earth Surface Processes and Landforms 39:1413-1420.

James, M.R., S. Robson, M. W. Smith. 2017. 3-D uncertainty-based topographic change detection with structure-from-motion photogrammetry: precision maps for ground control and directly georeferenced surveys. Earth Surface Processes and Landforms 42:1769-1788.

Javernick, L., J. Brasington, and B. Caruso. 2014. Modeling the topography of shallow braided rivers using Structure-from-Motion photogrammetry. Geomorphology 213:166-182.

Jones, J. I., A.L. Collins, P.S. Naden, and D.A. Sear. 2012a. The relationship between fine sediment and macrophytes in rivers. River Research and Applications 28:10061018.

Jones, J. I., J. F. Murphy, A. L. Collins, D. A. Sear, P. S. Naden, and P. D. Armitage. 2012b. The impact of fine sediment on macro-invertebrates. River Research and Applications 28:1055-1071.

Kemp, P., D. Sear, A. Collins, P. Naden, and I. Jones. 2011. The impacts of fine sediment on riverine fish. Hydrological Processes 25(11):1800-1821.

Kondolf, G. M., and M. G. Wolman. 1993. The sizes of salmonid spawning gravels. Water Resources Research 29(7):2275-2285.

Lague, D., N. Brodu, and J. Leroux. 2013. Accurate 3D comparison of complex topography with terrestrial laser scanner: Application to the Rangitikei canyon (NZ). ISPRS Journal of Photogrammetry and Remote Sensing 82:10-26.

Liao, J. C. 2007. A review of fish swimming mechanics and behavior in altered flow. Philosophical Transactions of the Royal Society B 362:1973-1999.

Lucieer, A., S. M. de Jong, D. Turner. 2014. Mapping landslide displacements using 
Structure from Motion (SfM) and image correlation of multi-temporal UAV photography. Progress in Physical Geography 31(1):97-116.

Marcarelli, A. M., C. J. Huckins, S. L. Eggert. 2015. Sand aggradation alters biofilm standing crop and metabolism in a low-gradient Lake Superior tributary. Journal of Great Lakes Research 41:1052-1059.

Marcus, W. A., S. C. Ladd, J. A. Stoughton, and J. W. Stock. 1995. Pebble counts and the role of the user-dependent bias in documenting sediment size distributions. Water Resources Research 31:2625-2631.

Marteau, B., D. Vericat, C. Gibbins, R. Batalla, and D. Green. 2017. Application of Structure-from-Motion photogrammetry to river restoration. Earth Surface Processes and Landforms 42:503-515.

May, C. L., B. Pryor, T. E. Lisle, and M. Lang. 2009. Coupling hydrodynamic modeling and empirical measures of bed mobility to predict the risk of scour and fill of salmon redds in a large regulated river. Water Resources Research 45:W05402

Molinos, J. G., and I. Donohue. 2009. Differential contribution of concentration and exposure time to sediment dose effects on stream biota. Journal of the North American Benthological Society 28:110-121.

Owens, P. N. R. J. Batalla, A. J. Collins, B. Gomez, D. M. Hicks, A. J. Horowitz, G. M. Kondolf, M. Marden, M. J. Page, D. H. Peacock, E. L. Petticrew, W. Salomons, and N. A. Trustrum. 2005. Fine-grained sediment in river systems: environmental significance and management issues. River Research and Applications 21:693-717.

Palmer, M. A., H. L. Menninger, and E. Bernhardt. 2010. River restoration, habitat heterogeneity and biodiversity: a failure of theory or practice. Freshwater Biology 55:205-222.

Pearson, E., M. W. Smith, M. J. Klaar, and L. E. Brown. 2017. Can high resolution 3D topographic surveys provide reliable grain size estimates in gravel bed rivers? Geomorphology 293:143-155.

Prosdocimi, M., S. Calligaro, G. Sofia, G. Dalla Fontana, and P. Tarolli. 2015. Bank erosion in agricultural drainage networks: new challenges from structure-frommotion photogrammetry for post-event analysis. Earth Surface Processes and 
Landforms 40:1891-1906.

Raven, E. K., S. N. Lane, R. I. Ferguson, and L. J. Bracken. 2009. The spatial and temporal patterns of aggradation in a temperate, upland, gravel-bed river. Earth Surface Processes and Landforms 34:1181-1197

Robert, A. 2011. Flow resistance in alluvial channels. Progress in Physical Geography 35(6):765-781.

Smith, M., D. Vericat, C. Gibbins. 2012. Through-water terrestrial laser scanning of gravel beds at the patch scale. Earth Surface Processes and Landforms 37:411-421.

Smith, M. W., J. L. Carrivick, and D. J. Quincey. 2016. Structure from motion photogrammetry in physical geography. Progress in Physical Geography 40(2):247275.

Suttle, K. B., M. E. Power, J. M. Levine, and C. McNeely. 2004. How fine sediment in riverbeds impairs growth and survival of juvenile salmonids. Ecological Applications 14(4):969-974.

Tamminga, A., C. Hugenholtz, B. Eaton, and M. Lapointe. 2015. Hyperspatial remote sensing of channel reach morphology and hydraulic fish habitat using unmanned aerial vehicle (UAV): A first assessment in the context of river research and management. River Research and Applications 31:379-391.

Walling, D. E. 1999. Linking land use, erosion and sediment yield in river basins. Hydrobiologia 410:223-240.

Waters, T. F. 1995. Sediment in streams: sources, biological effects, and control. American Fisheries Society Monograph 7.

Westoby, M. J., J. Brasington, N. F. Glasser, M. J. Hambrey, and J. M. Reynolds. 2012. "Structure-From-Motion" photogrammetry: A low-cost, effective tool for geoscience applications. Geomorphology 179:300-314.

Williams, D. D., and J. H. Mundie. 1978. Substrate size selection by stream invertebrates and the influence of sand. Limnology and Oceanography 23:1030-1033.

Wohl, E. E., D. J. Anthony, S. W. Madsen, and D. M. Thompson. 1996. A comparison of surface sampling methods for coarse fluvial sediments. Water Resources Research 32(10):3219-3226. 
Wohl, E., B. P. Bledsoe, R. B. Jacobson, N. L. Poff, S. L. Rathburn, D. M. Walters, and A. C. Wilcox. 2015. The natural sediment regime in rivers: broadening the foundation for ecosystem management. BioScience 65(4):358-371.

Wolman, M.G. 1954. A method of sampling coarse river-bed materials. Transactions of Geophysical Union 35:951-956.

Wood, P. J., and P. D. Armitage. 1997. Biological effects of sediment in the lotic environment. Environmental Management 21:203-217.

Woodget, A. S., P. E. Carbonneau, F. Visser, and I. P. Maddock. 2015. Quantifying submerged fluvial topography using hyperspatial resolution UAS imagery and structure from motion photogrammetry. Earth Surface Processes and Landforms 40(1):47-64.

Woodget, A. S., and R. Austrums. 2017. Subaerial gravel size measurement using topographic data derived from a UAV-SfM approach. Earth Surface Processes and Landforms 42(9):1434-1443. 


\section{Temporal dynamics of large wood, stream channel morphology, and substrates in a selectively logged watershed of the western Upper Peninsula, Michigan.}

\subsection{Abstract}

Streams in the western Upper Peninsula of Michigan and throughout the upper Great Lakes region have been impacted by historical logging, yet relative to other forested regions of North America, little is known about current conditions and the impacts of contemporary and historical logging in this region. This presents a management challenge due to the geomorphological, climatic, and biological differences between streams in the upper Great Lakes and those in the western US. What has been learned from the decades of research in the western US and elsewhere may not be applicable in this region. In this study we sought to characterize how large wood volume and abundance, streambed substrates, and channel morphology (coefficient of variation for width and depth, width:depth ratio) changed in six streams in a selectively-logged watershed in the western Upper Peninsula, Michigan since they were last surveyed in 2001. We expected that sites with higher volumes of large wood might be more temporally stable as indicated by less change in substrates and channel morphology between the two sampling periods. Four of the six streams showed decreased large wood volume and the number of large wood pieces decreased in all the sites from 2001 to 2015/2017. Substrate characteristics changed between the two sampling periods, with pebble count $\mathrm{D}_{84}$ values increasing in half the streams and decreasing in the other half, and percent fine sediment increasing in all but one. Changes in channel morphology were also variable between the sampling periods for coefficients of variations of channel width (two sites increased and four decreased), coefficients of variation for channel depth (four sites increased and two decreased), and width:depth ratios (three sites increased while three decreased). There was also no clear trend in stability of large wood and time since most recent logging for these sites. Although we expected to see differences between streams, it may be that 
continued logging of this watershed has resulted not only less wood, but smaller wood, and that not enough wood is present in these sites to detect a relationship with substrate composition and channel morphology

\subsection{Introduction}

Large woody material is an important component of forested streams that influences channel morphology by both inhibiting and promoting the movement of streambed materials. Large wood can lead to reduced particle transport by trapping fine sediments (Thompson 1995, May and Gresswell 2003) and can promote channel stability by preventing stream bank erosion (Gurnell et al. 2002). It also facilitates changes in channel morphology by directing or concentrating localized scour of sediments (Bisson et al. 1987, Andrus et al. 1988). In forested basins, large wood contributes to physical features of river habitat (e.g. channel morphology and substrate composition) that support instream biota (Angermeier \& Karr 1984) such as macroinvertebrates (Benke and Wallace 2003), fish (Dolloff and Warren 2003) and other organisms.

Instream wood can be dynamic as it is recruited, dispersed, and broken down over time (Wohl and Goode 2008). Resident times of instream wood range from a few years (Wohl and Goode 2008) to decades and centuries (Hyatt and Naiman 2001) depending on factors related to its size and shape, as well as river characteristics such as flow (Wohl and Goode 2008) and valley configuration (Morris et al. 2010, Jones et al. 2011). Jams of wood can persist for even longer periods of time (Wohl 2014), as new wood is added while existing wood is broken down via biological (Gulis et al. 2004) and physical processes (Merten et al. 2010a). As a result of the important roles that wood performs, its loss can negatively affect stream ecosystems (Naiman et al. 2002). When wood is removed from a channel, local flow characteristics change, initiating erosion and deposition as the stream adjusts to the new conditions (Smith et al. 1993). This often increases scouring of sediments (Beschta 1979, Diez et al. 2000, Dumke et al. 2010) and reduces channel stability (Bilby 1984, Gurnell \& Sweet 1998). In smaller streams, 
particularly in higher gradient systems, watershed disturbances that result in a loss of large wood can have long-term influences on sediment transport and storage (May and Gresswell 2003).

Streams in the upper Great Lakes region and elsewhere in the United States have been negatively impacted by significant logging activity (Wohl 2014). Many forests in Michigan were heavily logged throughout the late 1800s into the early 1900s (Maybee 1960), which degraded fluvial habitat and is partially attributed to the loss of native species like arctic grayling (Thymallus arcticus) from the state (Vincent 1962). Although this massive tree harvesting occurred more than a century ago, many forests throughout the state have been routinely managed through logging activity (Pugh 2018). Since the mid- $20^{\text {th }}$ century much of the logging that occurs in northern hardwood forests is selection harvest of single or small groups of trees rather than clear-cutting entire stands (Seymour 1995). To mitigate the impact of logging, best management practices (BMPs) were developed following the passage of the Clean Water Act in 1972 (Phillips and Blinn 2004) and suggest maintaining a $30 \mathrm{~m}$ buffer around the channel (MIDNR 2018) but allow for harvesting within the zone provided impacts to water quality and the stream are minimized (MIDNR 2018). Although BMPs can protect streams from the negative effects of forest harvest when implemented properly (Cristan et al. 2016), research from streams in the western Upper Peninsula, Michigan (Flaspohler et al. 2002) and elsewhere in the western US suggest variation in the following of BMPs (Ice et al. 2004) and that logging following BMPs may still result in degradation of stream ecosystems (Van Dusen et al. 2005).

There is comparatively less known about the conditions that exist in forested streams of the Upper Great Lakes (Cordova et al. 2007, see also Wohl et al. 2017) as well as the impacts of logging in this region (see Van Dusen et al. 2005) than elsewhere in North America such as the Pacific Northwest. This presents a challenge for understanding the implications of instream wood because it differs between regions as a result of factors including forest type (Harmon et al. 1986), logging history (Ralph et al. 1994), and 
geomorphology (Martin 2001, Livers \& Wohl 2016). The volume of wood in some Upper Great Lakes streams has been shown to be much lower than, for example, western streams where extensive wood related river research has been conducted (Cordova et al. 2007). While the mechanisms are not fully understood, selection logging in an Upper Great Lakes mixed hardwood forest has been associated with decreases in instream habitat quality and brook trout (Salvelinus fontinalis) density and biomass (Van Dusen et al. 2005), as well as bird species richness (Flaspohler et al. 2002).

In this study we investigated temporal dynamics of instream large wood, channel morphology, and substrate composition in selectively logged forested streams in western Upper Peninsula, Michigan. This was accomplished by comparing recent data gathered in this study to data collected when these sites were last surveyed in 2001 (Burgess 2008). We predicted that sites with more large wood in 2001 would have a more stable substrate composition and channel morphology (i.e. substrate characteristics would show less change between the two sampling periods).

\subsection{Methods}

\subsubsection{Study Sites}

The Otter River watershed is located in the western Upper Peninsula, Michigan and drains $465 \mathrm{~km}^{2}$ of land in Houghton, Baraga, and Ontonagon counties. The watershed is comprised of approximately $79 \%$ forest and $12 \%$ wetland, with the remaining $9 \%$ being a mix of agriculture, and grassland. Starting in the mid 1800s the forests in the Otter River Watershed along with other regions in the upper Great Lakes were extensively logged such that by 1935 they were less than half their original size (Leatherberry \& Spencer 1996). For this research, six second-order streams were chosen based on biological and physical data collected within the watershed in 2001 and 2002 (Huckins and Burgess 2004, Van Dusen et al. 2005, Burgess 2008; Figure 3.1). The six streams flow through selectively logged state and commercial forest land (See Table 3.1 for most recent logging) and join the West Branch $(\mathrm{n}=2)$ and the North Branch $(\mathrm{n}=4)$ of the Otter River 
before flowing into the Keweenaw Waterway via the main branch of the Otter and the Sturgeon Rivers (Figure 3.1). In 2015, a 100 m study reach containing multiple channel geomorphic units (e.g. pool, riffle, run) was relocated in each of the streams using GPS waypoints, and site descriptions (Burgess unpublished data). All sampling from Burgess (2008) and this study followed similar protocols unless noted otherwise.

Table 3.1 Past logging of Otter River Watershed sites. Years since adjacent logging data from Burgess (2008). Available catchment logging data provided by Mi-DNR.

\begin{tabular}{lcc}
\hline \multicolumn{1}{c}{ Site } & $\begin{array}{c}\text { Years since } \\
\text { adjacent logging }\end{array}$ & $\begin{array}{c}\text { Years since } \\
\text { catchment logging }\end{array}$ \\
\hline Beaver (BEC) & 35 & 15 \\
Bart (BTC) & 17 & - \\
North Bear (NBR) & 15 & 3 \\
Otter Siding Rd (OSR) & 28 & - \\
Thirteen Mile (THM) & 25 & - \\
West Br. Sante (WBS) & 25 & - \\
\hline
\end{tabular}

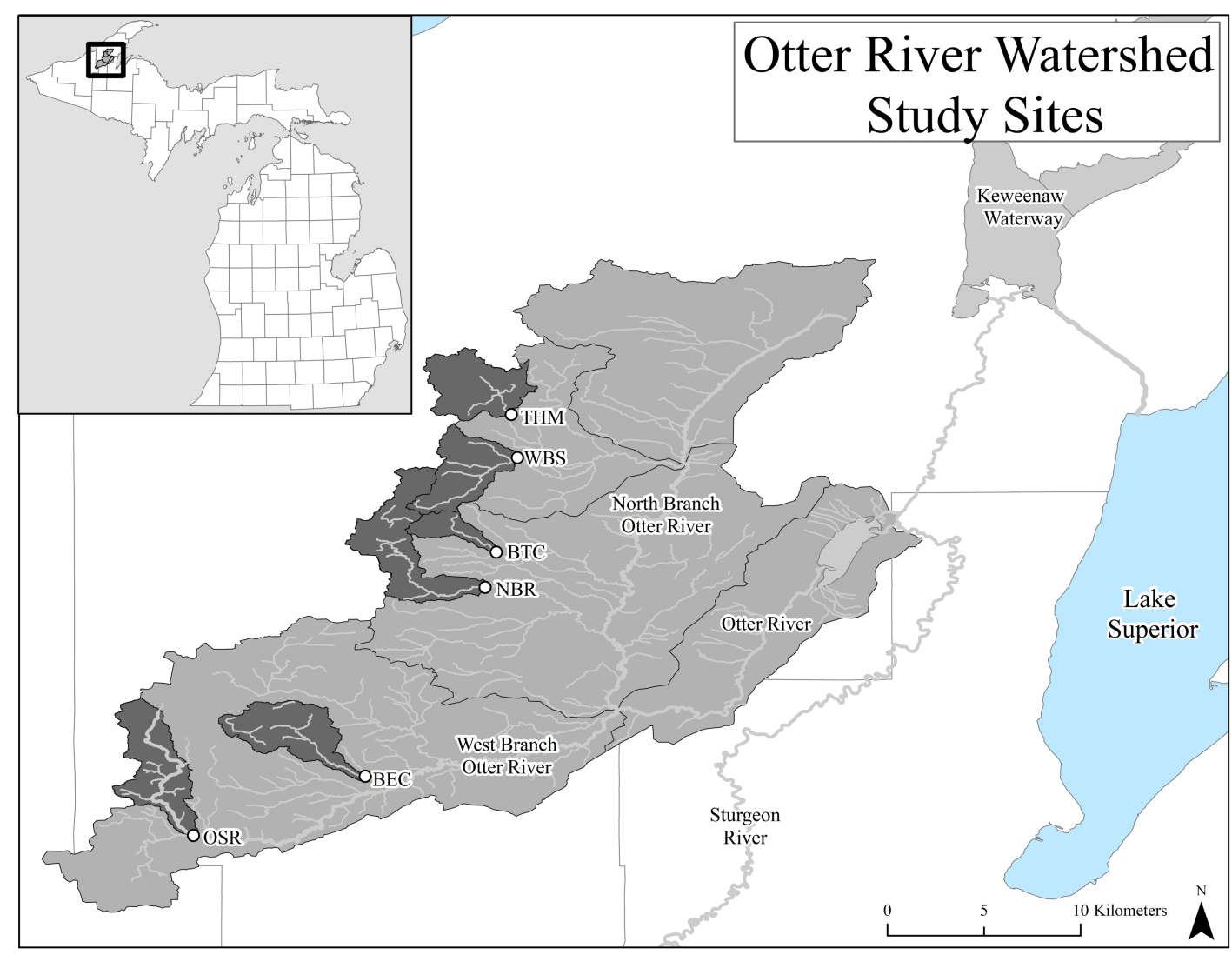

Figure 3.1 Map of study sites in Otter River Watershed, Michigan. Circles are the downstream boundary of each site. $\mathrm{BEC}=$ Beaver Creek, $\mathrm{BTC}=$ Bart Creek, NBR $=$ 
North Branch Bear Creek, OSR = Otter Siding Road, THM = Thirteen Mile Creek, WBS $=$ West Branch Sante Creek. Dark gray shaded areas represent the catchment area for each site. Light gray shaded area is the Otter River Watershed.

To approximate how larger scale climate and streamflow characteristics may have changed in the region to better understand changes in the watershed between 2001 and 2015/2017 we used data from two gaged rivers within $35 \mathrm{~km}$ of the study sites. The US Geological Survey maintains gaging stations on the Sturgeon (\#04040500) and Trap Rock (\#04043150) rivers, which drain $443 \mathrm{~km}^{2}$ and $73 \mathrm{~km}^{2}$, respectively. Cumulative $10 \%$ exceedance discharge estimates for these gaging stations incorporate data from as far back as 1913, and we compared these cumulative estimates to those quantified on an annual basis (available from 2006-present) to understand how annual discharges compared to the cumulative 10\% exceedance discharges in these rivers. Both rivers displayed similar trends, with three years of $10 \%$ exceedance discharges being greater than the long term $10 \%$ exceedance discharge (as much as 53\% greater), and the remaining 9 years being equal to or less than the long term exceedance value (as much as $57 \%$ lower). Based on the proximity of the Trap Rock and Sturgeon rivers to the Otter River Watershed, it is plausible that our study sites experienced similar trends in discharge during this period. Additionally, a National Oceanic and Atmospheric Administration (NOAA) storm event database search from 2001 to 2017 indicated 51 days with severe events (i.e. flash flood, flood, heavy rain, high wind, strong wind) for Houghton, County. Of these, 22 days of rain and/or flood events were recorded. Along with high wind and stream discharge periods due to storms, other disturbances that may have occurred in the Otter River watershed, but we are unaware of, include road and other developments, damming of streams, and impacts of invasive species such as emerald ash borer (Agrilus planipennis).

\subsubsection{Substrates}

A modified Wolman pebble count (Wolman 1954) was performed in the tributaries to characterize overall substrate size composition. Starting at the downstream boundary of the sites, individual substrate particles were indiscriminately pulled from the streambed 
and measured with calipers along their intermediate axis to the nearest $1 \mathrm{~mm}$. Particles were selected while moving upstream in a zig-zag path between the banks of the stream until $>150$ individual substrate particles were measured throughout the length of the site. Any particle encountered $\leq 2 \mathrm{~mm}$ was classified as a fine, e.g., sand (Wentworth 1922) and assigned a diameter of $2 \mathrm{~mm}$ for analysis. These data were used to quantify the $16^{\text {th }}$ $\left(\mathrm{D}_{16}\right), 50^{\text {th }}\left(\mathrm{D}_{50}\right)$ and $84^{\text {th }}$ percentile $\left(\mathrm{D}_{84}\right)$ substrate diameters. These data were also used to calculate substrate heterogeneity, defined as the ratio of $\mathrm{D}_{84} / \mathrm{D}_{50}$ (Laub et al. 2012), and the gradation coefficient, which quantifies the range of sediment size distribution and defined as half the sum of the $\mathrm{D}_{84} / \mathrm{D}_{50}$ and $\mathrm{D}_{50} / \mathrm{D}_{16}$ ratios, (Bunte and Abt 2001).

The bulk shovel measurement method (Hames et al. 1996) was used to quantify percent of fine sediment at the midpoint of transects at the downstream, midstream, and upstream of each of the sites. Total volume of each bulk sample of streambed substrates were measured via water displacement prior to being rinsed through 0.25 and $2 \mathrm{~mm}$ sieves to separate the fine $(0.25-2 \mathrm{~mm})$ from coarse particles $(>2 \mathrm{~mm})$. The percent fine substrate was calculated from the ratio of volume of fines and total volume from the bulk sample. For samples with very large amounts of fine sediment, the percent fine substrates were estimated as 100 - percent of coarse substrate particles, which were more efficient to quantify.

\subsubsection{Large Wood}

Large woody material, having a diameter $\geq 0.1 \mathrm{~m}$ and length $\geq 1 \mathrm{~m}$ (Naiman et al. 2002, Wohl et al. 2016) was surveyed using a Leica T11 total station (Leica Geosystems) to mark the end locations of wood to measure length, and a meter stick to measure the diameter to the nearest $0.01 \mathrm{~m}$ at the midpoint of each piece. From these data, abundances of large wood (i.e. number of pieces) were standardized per $100 \mathrm{~m}$ of stream to facilitate comparison to other studies. Volume of large wood was quantified by treating the logs as

a cylinder. Some of the sites contained large wood jams comprised of numerous pieces of large (as defined above) and small wood. For these features the perimeter of the jams were measured using the total station to produce a polygon representing the surface area 
which was multiplied by the average water depth at these locations to approximate jam volume. To facilitate comparison across sites, we standardized wood volume by dividing the volume by the area of the site to result in a metric of wood density (LWD $\mathrm{m}^{3} /$ Stream surface area $\mathrm{m}^{2}$ ). Initial measurements of large individual pieces of wood as well as jams in 2001 were not accomplished using a total station, but rather used a flexible tape and meter stick to measure length and diameter, respectively (Burgess 2008). In contrast to how we estimated wood volume within jams, during initial sampling all large wood encompassed within jams were individually measured and summed to quantify volume (Burgess 2008).

\subsubsection{Channel Morphology}

A topographic survey of each site was conducted using a Leica TS11 total station (Leica Geosystems). Starting at the downstream boundary of each site, the latitude, longitude, and elevation of spatial points were measured throughout the rivers and referenced using the local coordinate system. Point spacing in areas with greater topographic relief were more closely spaced relative to less dense point spacing in lower relief areas. Overall point spacing for each survey ranged from $1.0-2.1$ points $/ \mathrm{m}^{2}$. Burgess (2008) characterized channel width and depth by setting up a cross-channel transect within each of the pools, riffles and runs for each site. For each transect (transect range: 12-18 per tributary) the channel width was measured to the nearest $0.1 \mathrm{~m}$ and the water depth was measured to the nearest $0.01 \mathrm{~m}$ at five points equally spaced along the transect. Channel morphology data from transect measurements (2001) and total station surveys (2017) were used to calculate coefficients of variation (CV) for channel width and depth, which act as estimates of complexity in channel morphology (Laub et al. 2012). In addition, these data were used to calculate width:depth ratios based on mean depths of each site.

\subsubsection{Analysis}

To compare the data from the two sampling periods (2001 vs 2015/2017), paired-sample t-tests were performed for substrate characteristics including $\mathrm{D}_{16}, \mathrm{D}_{50}, \mathrm{D}_{84}$, percent fine, substrate heterogeneity and substrate gradation coefficients. Paired sample t-tests were 
also performed for large wood volume and abundance while a two-sample t-test was used for changes in large wood diameter. Channel morphology changes were analyzed using two-sample (mean width and depth), and paired sample (i.e. width:depth ratio, CV of channel width and depth) t-tests. All values reported are mean \pm standard deviation unless noted otherwise.

To visualize how the sites changed from 2001 to 2015/2017 we performed a Non-metric Multidimension Scaling (NMDS) analysis on metrics of substrates, channel morphology, and large wood volume using JMP 14.0 (SAS Institute, Cary, NC, USA). For substrates the $\mathrm{D}_{16}, \mathrm{D}_{50}$, and $\mathrm{D}_{84}$ were used, and for channel morphology the width:depth ratio as well as CV of width and depth for each site were used. In order to ensure that no data would disproportionally influence the ordination, a z-score transformation was done to normalize the data. For each variable (e.g. $\left.\mathrm{D}_{16}\right)$ the mean value was subtracted from each individual value and then divided by the standard deviation. After the NMDS was performed for both the 2001 and 2015/2017 data, they were plotted together, and vectors were added manually to connect the sites across time.

\subsection{Results}

\subsubsection{Substrates}

Major features of the streambed substrate size distribution within sites were remarkably similar between the two survey periods separated by 14 years. In both survey periods BEC, BTC and OSR tended to have the smallest substrate sizes while THM and WBS had the largest substrate particles. The $16^{\text {th }}$ percentile substrate diameters in 2001 were similar to those in $2015\left(\mathrm{t}_{5}=0, \mathrm{p}=1.0\right)$, and ranged from 2-12 mm, and 2-15 mm, respectively (Table 3.2 ). WBS had the largest $D_{16}$ value and was the only site with $D_{16}>2$ $\mathrm{mm}$ in both periods. Median substrate sizes $\left(\mathrm{D}_{50}\right)$ in 2001 ranged from $6-40 \mathrm{~mm}$, and were similar to estimates of $2-43 \mathrm{~mm}$ that we calculated from the same sites in 2015 ( $\mathrm{t}_{5}$ $=0.64, \mathrm{p}=0.55$; Table 3.2). For both sampling periods, THM and WBS had the largest $\mathrm{D}_{50}$, while BTC and OSR had the smallest $\mathrm{D}_{50}$ in 2001 was in BTC and the smallest D50 
in 2015 was in OSR. The values of substrate $D_{84}$ ranged from $27-85 \mathrm{~mm}$ in 2001 and 15 - $87 \mathrm{~mm}$ in 2015 (Table 3.2). Matching the pattern for median diameters, THM and WBS had the largest $\mathrm{D}_{84}$ values for both periods, while the smallest $\mathrm{D}_{84}$ values were found in OSR and BTC in 2001 and OSR and BEC in 2015 (Table 3.2). As with the $16^{\text {th }}$ and $50^{\text {th }}$ percentiles, no major change was detected in the $\mathrm{D}_{84}$ estimates between the two sampling periods $\left(\mathrm{t}_{5}=0.04, \mathrm{p}=0.97\right)$.

Table 3.2. Characteristics for Otter River Watershed sites from 2001 (upper, from Burgess 2008) and present-day sampling (lower). Channel Width, depth, and percent fine substrates are all mean \pm standard deviation. Sixteenth (D16), Median (D50) and 84th percentile substrate diameters (D84) were derived from Wolman pebble counts (Wolman 1954). Percent fine substrate was calculated from bulk sediment samples (see Hames et al. 1996).

\begin{tabular}{|c|c|c|c|c|c|c|}
\hline \multicolumn{7}{|c|}{2001} \\
\hline Site & $\begin{array}{l}\text { Width } \\
(\mathrm{m})\end{array}$ & Depth (m) & $\begin{array}{c}\mathrm{D}_{16} \\
(\mathrm{~mm})\end{array}$ & $\begin{array}{c}\mathrm{D}_{50} \\
(\mathrm{~mm})\end{array}$ & $\begin{array}{c}\mathrm{D}_{84} \\
(\mathrm{~mm})\end{array}$ & $\begin{array}{c}\text { Fine Substrates } \\
(\%)\end{array}$ \\
\hline Beaver (BEC) & $2.4 \pm 0.6$ & $0.16 \pm 0.08$ & 2 & 9 & 36 & $40 \pm 12$ \\
\hline Bart (BTC) & $2.5 \pm 0.7$ & $0.15 \pm 0.10$ & 2 & 6 & 30 & $20 \pm 3$ \\
\hline North Bear (NBR) & $3.8 \pm 1.0$ & $0.15 \pm 0.12$ & 2 & 28 & 72 & $30 \pm 9$ \\
\hline Otter Siding Rd (OSR) & $2.6 \pm 0.7$ & $0.21 \pm 0.14$ & 2 & 11 & 27 & $49 \pm 17$ \\
\hline Thirteen Mile (THM) & $2.5 \pm 0.6$ & $0.12 \pm 0.08$ & 5 & 40 & 83 & $16 \pm 2$ \\
\hline West Br. Sante (WBS) & $3.5 \pm 1.0$ & $0.10 \pm 0.09$ & 12 & 36 & 85 & $23 \pm 7$ \\
\hline \multicolumn{7}{|c|}{$2015 / 2017$} \\
\hline Site & $\begin{array}{l}\text { Width } \\
\text { (m) }\end{array}$ & Depth (m) & $\begin{array}{c}\text { D16 } \\
(\mathrm{mm})\end{array}$ & $\begin{array}{l}\text { D50 } \\
(\mathrm{mm})\end{array}$ & $\begin{array}{c}\mathrm{D} 84 \\
(\mathrm{~mm})\end{array}$ & $\begin{array}{c}\text { Fine Substrates } \\
(\%)\end{array}$ \\
\hline Beaver (BEC) & $3.2 \pm 0.9$ & $0.14 \pm 0.09$ & 2 & 7 & 43 & $31 \pm 11$ \\
\hline Bart (BTC) & $2.8 \pm 0.9$ & $0.12 \pm 0.07$ & 2 & 21 & 65 & $25 \pm 3$ \\
\hline North Bear (NBR) & $5.2 \pm 1.4$ & $0.23 \pm 0.17$ & 2 & 31 & 53 & $35 \pm 7$ \\
\hline Otter Siding Rd (OSR) & $3.7 \pm 0.9$ & $0.26 \pm 0.19$ & 2 & 2 & 15 & $65 \pm 41$ \\
\hline Thirteen Mile (THM) & $2.3 \pm 0.6$ & $0.13 \pm 0.10$ & 2 & 39 & 72 & $26 \pm 18$ \\
\hline West Br. Sante (WBS) & $3.3 \pm 0.8$ & $0.14 \pm 0.12$ & 15 & 43 & 87 & $27 \pm 10$ \\
\hline
\end{tabular}

Estimates of substrate heterogeneity were variable among the sites and between the sampling periods but no major change occurred from 2001 to $2015\left(\mathrm{t}_{5}=0.39, \mathrm{p}=0.72\right)$. In 2001 and 2015, substrate heterogeneity was high in BEC and low in THM (Table 3.3). Other sites with high substrate heterogeneity in 2001 and 2015 were BTC and OSR, respectively. Sites with low substrate heterogeneity differed in 2001 (WBS) versus 2015 (NBR). The gradation coefficient was similar between the two sampling periods $\left(t_{5}=\right.$ $1.65, \mathrm{p}=0.16$ ), and was lowest in WBS for both sampling periods while the highest occurred for NBR in 2001 and THM in 2015 (Table 3.3). There also did not appear to be 
a trend in substrate heterogeneity and gradation coefficient changes through time. From 2001 to 2015, BEC and OSR increased in substrate heterogeneity, while the remaining sites decreased, while the values of gradation coefficient increased from 2001 in all sites except WBS (Table 3.3).

Table 3.3. Otter River Watershed study site metrics of complexity from 2001 (upper, from Burgess 2008) and present-day sampling (lower). Substrate heterogeneity and gradation coefficient are derived from pebble count data. CV (coefficient of variation) for width and depth, and width:depth ratio are all from survey data.

\begin{tabular}{lccccc}
\hline \multicolumn{1}{c}{ Site } & \multicolumn{2}{c}{2001} \\
& $\begin{array}{c}\text { Substrate } \\
\text { Heterogeneity }\end{array}$ & $\begin{array}{c}\text { Gradation } \\
\text { Coefficient }\end{array}$ & $\begin{array}{c}\text { CV } \\
\text { Width }\end{array}$ & $\begin{array}{c}\text { CV } \\
\text { Depth }\end{array}$ & $\begin{array}{c}\text { Width:Depth } \\
\text { Ratio }\end{array}$ \\
\hline Beaver (BEC) & 4.0 & 4.3 & 30.8 & 61.9 & 15.0 \\
Bart (BTC) & 6.0 & 4.0 & 23.0 & 51.1 & 16.7 \\
North Bear (NBR) & 2.6 & 8.3 & 28.2 & 80.7 & 25.3 \\
Otter Siding Rd (OSR) & 2.5 & 4.0 & 27.7 & 68.8 & 12.4 \\
Thirteen Mile (THM) & 2.1 & 5.0 & 24.7 & 66.4 & 20.8 \\
West Sante (WBS) & 2.4 & 2.7 & 28.9 & 91.5 & 35.0 \\
\hline \multicolumn{1}{c}{ Site } & Substrate & Gradation & CV & CV & Width:Depth \\
& Heterogeneity & Coefficient & Width & Depth & Ratio \\
\hline Beaver (BEC) & 6.1 & 4.8 & 29.0 & 64.3 & 22.1 \\
Bart (BTC) & 3.1 & 6.8 & 34.6 & 58.3 & 21.7 \\
North Bear (NBR) & 1.7 & 8.6 & 27.7 & 73.9 & 20.4 \\
Otter Siding Rd (OSR) & 7.5 & 4.3 & 20.6 & 73.1 & 13.1 \\
Thirteen Mile (THM) & 1.8 & 10.7 & 27.3 & 76.9 & 16.9 \\
West Sante (WBS) & 2.0 & 2.4 & 20.7 & 85.7 & 20.7 \\
\hline
\end{tabular}

Percent fine substrates from bulk shovel samples varied both spatially and temporally in the Otter River Watershed sites (Table 3.2) although values in 2001 (mean $30 \pm 14 \%$ ) were not significantly different from those in 2015 (mean $35 \pm 22 \%)\left(\mathrm{t}_{17}=0.72, \mathrm{p}=0.48\right)$. Percent fine substrates ranged from $16 \pm 2 \%$ to $49 \pm 17 \%$ in 2001 and from $25 \pm 3 \%$ to $65 \pm 41 \%$ in 2015. THM had the lowest percent fine substrates and OSR had the highest in 2001. However, during the more recent sampling, the BTC streambed had the lowest percent fine substrate while OSR had the highest. Change in percent fines ranged from a $9 \%$ decrease in BEC to a $16 \%$ increase in OSR (mean change: $5 \%$ ), indicating little change in these sites over the 14 year period. 


\subsubsection{Large Wood}

The volume of large wood differed within and among sites during sampling. When considering the differences between sampling periods no significant change in mean volume from $2001\left(0.015 \pm 0.011 \mathrm{~m}^{3} \mathrm{~m}^{-2}\right)$ and $2017\left(0.012 \pm 0.009 \mathrm{~m}^{3} \mathrm{~m}^{-2}\right)$ was detected $\left(\mathrm{t}_{5}\right.$ $=0.67, p=0.53$ ). However, four of the sites decreased (mean decrease of $34 \%$ ), with the largest decrease in NBR (73\%) and BEC (63\%; Figure 3.2). In contrast, relative wood volume increased by nearly $200 \%$ in OSR (198\%) and 50\% in WBS. OSR was the only site where beaver (Castor canadensis) activity was detected and it had the highest volume of large wood $\left(0.028 \mathrm{~m}^{3} \mathrm{~m}^{-2}\right)$ in 2017 (Figure 3.2). In 2001, the largest volume of large wood $\left(0.035 \mathrm{~m}^{3} \mathrm{~m}^{-2}\right)$ was measured in BEC and the lowest $\left(0.004 \mathrm{~m}^{3} \mathrm{~m}^{-2}\right)$ was in WBS (Figure 3.2). Wood volumes in the remaining four sites ranged from $0.008-0.018$ $\mathrm{m}^{3} \mathrm{~m}^{-2}$. Volume of large wood was also low $\left(<0.005 \mathrm{~m}^{3} \mathrm{~m}^{-2}\right)$ in NBR, THM and WBS in 2017 (Figure 3.2). Volume of large wood in BEC and BTC were similar in 2017 (0.013$\left.0.014 \mathrm{~m}^{3} \mathrm{~m}^{-2}\right)$, but less so in 2001 .

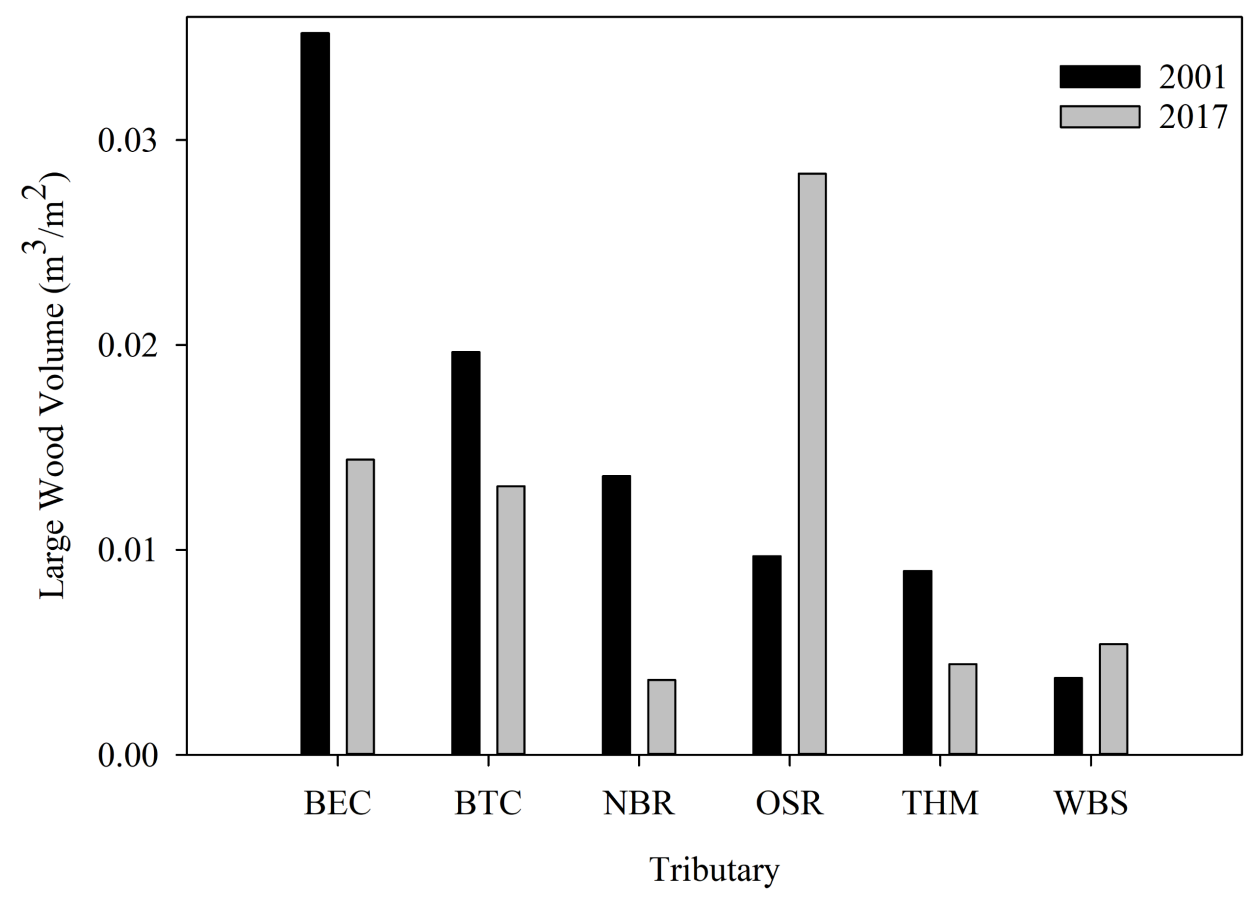

Figure 3.2. Large wood volume $\left(\mathrm{m}^{3} \mathrm{~m}^{-2}\right)$ from Burgess (2008) sampling (black bars) and our sampling (gray bars) of Otter River Watershed, MI sites. 
The mean number of large wood pieces encountered in each $100 \mathrm{~m}$ long site decreased from 2001 ( $42 \pm 24$ pieces) to 2017 ( $20 \pm 12$ pieces $)\left(t_{5}=3.12, p=0.03\right.$; Figure 3.3). The decrease in large wood abundance ranged from $13 \%$ in THM to $82 \%$ in NBR, with a mean for all sites of $45 \%$ (Figure 3.3). For both periods, large wood abundance was highest in BEC (Figure 3.3). The sites with the lowest abundance of large wood were also similar from 2001 and 2017. In 2001, THM and WBS each contained 15 pieces per 100 $\mathrm{m}$, while in 2017, THM decreased to 13 pieces per $100 \mathrm{~m}$ and WBS to 11 pieces per 100 . We did not observe a clear trend when comparing the time since most recent logging adjacent to sites or within their catchment (Table 3.1) to changes in relative wood volume or wood abundance between the two sampling periods (Figure 3.4).

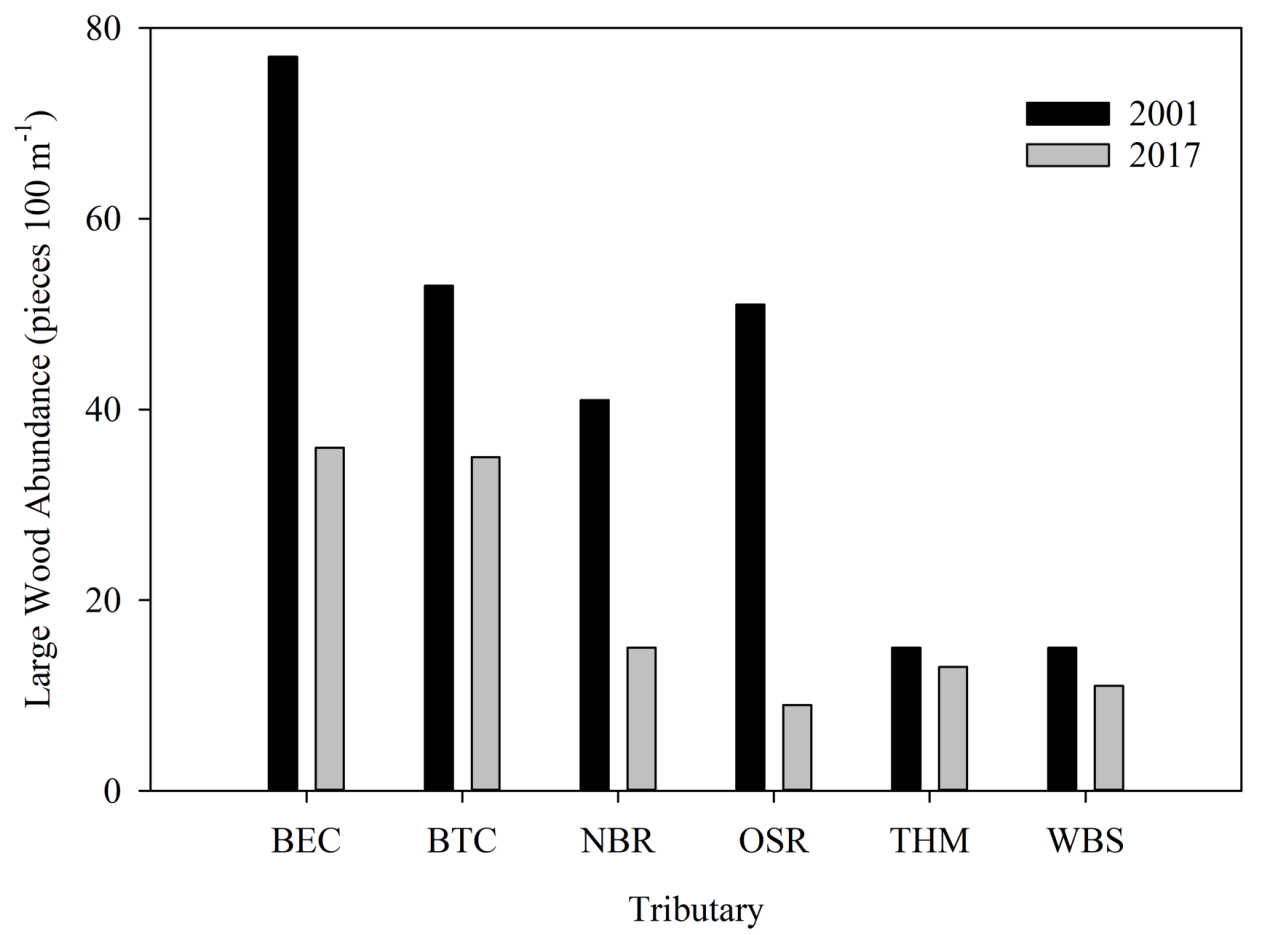

Figure 3.3. Large wood abundance from Burgess (2008) sampling (black bars) and our sampling (gray bars) of Otter River Watershed, MI sites. 

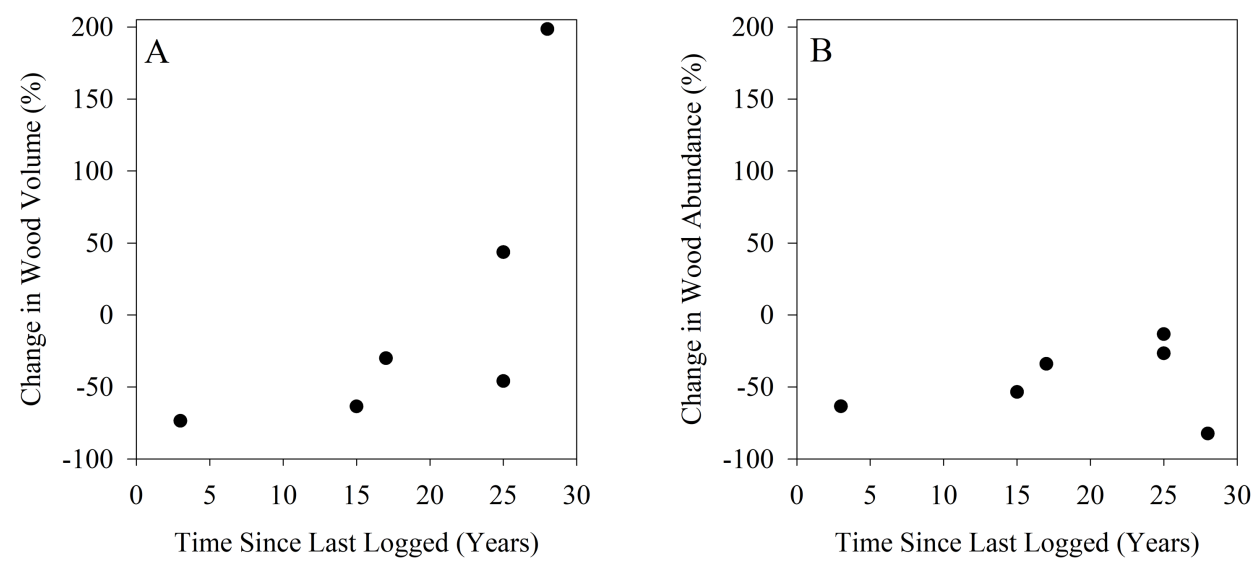

Figure 3.4 How large wood volume (A) and abundance (B) changed in relation to time since most recent logging occurred adjacent or within the catchment of Otter River Watershed, MI sites.

The mean diameter of large wood was similar between the two sampling periods and ranged from $0.19-0.28 \mathrm{~m}$ in 2001 and $0.16-0.25 \mathrm{~m}$ in 2017 (Figure 3.5). From 2001 to 2017 the diameter of the largest wood decreased as well as variation in diameters measured (Figure 3.6). The mean diameters decreased in all sites except for WBS, which increased (Figure 3.5). However, NBR and OSR were the only sites where mean changes decreased significantly (Figure 3.5; $\mathrm{t}_{5}=3.12, \mathrm{p}=0.03$ for both). The maximum diameter in 2001 was $0.90 \mathrm{~m}$ in BTC, while in 2017, the maximum diameter measured was in BEC at $0.66 \mathrm{~m}$ (Figure 3.6). 


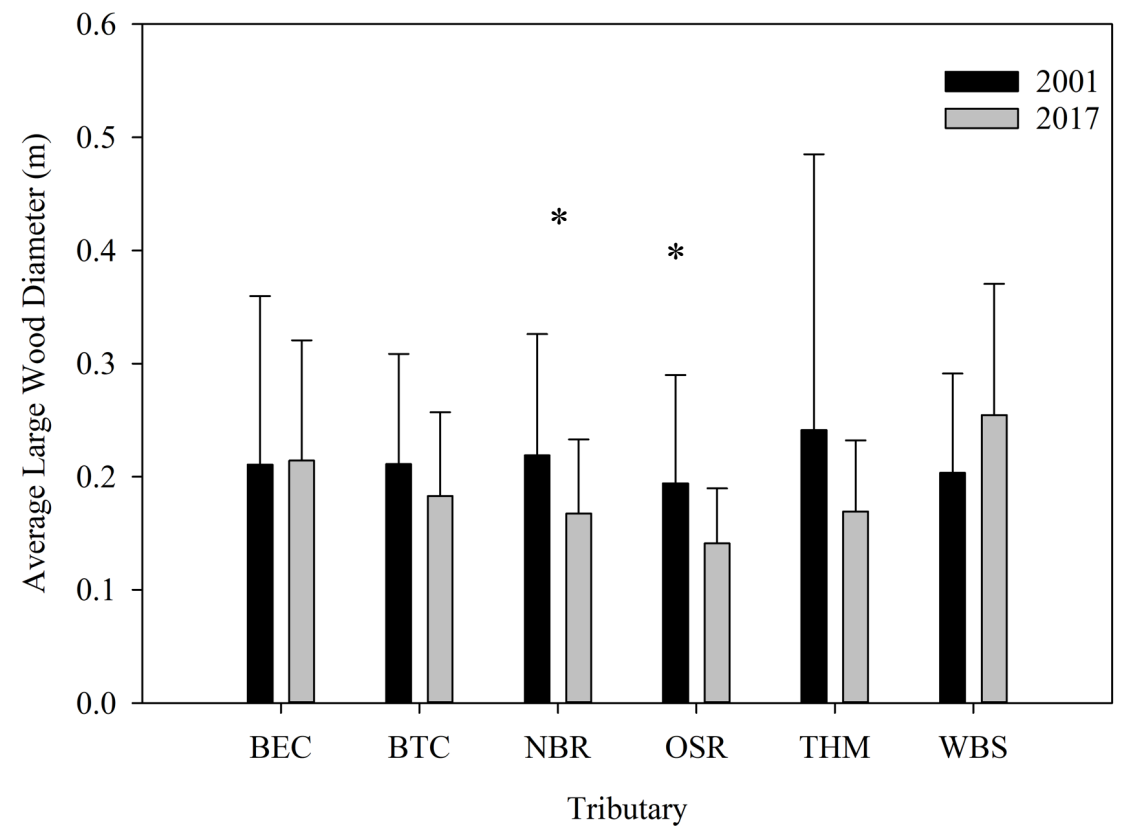

Figure 3.5. Mean \pm standard deviation for large woody material diameters from Burgess (2008) sampling (black bars) and our sampling (gray bars) of Otter River Watershed, MI sites. Asterisks indicates significant change $(\mathrm{p}<0.05)$.
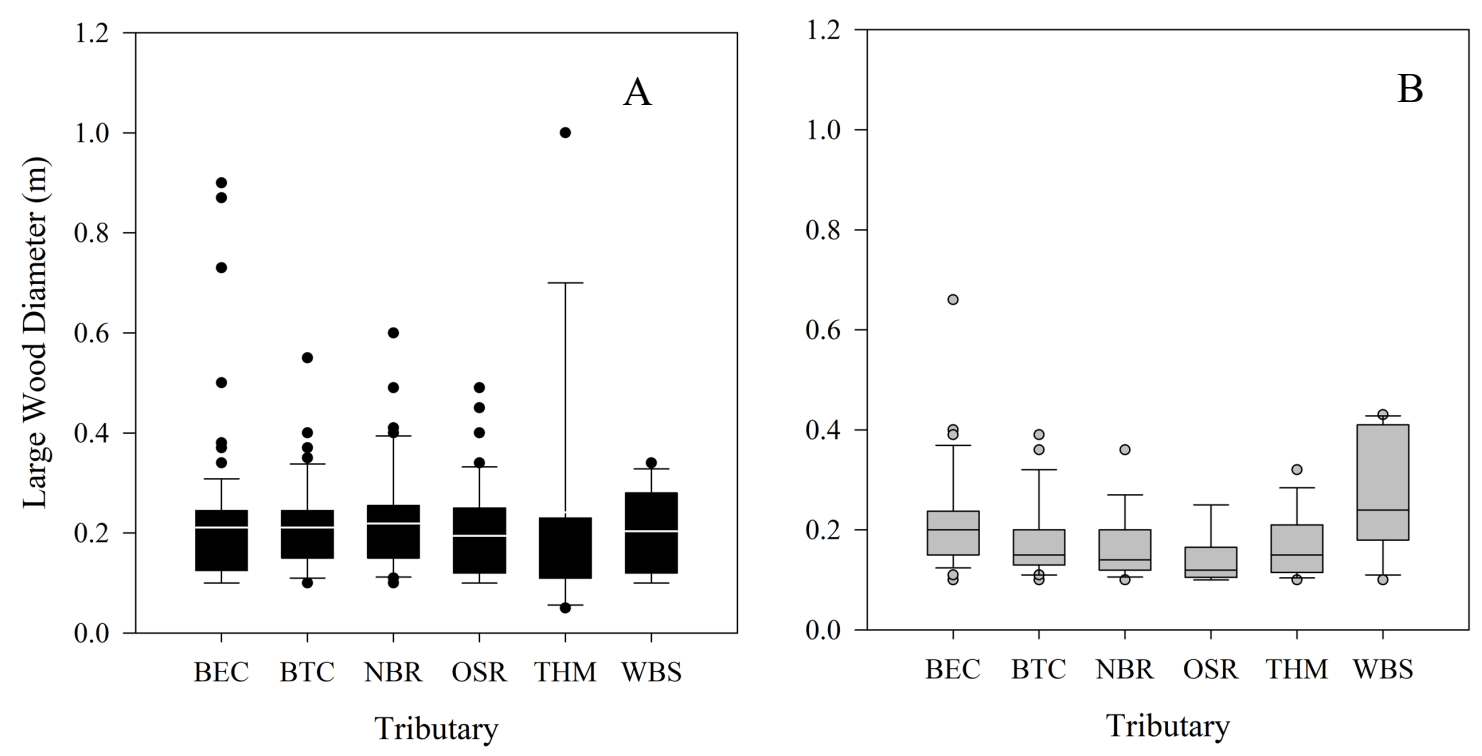

Figure 3.6. Box plots for large woody material diameters in six tributaries of the Otter River Watershed, MI based on surveys in (A) Burgess (2008) and (B) 2017. Box boundaries and middle line represent $25^{\text {th }}, 50^{\text {th }}$, and $75^{\text {th }}$ percentiles, respectively. Whiskers are the $10^{\text {th }}$ and $90^{\text {th }}$ percentile, and points are individual outliers. 


\subsubsection{Channel Morphology}

Similar to the pattern detected for substrates, the overall channel morphologies of these sites apparently change little over the 14 year period. In 2001, mean channel widths ranged from $2.4 \pm 0.6$ in BEC to $3.8 \pm 1.0$ in NBR, and when resampled in 2017, channel widths ranged from $2.3 \pm 0.6$ in THM to $5.2 \pm 1.4$ in NBR (Table 3.2; Figure 3.7), with significant increases detected for BEC $\left(\mathrm{t}_{26}=4.16, \mathrm{p}=<0.01\right)$, NBR $\left(\mathrm{t}_{18}=4.07, \mathrm{p}=<0.01\right)$ and OSR $\left(\mathrm{t}_{16}=5.31, \mathrm{p}=<0.01\right)$. Mean channel depth was greatest in OSR for both sampling periods (2001: $0.21 \pm 0.14,2017: 0.26 \pm 0.19)$, and it was lowest in WBS (0.10 $\pm 0.09)$ in 2001 and BTC $(0.12 \pm 0.07)$ in 2017 (Table 3.2; Figure 3.7). Between 2001 and 2017, significant decreases in channel depth occurred for BTC $\left(\mathrm{t}_{90}=4.47, \mathrm{p}=\right.$ $<0.01)$, while depths increased in NBR $\left(\mathrm{t}_{94}=3.83, \mathrm{p}=<0.01\right)$ and WBS $\left(\mathrm{t}_{139}=2.38, \mathrm{p}=\right.$ 0.02 ). Maximum channel depth in 2001 ranged from $0.3-0.6 \mathrm{~m}$, and $0.44-1.03 \mathrm{~m}$ in 2017, respectively, and OSR was the deepest during both sampling periods. Width:depth ratio averaged $20.9 \pm 8.2$ in 2001 and $19.5 \pm 3.5$ in 2017 and were not significantly different $\left(\mathrm{t}_{5}=0.54, \mathrm{p}=0.61\right)$. OSR had the narrowest channel width relative to depth in 2001 and 2017 (Table 3.3), and NBR and BEC had the widest channels relative to depth during these periods (Table 3.3). The coefficient of variation (CV) of widths shifted between the two sampling periods, but the differences were not significant $(\mathrm{t}(5)=0.19, \mathrm{p}$ $=0.85)$. BTC went from having the smallest CV for width in 2001 to the largest in 2017 (Figure 3.8). In 2001, BEC had the largest CV of width and in 2017 OSR had the smallest (Table 3.3). Across all sites, CV for channel depth was similar between the two sampling periods ( $\mathrm{t}_{5}=0.69, \mathrm{p}=0.52$ ), and WBS had the largest $\mathrm{CV}$ and BTC had the smallest CV of channel depth (Figure 3.7). 

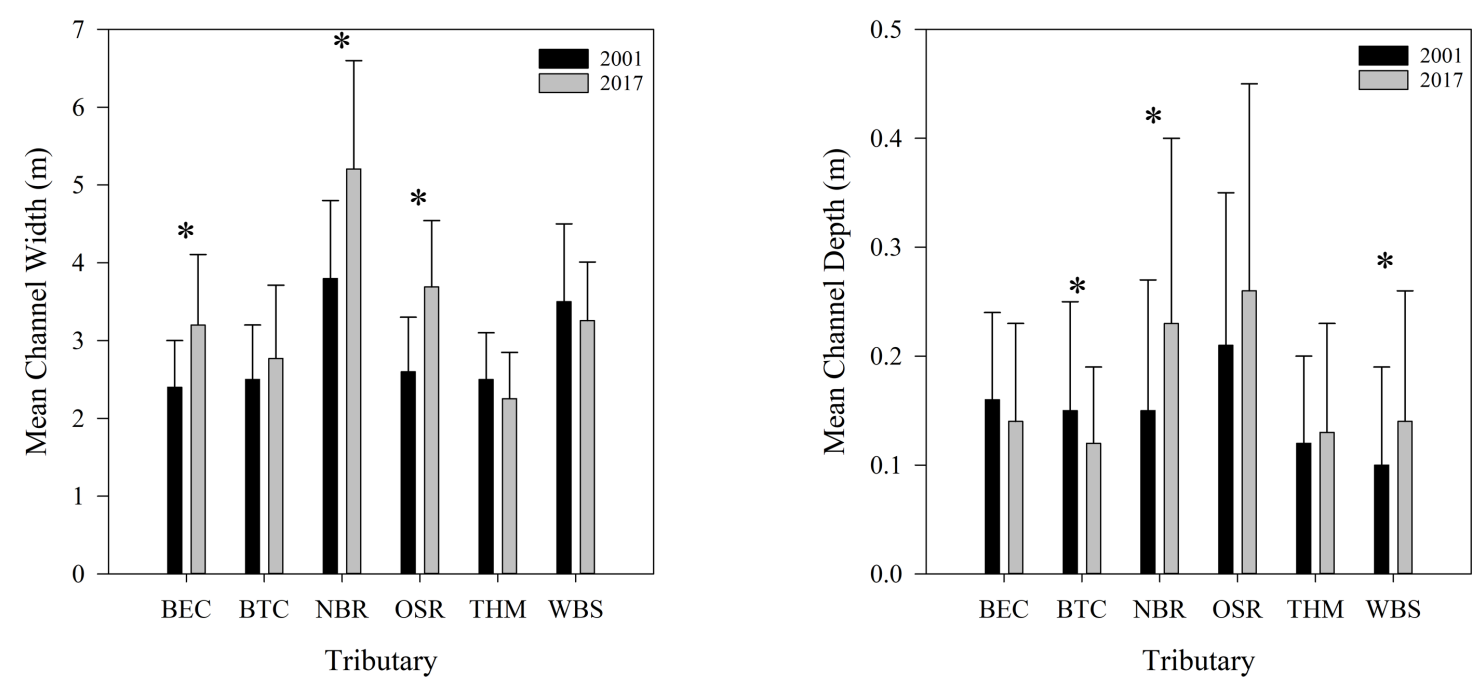

Figure 3.7. Mean \pm standard deviation for channel width and depth from Burgess (2008) data (black bars) and our sampling (gray bars) of Otter River Watershed, MI sites. Asterisks indicates significant change in channel width or depth $(\mathrm{p}<0.05)$.

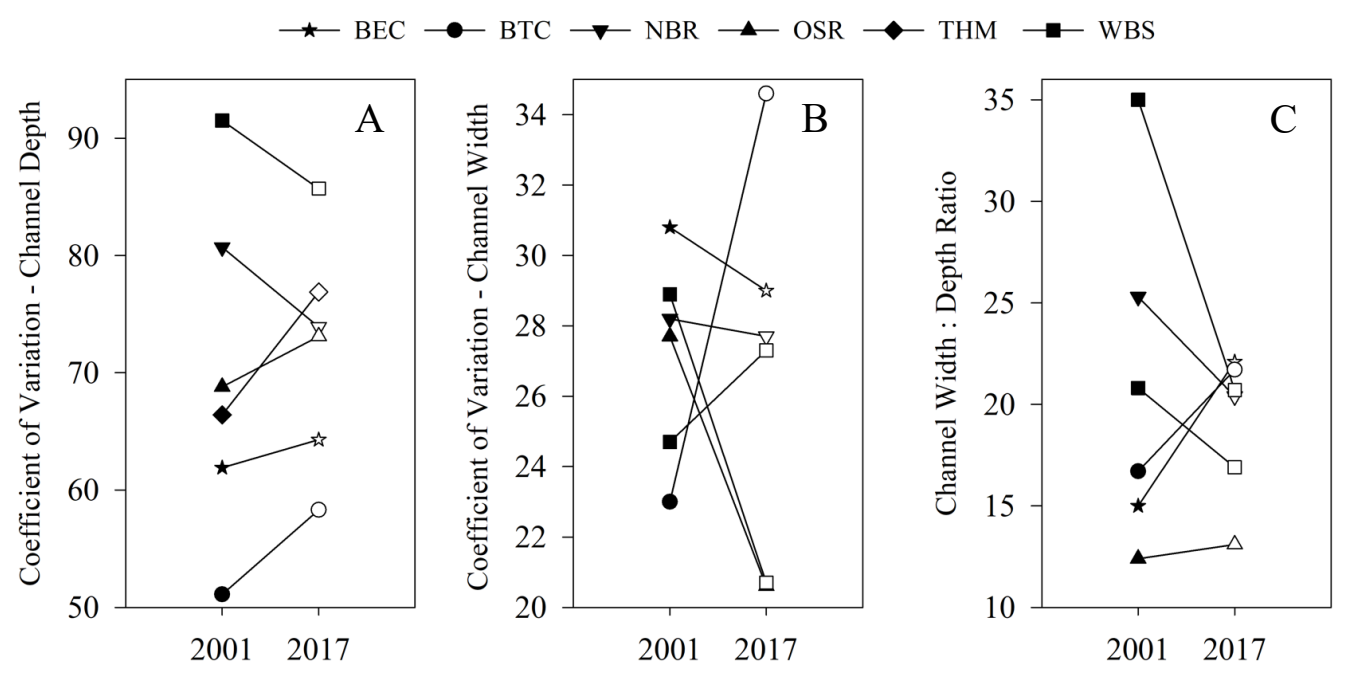

Figure 3.8. Coefficient of variation for (A) channel depth and (B) channel width, along with (C) channel width:depth ratios from 2001 (Burgess 2008) and 2017. Black lines connect sites over time and illustrate changes that have occurred between sampling periods.

\subsubsection{Differences Between Sampling Periods}

The results of the NMDS mostly support the single variable analyses above that showed little change in substrate characteristics and channel morphology (e.g. CV Width). Based on the results of the NMDS, many of the sites did not differ considerably from 2001 to 
2015/2017 in multidimensional space, and there does not appear to be a uniform temporal change in the direction or extent of change in large wood volume in the tributaries from 2001 over the 14 years between sampling (Figure 3.9). In the NMDS, WBS and OSR changed the most from 2001, and these sites had the smallest and an intermediate volume of large wood, respectively. OSR had the greatest change in wood volume (198\% increase), but WBS changed relatively little compared to other sites (Figure 3.2). NBR had a similar relatively volume of large wood to OSR in 2001 (Figure 3.2) as well as the second greatest change in volume (73\% decrease), and yet was the site with the greatest similarly (i.e. shortest distance) in the ordination between 2001 and 2015/2017 (Figure 3.9).

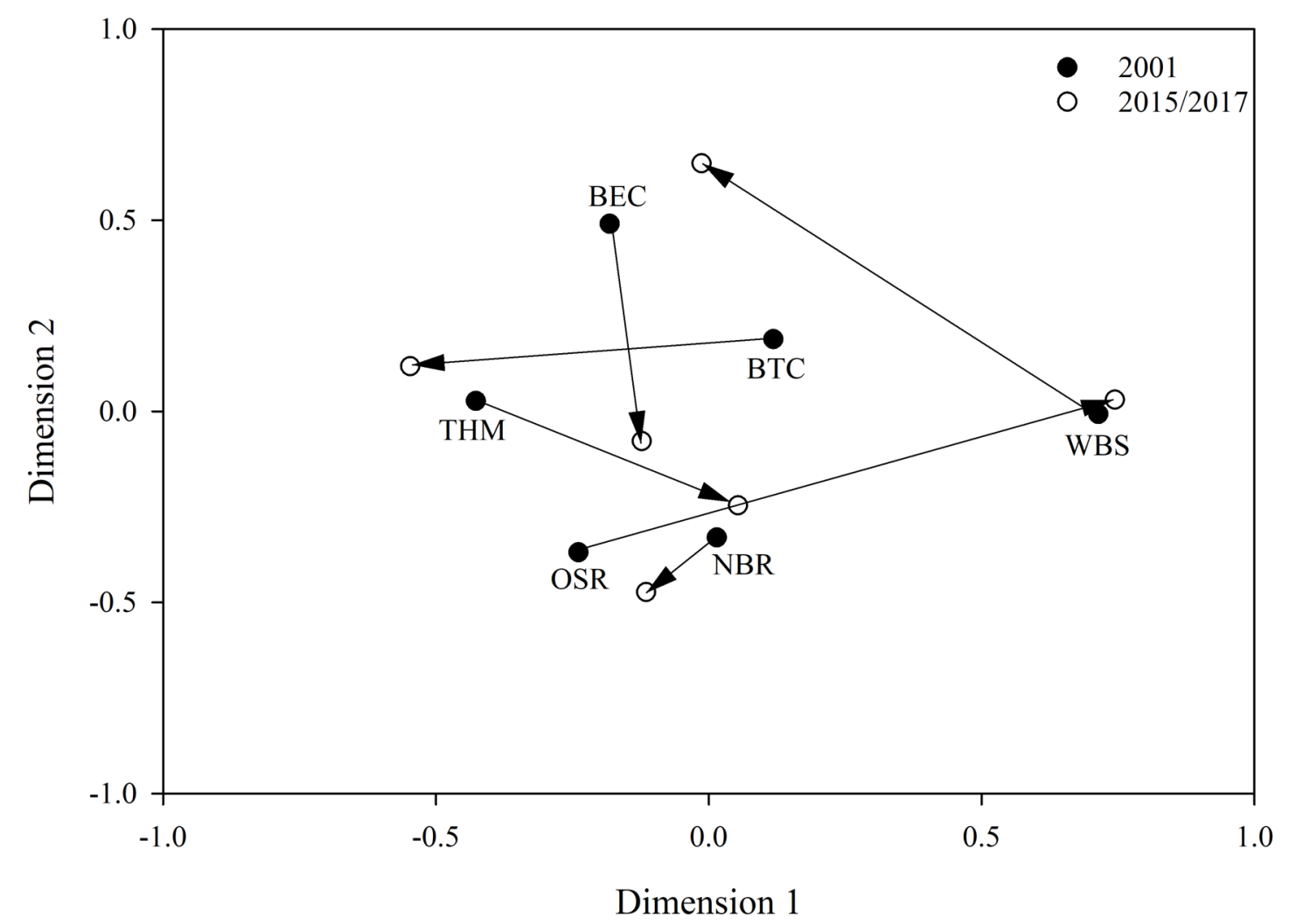

Figure 3.9. Non-metric multidimensional scaling (NMDS) illustrating temporal dynamics of physical channel features of tributaries in the Otter River Watershed from 2001 (black circles) to 2015/2017 (white circles). Variables used in the ordination included: Coefficients of Variation (CV) of channel width and depth, width:depth ratio, D16, D50, and D84 from pebble counts, and volume of large instream wood. 


\subsection{Discussion}

Hardwood forests adjacent to all six of these northern Great Lakes $2^{\text {nd }}$ order headwater tributaries had been selection logged at least once within the last 35 years (mean: 24 years; range: $15-35$ years since log removals) and additional logging in their catchments has occurred for at least two tributaries (BEC: 15 years, NBR: 3 years). Since 2001, large wood abundances has decreased in all the sites (Figure 3.3), and volume has decreased substantially in four of the sites (Figure 3.2), yet we found that their dominant features of streambed substrate composition and channel morphologies were remarkably unchanged during the 14 years between surveys. We also did not identify a trend between the time since most recent logging and changes in wood volume or abundance (Figure 3.4). We predicted that greater stability in substrate composition and channel morphology would occur in tributaries with the greatest amount of instream wood, yet no such relationship was detected (Figure 3.9). It may be that relative wood volumes are too low in these sites to have a major influence on the channels and that other local and/or landscape factors are controlling the physical characteristics (e.g. substrates and channel morphology) of these tributaries, or that the temporal and/or spatial scale of this study is too small to reveal these relationships.

Because BEC, BTC, and NBR had the highest wood volumes in 2001 (Figure 3.2), we predicted they would have the most stable channel characteristics and streambed substrates indicated by the lowest changes in substrate composition (e.g. $\mathrm{D}_{50}$ ), coefficient of variation of width and depth, and width:depth ratio. BEC and NBR were sites with some of the lowest change in CV of width and depth (Figure 3.8), and substrate composition (Table 3.2, Table 3.3), but other sites with less wood (i.e. OSR, THM, and WBS) also exhibited little change in these metrics. Further, BTC had abundant instream wood and displayed the greatest change in CV of width over 14 years (Figure 3.8), which is contrary to what would be expected under this scenario.

Substrate heterogeneity and gradation coefficient also did not follow the expected trends based on our assumptions. Despite BEC having the largest wood volume in 2001 and 
losing $>50 \%$ of large wood (both volume and abundance) by 2017 , substrate heterogeneity and gradation coefficient both increased. In comparison, BTC and NBR lost $>30 \%$ and $>60 \%$ of wood volume and abundance, respectively, but decreased in substrate heterogeneity (Table 3.3). The use of substrate heterogeneity, in particular, may not have been an appropriate metric for describing substrates in these sites because increased heterogeneity does not necessarily correspond to coarser substrates. For example, OSR increased in fine sediment between 2001 and 2015 based on pebble count percentiles (i.e. $\mathrm{D}_{16}, \mathrm{D}_{50}, \mathrm{D}_{84}$ ) and percent fine estimates (Table 3.2), yet also had the greatest increase in substrate heterogeneity (Table 3.3).

Undisturbed forests intercept precipitation and allow it to infiltrate the soil and transpire or evaporate before reaching a stream (Moore and Wondzell 2005), which stabilizes stream flows by increasing the time between when a storm occurs and a resultant increase in stream discharge (Jones 2000). Forestry management practices such as logging have been associated with reduced wood recruitment (Nowakowski and Wohl 2008), which is linked to decreased stream channel stability (Bilby 1984) and increased fine sediment in streams (Rashin et al. 2006). These watershed disturbances can have long term influences on smaller streams, particularly in higher gradient systems (May and Gresswell 2003). The infrastructure used for modern forestry operations (e.g. roads, skid tracks) can also lead to erosion (e.g. Pacific Northwest; Hassan et al. 2005), and combined with temporary increases in water yield after harvest can lead to additional channel erosion and sediment delivery to streams. Harvesting trees as well as the infrastructure needed to carry out these operations (e.g. trails and roads) can increase overland flow and result in flashier streams following storm events as well as increased erosive and transport capacity of sediments within streams (Moore and Wondzell 2005). Negative impacts of logging on stream habitat was noted in an earlier study of these same Otter River watershed tributaries, in which a striking association was detected between brook trout abundance, aquatic macroinvertebrate composition, as well as the amount of fine sediment, relative to the number of years since the adjacent forests were last selection logged (VanDusen et al. 2005). Despite these prior findings and observing decreased 
wood in nearly all our sites, we did not observe a trend between logging history and changes in large wood (Figure 3.4). This raises an important question regarding why we did not observe the predicted pattern between large wood and channel morphology and substrates.

Stream channels adjust to disturbances such as changes in sediment, wood, and water inputs, (Heitmuller 2014) and it may be that disturbances in the Otter River Watershed during this 14 year period have not been severe enough to push these systems out of equilibrium or there was not sufficient variation among the sites to detect. Typically, channel adjustment occurs on temporal scales ranging from decades to centuries (Beechie et al. 2006), and anthropogenic disturbances (e.g. dams) can change this frequency (Kloehn et al. 2008). It may be that on this relatively short time scale these sites have yet to adjust or have reached some alternative stable state (see Scheffer et al. 2001, Livers et al. 2018) outside of what would occur in an unlogged watershed. Given that the Otter River watershed is managed for timber on an approximate 10-20 year logging rotation (Pedersen 2006, Brad Carlson Michigan DNR, personal communication, 04/10/2020), it is possible that these sites are being maintained in disturbed conditions because not enough time passes between subsequent harvesting to return to a prior undisturbed state (Andrus et al. 1988, Merten et al. 2010b) or simply that the temporal scale of this study was too short to observe these changes (Hasting et al. 2018). One potential outcome of the logging frequency in these Otter River Watershed sites is fewer larger diameter wood, as indicated by fewer outliers and pieces $>0.4 \mathrm{~m}$ in diameter for 2017 and the difference between the $10^{\text {th }}$ and $90^{\text {th }}$ percentiles for diameters being smaller in 2017 (Figure 3.6). It may be that the forests that supply wood to these streams are moving towards an alternative stable state characterized by smaller diameter trees.

The pattern of lower volumes of large wood as well as instream wood with smaller diameters across these six Otter River Watershed tributaries may be a general result occurring elsewhere in the region. The volume of wood found in these sites is within the range of what Cordova et al. (2007) and Morris et al. (2007) observed in streams in 
secondary growth forested watersheds in the western Upper Peninsula, Michigan, and what Johnson et al. (2003) observed in 35 reaches (across 12 streams) in Michigan and 36 streams in Minnesota (Table 3.4).

Table 3.4 Summary of large wood characteristics in forested rivers from studies throughout North America and this study. ** Minimum size $0.3 \mathrm{~m}$ diameter, $3.0 \mathrm{~m}$ length.

\begin{tabular}{lcccc}
\hline \multicolumn{1}{c}{ Study } & Location & $\begin{array}{c}\text { Wood } \\
\text { Abundance } \\
(\# / 100 \mathrm{~m})\end{array}$ & Mean Wood Volume $\left(\mathrm{m}^{3} / \mathrm{m}^{2}\right)$ & $\begin{array}{c}\text { Mean Wood } \\
\text { Diameter } \\
(\mathrm{m})\end{array}$ \\
\hline Cordova et al. 2007 & MI & $33 \pm 3$ & 0.009 & 0.18 \\
Johnson et al. 2003 & MI & - & MI: 0.002 (Range: 0-0.031) & - \\
Morris et al. 2007 & MN & - & MN: 0.002 (Range: 0-0.012) & - \\
Robison \& Beschta 1990 & MI & $13 \pm 9$ & - & $0.16-0.43$ \\
Stewart et al. 2012 & AL & $35-41$ & 0.066 & - \\
Beechie \& Sibley 1997 & WA & $5-66$ & 0.016 (Range: $0.001-0.066)$ & $0.22-0.38$ \\
Benda \& Bigelow 2014 & CA & - & 0.030 (Range: $0.001-0.106)$ & $0.18-0.43$ \\
Reeves et al. 1993 & OR & $0.5-12^{* *}$ & - & - \\
Burgess 2008 & MI & $15-77$ & 0.015 (Range: $0.004-0.035)$ & $0.19-0.24$ \\
Otter River Sites & MI & $9-36$ & 0.011 (Range: $0.004-0.028)$ & $0.10-0.24$ \\
\hline
\end{tabular}

Large wood abundance in our sites is also similar to streams in the upper Great Lakes and elsewhere in the US (Table 3.4). Our estimates for large wood abundance are within the ranges observed by Morris et al. (2007) and Cordova et al. (2007) in other watersheds located in Michigan's Western Upper Peninsula (Table 3.4). Even streams in old growth forested regions have similar abundances of large wood (19 \pm 5 pieces per $100 \mathrm{~m}$; Morris et al. 2007) to what we measured, however, the volume in these streams are nearly $5 \mathrm{x}$ that of nearby secondary growth forested streams (Morris et al. 2007) indicating the individual pieces or the jams were larger. Robison and Beschta (1990) and Stewart et al. (2012) observed similar large wood abundances, ranging from $25-41$ pieces per $100 \mathrm{~m}$ in Alaska and Alabama, respectively. In the Pacific Northwestern US, Beechie and Sibley (1997) observed a wide range of large wood abundances (5-66 pieces per $100 \mathrm{~m})$ in streams with similar gradients $(<0.02)$ to our Otter River Watershed sites. In unmanaged forested streams, volumes of large wood are often greater than in streams located in managed forests. Harmon et al. (1986) compiled data from 11 studies across six states 
and Canada and found $>40 \%$ of reaches in unmanaged forests (stand age: $85-1000$ years) having large wood volumes of $0.05 \mathrm{~m}^{3} / \mathrm{m}^{2}$, with a maximum of $0.45 \mathrm{~m}^{3} / \mathrm{m}^{2}$.

The retention of instream wood is partially determined by the mass of the wood, which scales with its length and diameter (Merten et al. 2011). Mean large wood diameters measured in the Michigan sites in this study $(0.19 \pm 0.09 \mathrm{~m})$ were similar to those observed by Cordova et al. (2007) and Morris et al. (2007) in Michigan's Western Upper Peninsula (Table 3.4). In addition, Cordova et al. (2007) measured a maximum wood diameter $(0.67 \mathrm{~m})$ very similar to what we encountered in the Otter River Watershed sites $(0.66 \mathrm{~m})$. Similar results have been observed in the Southeastern United States (Steward et al. 2012), as well as in the Pacific Northwest (Beechie and Sibley 1997) and California (Benda and Bigelow 2014; Table 3.4). However, many western streams contain much larger wood. For example mean diameters in some of the sites that Beeche and Sibley (1997) and Benda and Bigelow (2014) sampled were nearly 2 times larger than the diameters we measured in this study, while unmanaged forested streams can contain mean diameters $>4 \mathrm{x}$ that of what was found in our sites (Benda and Bigelow 2014).

Selection logging has been documented to negatively impact some forested streams. A long-term study in northern California showed suspended sediment loads returned to prelogging levels about a decade after being cut, but increased again over 30 years after being cut as a result of deteriorating roads (Keppeler et al. 2009). VanDusen et al. (2005) found in these same tributaries in the Otter River Watershed that those logged within 10 years had higher amounts of fine sediment than those with 10+ years since logging. Kasran and Nik (1994) noted a nearly 300\% increase in suspended sediment two years post logging, followed by a return to pre-logging levels by year three in Malaysia. Wright et al. (1990) assessed the effect of selection logging as well as the road construction associated on streamflow following storm events in a small $\left(4 \mathrm{~km}^{2}\right)$ watershed in northwestern California. Following logging activities $(\sim 15 \%$ of the watershed), lag times between storms and peak streamflow decreased by $\sim 1.5 \mathrm{hr}$, which increased the volume and peak of very small storms, but had negligible effects during 
large storms, concluding that selection logging may not have significantly negative impacts on streamflow.

In this study we did not detect a relationship between instream large wood and stability in substrate composition or channel morphology in $2^{\text {nd }}$ order headwater tributaries in the Otter River Watershed. The volume and abundance of large wood decreased within a majority of these sites, as well as the proportion of larger diameter wood (e.g. $>0.5 \mathrm{~m}$ ) since they were sampled in 2001 by Burgess (2008). This may suggest that under the current harvesting regime, there may not be enough instream large wood to detect a pattern between wood and substrate or channel morphology. Additionally, streams in the Otter River watershed may be in an alternative stable state or in a transient equilibrium like state after the most recent logging. Recurring disturbance from rotational selection logging could limit the amount and size of large wood available for recruitment and add to other perturbations that occur on the landscape to maintain these sites in a disturbed state. If management of similar forested upper Great Lakes streams is to be successful, the target conditions need to consider the constraints that are imposed by past and present management practices as well as a more comprehensive understanding of what controls the physical conditions of these streams.

\subsection{References}

Andrus, C. W., B. A. Long, and H. A. Froehlich. 1988. Woody Debris and Its Contribution to Pool Formation in a Coastal Stream 50 Years after Logging. Canadian Journal of Fisheries and Aquatic Sciences 45:2080-2086.

Angermeier, P. L., and J. R. Karr. 1984. Relationships between Woody Debris and Fish Habitat in a Small Warmwater Stream. Transactions of the American Fisheries Society 113:716-726.

Beechie, T. J. and T. H. Sibley. 1997. Relationship between channel characteristics, woody debris, and fish habitat in northwestern Washington streams. Transactions of the American Fisheries Society 126(): 217-229.

Beechie, T. J., M. Liermann, M. M. Pollock, S. Baker, J. Davies. 2006. Channel pattern 
and river-floodplain dynamics in forested mountain river systems. Geomorphology 78: $124-141$.

Benda, L., and P. Bigelow. 2014. On the patterns and processes of wood in northern California streams. Geomorphology 209: 79-97.

Benke, A. C., and J. B. Wallace. 2003. Influence of wood on invertebrate communities in streams and rivers. American Fisheries Socieity Symposium 37: 149-177

Beschta, R. 1979. Debris removal and its effects on sedimentation in an Oregon coast range stream. Northwest Science 53(1):71-77.

Bilby, R. E. 1984. Removal of woody debris may affect stream channel stability. Journal of Forestry 82(10):609-613.

Bisson, P. A., R. E. Bilby, M. D. Bryant, C. A. Dolloff, G. B. Grette, R. A. House, M. L. Murphy, K. V. Koski, and J. R. Sedell. 1987. Large woody debris in forested streams in the Pacific Northwest: past, present, and future. Pages 143-190 in E. O. Salo and T. W. Cundy, editors. Streamside Management: Forestry and Fishery Interactions. University of Washington, Seattle, Washington.

Bunte, K., and S. R. Abt. 2001. Sampling surface and subsurface particle-size distributions in wadable gravel- and cobble-bed stream for analyses in sediment transport, hydraulics, and streambed monitoring. Gen. Tech. Rep. RMRS-GTR-74. Fort Collins, CO: U.S. Department of Agriculture, Forest Service, Rocky Mountain Research Station.

Burgess, A. F. 2008. Macroinvertebrate communities, organic matter, and physical habitat conditions across headwater streams of the Otter River, in Michigan's upper peninsula. Michigan Technological University. Houghton, MI.

Cordova, J. M., E. J. Rosi-Marshall, A. M. Yamamuro, and G. A. Lamberti. 2007. Quantity, controls and function of large woody debris in midwestern USA streams. River Research and Applications. 23: 21-33.

Cristan, R., W. M. Aust, M. C. Bolding, S. M. Barrett, J. F. Munsell, and E. Schilling. 2016. Effectiveness of forestry best management practices in the United States: literature review. Forest Ecology and Management 360(): 133-151.

Diez, J. R., S. Larranaga, A. Elosegi, J. Pozo. 2000. Effect of removal of wood on 
streambed stability and retention of organic matter. Journal of the North American Benthological Society 19(4):621-632.

Dolloff, C. A., and M. L. Warren Jr. 2003. Fish relationship with large wood in small streams. American Fisheries Society Symposium 37: 179-193.

Dumke, J. D., T. R. Hrabik, V. J. Brady, K. B. Gran, R. R. Regal, and M. J. Seider. 2010. Channel Morphology Response to Selective Wood Removals in a Sand-Laden Wisconsin Trout Stream. North American Journal of Fisheries Management 30:776-790.

Flaspohler, D. J., C. J F. Huckins, B. R. Bub, and P. J. Van Dusen. 2002. Temporal patters in aquatic and avian communities following selective logging in the upper Great Lakes region. Forest Science 48(2): 339-349.

Gulis, V., A. M. Rosemond, K. Suberkropp, H. S. Weyers, and J. P. Benstead. 2004. Effects of nutrient enrichment on the decomposition of wood and associated microbial activity in streams. Freshwater Biology 49(): 1437-1447

Gurnell, A. M., and R. Sweet.1998. The distribution of large woody debris accumulations and pools in relation to woodland stream management in a small, low-gradient stream. Earth Surface Processes and Landforms 23:1101-1121.

Gurnell, A. M., H. Piegay, F. J. Swanson, and S. V. Gregory. 2002. Large Wood and Fluvial Processes. Freshwater Biology 47:601-619.

Harmon, M. E., J. F. Franklin, F. J. Swanson, P. Sollins, S. V. Gregory, J. D. Lattin, N. H. Anderson, S. P. Cline, N. G. Aumen, J. R. Sedell, G. W. Lienkaemper, K. Cromack Jr., and K. W. Cummins. 1986. Ecology of coarse woody debris in temperate ecosystems. Advances in Ecological Research 15: 133-263.

Hames, D. S., B. Conrad, A. Pleus, and D. Smith. 1996. Field comparison of the McNeil sampler with three shovel-based methods used to sample spawning substrate composition in small streams. Northwest Indian Fisheries Commission.

Hassan, M. A., M. Church, T. E. Lisle, F. Brardinoni, L. Benda, and G. E. Grant. 2005. Sediment transport and channel morphology of small, forested streams. Journal of the American Water Resources Association 41(4): 853-876.

Hasting, A., K. C. Abbott, K. Cuddington, T. Francis, G. Gellner, Y. Lai, A. Morozov, S. 
Petrovskii, K. Scranton, and M. L. Zeeman. 2018. Transient phenomena in ecology. Science 361:

Heitmuller, F. T. 2014. Channel adjusts to historical disturbances along the lower Brazos and Sabine Rivers, south-central USA. Geomorphology 204(): 382-398.

Huckins, C. and A. Burgess. 2004. The influence of forest management on stream communities in the Upper Peninsula of Michigan. Michigan Department of Environmental Quality, Office of the Great Lakes Report to Michigan \& Great Lakes Protection Fund. Lansing, MI:

Hyatt, T. L., R. J. Naiman. 2001. The residence time of large woody debris in the Queets River, Washington, USA. Ecological Applications 11(1): 191-202.

Ice, G., L. Dent, J. Robben, P. Cafferata, J. Light, B. Sugden, and T. Cundy. 2004. Programs assessing implementation and effectiveness of state forest practice rules and BMPs in the west. Water, Air, and Soil Pollution: Focus: 4: 143-169.

Johnson, L. B., D. H. Breneman, and C. Richards. 2003. Macroinvertebrate community structure and function associated with large wood in low gradient streams. River Research and Applications 19(): 199-218.

Jones, J. A. 2000. Hydrologic processes and peak discharge response to forest removal, regrowth, and roads in 10 small experimental basins, western Cascades, Oregon. Water Resources Research 36(9): 2621-2642.

Jones, T., L. Daniels, and S. Powell. 2011. Abundance and function of large woody debris in small, headwater streams in the Rocky Mountain Foothills of Alberta, Canada. River Research and Applications 27:297-311.

Kasran, B. and A. R. Nik. 1994. Suspended sediment yield resulting from selective logging practices in a small watershed in peninsular Malaysia. Journal of Tropical Forest Science 7(2): 286-295.

Keppeler, E., L. Reid, T. Lisle. 2008. Long-term patterns of hydrologic response after logging in a coastal redwood forest. The Third Interagency Conference on Research in the Watersheds, 8-11 September 2008, Estes Park, CO: 265- 271.

Kloehn, K. K., T. J. Beechie, S. A. Morley, H. J. Coe, and J. J. Duda. 2008. Influence of dams on river-floodplain dynamics in the Elwha River, Washington. Northwest 
Science 82(sp1): 224-235.

Laub, B. G., D. W. Baker, B. P. Bledsoe, and M. A. Palmer. 2012. Range of variability of channel complexity in urban, restored and forested reference streams. Freshwater Biology 57(): 1076-1095.

Leatherberry, E. C., and J. S. Spencer, Jr. 1996. Michigan forest statistics, 1993. USDA Forest Service Resources Bulletin NC-170.

Livers, B., and E. Wohl. 2016. Sources and interpretation of channel complexity in forested subalpine streams of the southern Rocky Mountains. Water Resources Research 52: 3910-3929.

Livers, B., E. Wohl, K. J. Jackson, and N. A. Sutfin. 2018. Historical land use as a driver of alternative states for stream form and function in forested mountain watersheds of the southern Rocky Mountains. Earth Surface Processes and Landforms 43: 669684.

May, C. L., and R. E. Gresswell. 2003. Process and rates of sediment and wood accumulation in headwater streams of the Oregon coast range, USA. Earth Surface Processes and Landforms 28: 409-424.

Maybee, R. H. 1960. Michigan's White Pine Era 1840-1900. Michigan Historical Commission, Lansing, MI.

Martin, D. J. 2001. The influence of geomorphic factors and geographic regions on large woody debris loading and fish habitat in Alaska coastal streams. North American Journal of Fisheries Management 21:429-440.

Merten, E., J. Finlay, L. Johnson, R. Newman, H. Stefan, and B. Vondracek. 2010a. Factors influencing wood mobilization in streams. Water Resources Research 46: W10514.

Merten, E. C., N. A. Hemstad, R. K. Kolka, R. M. Newman, E. S. Verry, and B. Vondracek. 2010b. Recovery of sediment characteristics in moraine, headwater streams of northern Minnesota after forest harvest. Journal of the American Water Resources Association 46(4): 733-743.

Merten, E., J. Finlay, L. Johnson, R. Newman, H. Stefan, and B. Vondracek. 2011. Environmental controls of wood entrapment in upper Midwestern streams. 
Hydrological Processes. 25: 593-602.

MIDNR (Michigan Department of Natural Resources). 2018. Michigan forestry best management practices for soil and water quality. Michigan Department of Natural Resources, Lansing.

Moore, R. D., and S. M. Wondzell. 2005. Physical hydrology and the effects of forest harvest in the pacific northwest: a review. Journal of the American Water Resources Association 41(4): 763-784.

Morris, A. E., P. C. Goebel, and B. J. Palik. 2007. Geomorphic and riparian forest influences on characteristics of large wood and large-wood jams in old-growth and second-growth forests in northern Michigan, USA. Earth Surface Processes and Landforms 32(): 1131-1153.

Morris, A. E. L., P. C. Goebel, and B. J. Palik. 2010. Spatial distribution of large wood jams in streams related to stream-valley geomorphology and forest age in Northern Michigan. River Research and Applications 90():835-847.

Naiman, R. J., E. V. Balian, K. K. Bartz, R. E. Bilby, J. L. Latterell. 2002. Dead wood dynamics in stream ecosystems. USDA Forest Service Gen. Tech. Rep. PSW-GTR181.

Nowakowski, A. L., and E. Wohl. 2008. Influences of wood load in mountain streams of the Bighorn National Forest, Wyoming, USA. Environmental Management 42(): $557-571$.

Pedersen, L. 2006. Michigan state forest timber harvest trends - a review of recent harvest levels and factors influencing future levels. Michigan Department of Natural Resources

Phillips, M. J., and C. R. Blinn. 2004. Best management practices compliance monitoring approaches for forestry in the eastern United States. Water, Air and Soil Pollution: Focus 4: 263-274.

Pugh, S. A. 2018. Forests of Michigan, 2017. U. S. Department of Agriculture, Forest Service Resource Update FS-153

Ralph, S. C., G. C. Poole, L. L. Conquest, and R. J. Naiman. 1994. Stream channel morphology and woody debris in logged and unlogged basins of Western 
Washington. Canadian Journal of Fisheries and Aquatic Sciences 51:37-51.

Rashin, E. B., C. J. Clishe, A. T. Loch, and J. M. Bell. 2006. Effectiveness of timber harvest practices for controlling sediment related water quality impacts. Journal of the American Water Resources Association 42(5): 1307-1327.

Reeves, G. H., F. H. Everest, and J. R. Sedell. 1993. Diversity of juvenile anadromous salmonid assemblages in coastal Oregon basins with different levels of timber harvest. Transactions of the American Fisheries Society 122(3): 309-317.

Robson, E. G., and R. L. Beschta. 1990. Identifying trees in riparian areas that can provide coarse woody debris to streams. Forest Science 36(3): 790-801.

Scheffer, M., S. Carpenter, J. A. Foley, C. Folke, and B. Walker. 2001. Catastrophic shifts in ecosystems. Nature 413(): 591-596.

Seymour, R. S. 1995. The northern region. Pages 31-79 in J. W. Barrett, editor. Regional silviculture of the United States, 3rd edition. Wiley, New York.

Smith, R. D., R. C. Sidle, P. E. Porter, and J. R. Noel 1993. Effects of experimental wood removal of woody debris on the channel morphology of a forest, gravel-bed stream. Journal of Hydrology 152(4):153-178.

Stewart, P. M., S. Bhattarai, M. W. Mullen, C. K. Metcalf, and E. G. Reatugui-Zirena. 2012. Characterization of large wood and its relationship to pool formation and macroinvertebrate metrics in southeastern coastal plain streams, USA. Journal of Freshwater Ecology 27(3): 351-365.

Thompson, D. M. 1995. The effects of large organic debris on sediment processes and stream morphology in Vermont. Geomorphology 11: 235-244.

Van Dusen, P. J., C. J F. Huckins, and D. J. Flaspohler. 2005. Association among selection logging history, brook trout, macroinvertebrates, and habitat in Northern Michigan headwater streams. Transactions of the American Fisheries Society 134(): 762-774.

Vincent, R. E. 1962. Biogeographical and Ecological Factors Contributing to the Decline of Arctic Grayling, Thymallus Arcticus Pallas, in Michigan and Montana. The University of Michigan. Ann Arbor, MI.

Wentworth, C. 1922. A scale of grade and class terms for clastic sediments. The Journal 
of Geology 30(5):377-392.

Wohl, E. and J. R. Goode. 2008 Wood dynamics in headwater streams of the Colorado Rocky Mountains. Water Resources Research 44. W09429.

Wohl, E. 2014. A legacy of absence: wood removal in US rivers. Progress in Physical Geography 38(5): 637-663.

Wohl, E., B. P. Bledsoe, K. D. Fausch, N. Krammer, K. R. Bestgen, and M. N. Gooseff. 2016. Management of large wood in streams: and overview and proposed framework for hazard evaluation. Journal of the American Water Resources Association 52(2): 315-335.

Wohl, E., K. B. Lininger, M. Fox, B. R. Baillie, and W. D. Erskine. 2017. Instream large wood loads across bioclimatic regions. Forest Ecology and Management 404:370380.

Wolman, M. G. 1954. A method of sampling coarse river-bed materials. Transactions of the American Geophysical Union 35(6):951-956.

Wright, K. A., K. H. Sendek, R. M. Rice, and R. B. Thomas. 1990. Logging effects on streamflow: storm runoff at Casper Creek in northwest California. Water Resources Research 26(7): 1657-1667. 


\section{Associations between large wood and streambed complexity in headwater streams in the western Upper Peninsula, Michigan.}

\subsection{Abstract}

Complexity is an important feature to fluvial ecosystems. In forested streams, large wood can indirectly and directly contribute to the complexity that support biota. In this study we quantified large wood and channel morphology in six forested streams of the western Upper Peninsula and used variograms to describe the complexity in stream channel morphology. Our goal was to determine if a connection exists between the volume and amount of instream large wood and the complexity of the channel streambed. Based on previous work, we expected a positive relationship between large wood and channel complexity. Large wood volumes ranged from $<0.01 \mathrm{~m}^{3} \mathrm{~m}^{-2}$ to $>0.10 \mathrm{~m}^{3} \mathrm{~m}^{-2}$, and the sites visually align into three groups based on overall complexity in channel morphology. However, this complexity as derived from variograms did not show a trend with the volume of large wood present in the stream channel. The two sites with the lowest volume of wood had the highest complexity in channel morphology, but the opposite did not hold true for sites with the greatest volume of wood. Our findings may be a result of large wood in these streams being relatively smaller and in lower abundance than for streams where the majority of research has occurred in the western US. In addition, there may be other underlying landscape and environmental features that influence the morphological complexity in these streams.

\subsection{Introduction}

Rivers are complex systems that are often categorized into discrete features at spatial scales ranging from micro-habitats based on streambed sediments up to the whole river system (Frissell et al. 1986). Within that range are critical distinctions at the channel geomorphic unit (CGU) scale (e.g. $10^{0}-10^{1} \mathrm{~m}$ ), and complexity at that level along with substrate composition are considered important features of rivers, such as those with 
more diverse habitat may support greater diversity for invertebrates (Beisel et al. 2000, Brown 2003) and abundance of some life stages of fish (Roni et al. 2008). The availability of specific habitat and its spatial arrangement can determine or influence community structure and dynamics of flowing ecosystems (Palmer et al. 2000).

Complexity alters downstream fluxes of water by slowing and diverting flow and results in more complex channel forms having greater hyporheic exchange (Buffington \& Tonina 2009) and longer transient storage times. This has implications for ecosystem processes such as biogeochemical cycling (Gooseff et al. 2007, Kaufmann and Faustini 2012) and organic matter retention (Sheldon and Thoms 2006, Diez et al. 2000). For biota, particularity invertebrates, more heterogeneous habitats are thought to increase niche availability, leading to higher species abundance and richness (Beisel et al. 2000, Boyero 2003). In more heterogeneous river systems such as those with beaver activity, disturbances such as intermittent drought can have a lesser impact because water stored by beaver dams during wet seasons is released during dry periods (Hood \& Bayley 2008).

Wohl (2016) and Faustini and Jones (2003) suggested large wood is an important component of rivers that influences and contributes to the morphological complexity. Wood influences channel morphology (Keller and Swanson 1979) and has been associated with greater geomorphic complexity (Abbe and Montgomery 1996, Wohl 2011) such as the spacing and number of pools (Montomery et al. 1995, Beechie and Sibley 1997, Gurnell and Sweet 1998). However, these relationships are complex and not necessarily universal because they depend on factors such as wood stability (Abbe and Montgomery 2003), size of wood available to the channel, and channel size (Robison \& Beschta 1990, Buffington et al. 2002).

Rivers throughout the United States have been disrupted through the removal of large wood (Wohl 2014), which can reduce channel stability (Bilby 1984) and simplify channel morphology, thus decreasing heterogeneity (Collins et al. 2012). As a result, many restoration projects add wood back to streams (Palmer et al. 2010), and there has been 
some success in increasing morphological complexity (Brooks et al. 2004) and habitat availability (Gerhard and Reich 2000). For example, in a wood addition study in the Western Upper Peninsula, Michigan, total annual coarse benthic organic matter storage was relatively low after one year $(\sim 4 \%)$, but increased to $\sim 15 \%$ by year two, indicating a gradual increase over time (Entrekin et al. 2008). In addition, overall change in macroinvertebrate production was stream and habitat dependent, which may have been influenced by the short sampling period (Entrekin et al. 2009). For example, in a wood addition study in the Western Upper Peninsula, Michigan, total annual coarse benthic organic matter storage was relatively low after one year ( $\sim 4 \%)$, but increased to $\sim 15 \%$ by year two, indicating a gradual increase over time (Entrekin et al. 2008). In addition, overall change in macroinvertebrate production was stream and habitat dependent, which may have been influenced by the short sampling period (Entrekin et al. 2009). Davidson and Eton (2013) modeled the effects of differing wood volumes in an intermediate-sized channel and found that wood additions increased morphological heterogeneity by promoting the storage of sediments important for fish spawning and increased the frequency of pools and variability in cross-channel depth. However, the strength of these relationships between instream wood and channel heterogeneity are likely dependent on other landscape and environmental factors.

Although simply adding wood to rivers has not necessarily increased channel complexity (Roni et al. 2015), as new methods of sampling are developed it is worth reconsidering how wood and channel complexity are related. There continues to be a need to identify these complex relationships and understand their variability across forested rivers, especially those in upper Great Lakes that are not as well studied as rivers in the western US (Cordova et al. 2007), where much of the understanding about wood in rivers comes from (Wohl 2017).

If restoring heterogeneity is the goal of a particular project, then the way heterogeneity or complexity is quantified needs to be considered (Cooper et al. 1997). There are several ways in which complexity can be quantified in rivers including metrics related to 
velocity/flow, the size and spatial arrangement of substrates, and the longitudinal, lateral, and planform morphology of rivers (see Wohl 2016). Many studies have focused on and report mean values to characterize the abiotic conditions in rivers, and some suggest that the variance in data should be used rather than means (Palmer et al. 1997). This is because variance might indicate which factors are most important for causing observed patterns, the changes in variance at different scales may reveal the heterogeneity of a system, and variance can show appropriate domains for sampling a particular environmental factor (Palmer et al. 1997). Along with a need to understanding heterogeneity, it has been argued that simply quantifying the amount of large wood and the number of CGUs does not provide enough information to make meaningful habitat management decisions (Ralph et al. 1994, Buffington et al. 2002), and that considering on a continuum may be more appropriate (Legleiter 2014a).

One potential tool for this assessment are variograms, which are models used in geostatistics to quantify the dissimilarity between data as a function of distance between measurements (Goovaerts 1997). They describe the spatial dependence among data points and determine at what distance between two individual data points the values are no longer correlated. For example, considering how the spatial autocorrelation of channel topography differs among streams or following restoration (Legleiter 2014b). In general, as the distance between points increases, so does the variability between values such that measurements closer to each other in space tend to be more similar. Variogram modelling has previously been used in terrestrial ecosystems to characterize the heterogeneity of vegetation cover from normalized difference vegetation index imagery at the landscape scale (Garrigues et al. 2006). Variograms have been used to characterize the distribution of fish throughout a network of headwater streams (Ganio et al. 2005), the spatial variability of river flow (David et al. 2013, Chiverton et al. 2015), as well as to compare channel morphology among reaches (Chappell et al. 2003, Legleiter 2014b). Variograms are defined as half the average squared difference of all measurements (e.g. elevation) that are separated by a particular lag vector and represented by the following equation (Goovaerts 1997): 


$$
\gamma(h)=\frac{1}{2 N(h)} \sum_{\alpha=1}^{N(h)}\left[z\left(u_{\alpha}\right)-z\left(u_{\alpha}+h\right)\right]^{2}
$$

Where $h$ is the lag vector that separates pairs of measurements $(\mathrm{z})$ at the locations $z\left(u_{\alpha}\right)$ and $z\left(u_{\alpha}+h\right)$. Finally, $N(h)$ is equal to the number of pairs at the given lag distance. Theoretically, at a lag distance of zero the variance should also zero, however there are circumstances for variograms where this is not true (i.e. $\gamma(0)>0$ ), which is called a nugget effect (Figure 4.1, Isaaks and Srivastava 1989). The nugget represents either variability in the data that occurs below the sampling scale or errors in the measurements (Goovaerts 1997). At some lag distance (h), measurements are no longer correlated. This point is called the sill and represents the total variance of the data (Figure 4.1). The lag distance at which the sill is reached is called the range and represents the maximum spatial scale at which data are correlated (Figure 4.1). Spatial dependence can relate to the heterogeneity of a system by considering the range and sill of the variogram. A higher sill and shorter range indicate a more heterogenous dataset (more overall variability in the data, and data points that are correlated over relatively short spatial scales) while a lower sill and longer range indicate a less heterogenous dataset (less overall variability and correlated over relatively longer spatial scales).

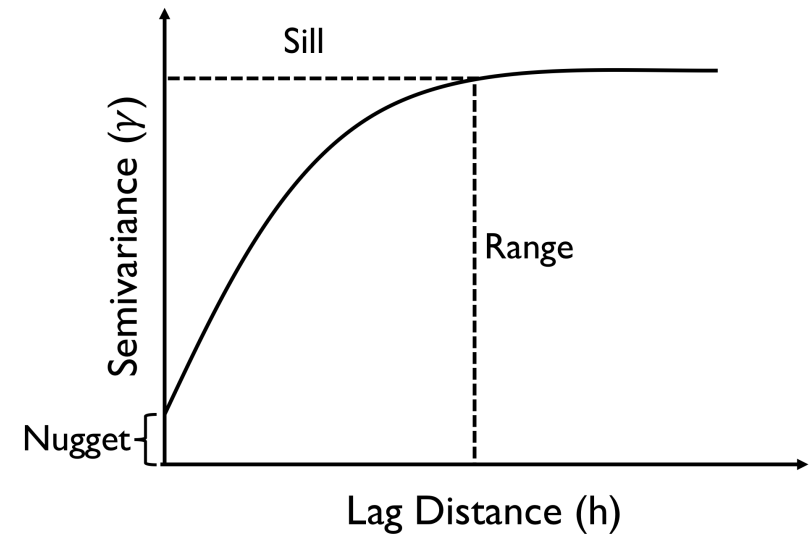

Figure 4.1. Theoretical variogram showing sill, range, and nugget effect.

In this study we sought to characterize the amount of large woody material and develop variograms based on longitudinal and lateral channel morphology as an estimate of spatial complexity in selectively logged forested rivers in Michigan's western Upper 
Peninsula. We then compared the spatial complexity to the volume of instream large woody material in each of the rivers to evaluate if there were potential associations between large wood and streambed morphology. If an association between this estimate of channel complexity and large wood in these rivers is found, it could be a useful tool to guide management as wood additions are often part of projects aimed at restoring or maintaining habitat (e.g. pools and other erosional habitat).

\subsection{Methods}

\subsubsection{Study Sites}

The Otter River watershed is located in the western Upper Peninsula, Michigan and drains $\sim 465 \mathrm{~km}^{2}$ of mostly forested landscape (USDA-NRCS 2008; Figure 4.2). The forested regions are characterized by northern hardwood species (e.g. sugar maple, Acer saccharum) with tag alder (Alnus rugosa) being common along streams (VanDusen et al. 2005). Including parts of Baraga, Houghton, and Ontonagon counties, the soils range from moderately to well drained sandy loams or loams (Schwenner 1991). From the middle 1800 s until approximately $1935,50 \%$ of the forests in parts of the upper Great Lakes region, including those in the Otter River Watershed, were cut (Leatherberry and Spencer 1996), which, along with the development of roads resulted in sedimentation in streams (Verry and Dolloff 2000). Since 1987, best management practices (BMP) for harvesting suggest maintaining a minimum $30 \mathrm{~m}$ buffer around the streams (MI-DNR 2018). Although these local BMPs do not dissuade harvesting within the buffer zone of the channel as long as the water quality functions within this region are maintained, and there is "little chance of significant soil disturbance, no chance of water sedimentation, and only select trees are being removed" (MI-DNR 2018).

Six second-order tributaries of the Otter River distributed within the Otter River watershed were selected based on previous research in the region (Figure 4.2; VanDusen et al. 2005, Burgess 2008). Thirteen Mile Creek (THM) and West Branch Sante (WBS) are located in the Sante sub-watershed, Bart Creek (BTC) and North Branch Bear (NBR) 
are located in the North Branch Otter sub-watershed, and Beaver Creek (BEC) and Otter Siding Road (OSR) are located in the West Branch Otter sub-watershed. The tributary drainage areas range from $\sim 3-12 \mathrm{~km}^{2}$ of selectively logged forest underlain by a mixture of fine and coarse textured glacial and lacustrine material. In each of the tributaries, a 100-m long site was identified based on previous research (Burgess 2008). These sites were comprised of multiple CGUs with slopes ranging from $0.5-1.7 \%$ and mean channel widths and depths ranging from 2.2-4.9 $\mathrm{m}$ and 0.12-0.25 m, respectively (Table 4.1).

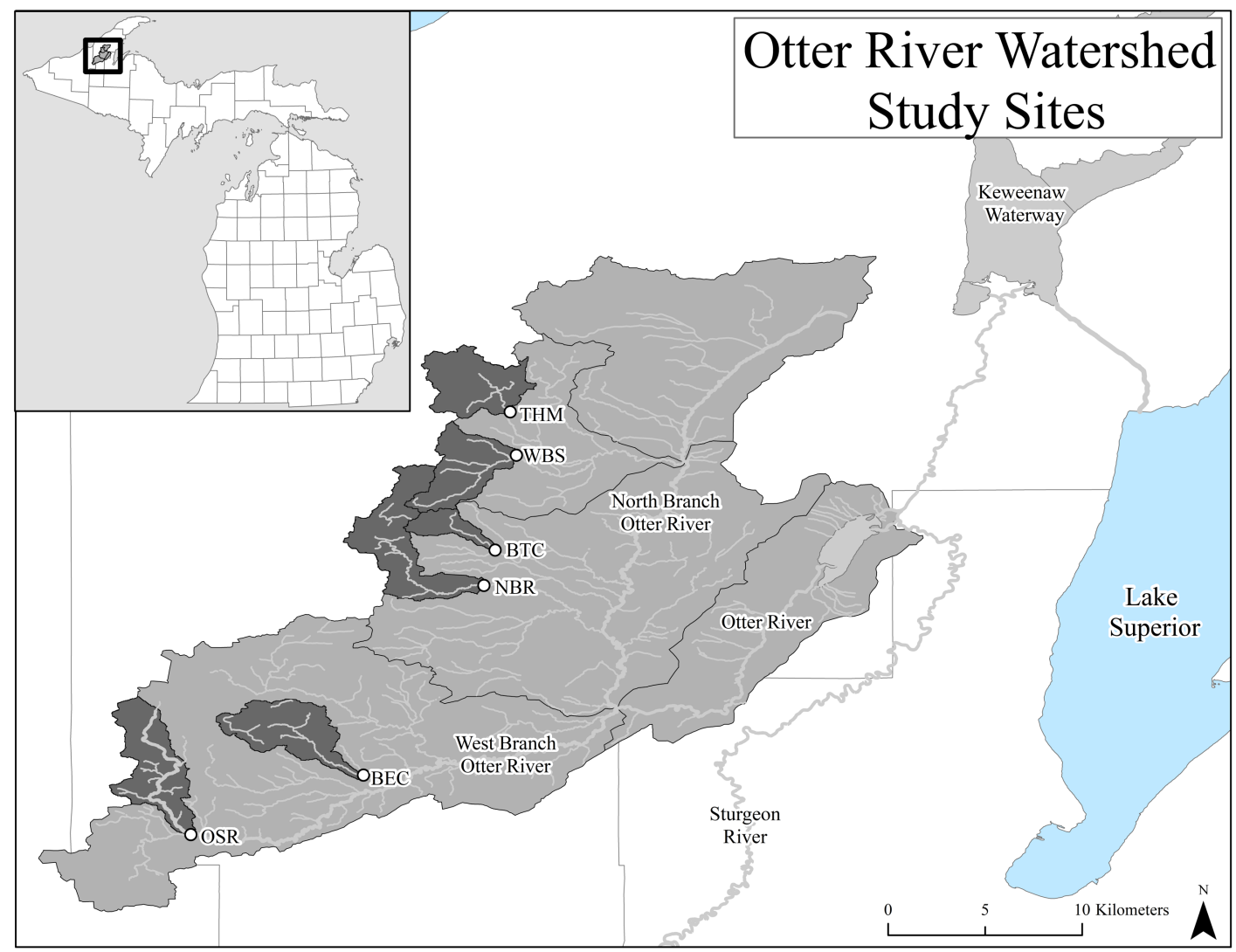

Figure 4.2. Map of study sites in Otter River Watershed, Michigan. Circles are the downstream boundary of each site. $\mathrm{BEC}=$ Beaver Creek, $\mathrm{BTC}=$ Bart Creek, NBR $=$ North Branch Bear Creek, OSR = Otter Siding Road, THM = Thirteen Mile Creek, WBS $=$ West Branch Sante Creek. Dark gray shaded areas represent the catchment area for each site. Light gray shaded area is the Otter River Watershed. 
Table 4.1. Otter River Watershed tributary site characteristics. Channel widths and depths were measured in 2015/2017 and are reported as mean \pm standard deviation.

\begin{tabular}{lcccc}
\hline \multicolumn{1}{c}{ Site } & $\begin{array}{c}\text { Drainage } \\
\text { area } \\
\left(\mathrm{km}^{2}\right)\end{array}$ & $\begin{array}{c}\text { Channel } \\
\text { Slope } \\
(\%)\end{array}$ & $\begin{array}{c}\text { Channel } \\
\text { Width } \\
(\mathrm{m})\end{array}$ & $\begin{array}{c}\text { Channel } \\
\text { Depth } \\
(\mathrm{m})\end{array}$ \\
\hline Beaver (BEC) & 10.0 & 0.95 & $3.2 \pm 0.9$ & $0.14 \pm 0.09$ \\
Bart (BTC) & 3.1 & 1.46 & $2.8 \pm 0.9$ & $0.12 \pm 0.07$ \\
North Branch Bear (NBR) & 12.4 & 0.66 & $5.2 \pm 1.4$ & $0.23 \pm 0.17$ \\
Otter Siding Road (OSR) & 11.0 & 0.49 & $3.7 \pm 0.9$ & $0.26 \pm 0.19$ \\
Thirteen Mile (THM) & 9.6 & 1.19 & $2.3 \pm 0.6$ & $0.13 \pm 0.10$ \\
West Branch Sante (WBS) & 8.8 & 1.71 & $3.3 \pm 0.8$ & $0.14 \pm 0.12$ \\
\hline
\end{tabular}

\subsubsection{Field Survey Methods}

A topographic survey of each site was conducted using a Leica TS11 total station (Leica Geosystems) and used to characterize channel morphology. All sampling occurred from August - October 2017. Starting at the downstream boundary of each site, the latitude, longitude and elevation ( $\mathrm{z}$ ) were measured for points throughout the sites and referenced to the local coordinate system using previously established benchmarks. We more closely spaced points in areas of greater topographic relief while those of lower relief were more spread out. Overall point spacing for each survey ranged from $1.0-2.1$ points $/ \mathrm{m}^{2}$.

All large woody material, defined as having a diameter $\geq 10 \mathrm{~cm}$ and length $\geq 1 \mathrm{~m}$ (Gurnell et al. 2002), was surveyed in each of the sites. Throughout each study site, the end locations of each piece of large wood were measured using the total station, and the diameter was measured at the midpoint to the nearest $0.01 \mathrm{~m}$ using a meter stick. Volume of large wood was quantified by treating the logs as a cylinder. Some of the sites contained wood jams comprised of numerous pieces of large (as defined above) and small wood. For these features the perimeter of the jams were measured using the total station to produce a polygon representing the surface area, which was multiplied by the average water depth at these locations to approximate jam volume. In addition to quantifying total volume of large wood in each site, we standardized wood volume by channel area to facilitate comparison across sites (i.e. $L W D \mathrm{~m}^{3} / \mathrm{m}^{2}$ ). 
A Wolman pebble count (Wolman 1954) was performed in each of the tributaries to characterize overall substrate composition. Starting at the downstream boundary of the site, individual substrate particles were indiscriminately pulled from the streambed and measured with calipers along their intermediate axis to the nearest $1 \mathrm{~mm}$. Particles were collected while moving upstream in a zig-zag path between the wetted width of the stream until $>150$ individual substrate particles were measured throughout the length of the site. Any sand encountered was classified as such and assigned a diameter of $2 \mathrm{~mm}$, which represents the upper size limit for sand (Wentworth 1922). From these data, median $\left(\mathrm{D}_{50}\right)$ and $84^{\text {th }}$ percentile $\left(\mathrm{D}_{84}\right)$ substrate diameters were quantified

\subsubsection{Geostatistical Analysis}

All geostatistical analysis was done in Matlab using code developed and shared by C. Legleiter (U.S. Geological Survey) and P. Kyriakidis (Cyprus University of Technology). The meandering nature of natural rivers make Euclidean distances unsuitable for this type of analysis (Rathbun 1998, Legleiter and Kyriakidis 2008). Thus, the original survey data were converted from Cartesian to a channel-centered coordinate system, where $\mathrm{x}$ and $\mathrm{y}$ coordinates become streamwise (S) and across-stream (i.e., normal) (n), respectively (Legleiter and Kyriakidis 2006). Briefly, this was done by (1) defining and applying a smoothing filter to the initial curved centerline of the channel, (2) creating a splined centerline from this data and resampling with a regular spacing, (3) determining the normal vector and curvature at each of the vertices on the resampled centerline, and (4)

calculating the centerline distances of points within a user defined polygon (Legleiter and Kyrikidis 2006). A trend model that accounted for channel slope, depth, and width was used to create dimensionless variables that express distances in terms of channel widths so that comparisons could be made between the different sized tributary sites. For example, if mean channel width was $0.5 \mathrm{~m}$, then $3.0 \mathrm{~m}$ of stream was equal to six stream widths. Elevation survey data was regressed against distance downstream to account for channel gradient, and the residuals were scaled to the average channel depth to account for depth and channel slope (Legleiter 2014a). By transforming the data to dimensionless 
variables, we were able highlight the channel morphology while accounting for the channel size differences among sites. These data were then used to develop variogram models for each of the sites.

One dimensional experimental variograms were quantified for the streamwise (S) and normal (n) directions by defining a lag spacing and tolerance, angular tolerance, and bandwidth (Legleiter 2014a). The lag spacing and lag spacing tolerance chosen was based on the distance between survey points, and the angular tolerance and bandwidth determined the angle and size of the search window (Oliver and Webster 2015). For these data, the lag spacing and tolerance were set to the average and half the average distance between measurements, respectively, while the angular tolerances were set to $22.5^{\circ}$ (Deutch 2015). Finally, the bandwidths for the streamwise and normal experimental variograms were chosen such that the lag spaced transects would not interact, and that data for the normal search sectors would not be influenced by streamwise search sectors (Legleiter 2014a). With the experimental variograms plotted, the model variograms in the $\mathrm{S}$ and $\mathrm{n}$ directions were first developed by visual approximation. The type (e.g. exponential, spherical, nugget), partial sills, and ranges for each nested model were manually estimated and adjusted until the model visually fit the experimental variogram reasonably well (Legleiter 2014a). These initial model parameters were optimized through an iterative approach to minimize the difference between the experimental and model variograms. This process involved choosing a maximum lag distance to include in the model and applying a weight to the model fit based on the number of measurements at each lag distance (Legleiter 2014a).

The final one dimensional streamwise and normal model variogram parameters were then used to calculate metrics that helped characterize the spatial arrangement of channel morphology, including the total sill $\left(\sigma^{2}\right)$, integral range $\mathrm{A}$, and the dispersion variance. These values were calculated for the one dimensional streamwise and normal models, and for a combined two dimensional (i.e. combining the streamwise and normal models) anisotropic variogram models. The total sill was equal to the overall variance observed in 
the survey data and was the sum of all partial sills from the nested variogram models. For topographic survey data, a higher total sill represents greater variability in elevation, while a lower total sill represents less variability (Legleiter 2014a). The integral range (A) condensed all partial sills and range lengths of the nested variogram model into a metric that represented the change in topography such that larger values of A represented steeper elevation changes while lower values of A represented more gradual changes in elevation. Finally, the dispersion variance represented the spatial heterogeneity within a defined region (e.g. a 1x8 stream width rectangle) and conveys the rate that the variance changed as a function of the region.

To aid in interpretation, the integral range and dispersion variance were also visualized as a heat map by representing the full two-dimensional anisotropic variogram model in what is called a variogram map (Legleiter 2014a). The variogram map shows all lag distance values, with the $\mathrm{x}$ and $\mathrm{y}$ axis representing the streamwise and normal direction lag distances, respectively, and the value of each pixel representing the variogram value at that lag distance. The center location on the heat map represents a distance of zero stream widths between points in the channel, and the cooler colors near the center (lag distances near zero) represent low semivariance values and thus relatively little variability between measurements at these lag distances. On the variogram map these can be thought of as points of low elevation. Moving away from the center in any direction (i.e. increasing the lag distance) the semivariance increases as the variance increases until eventually reaching the sill, which is the overall variance in the data (Legleiter 2014a). Sites with larger total sills (e.g. larger difference between the lowest and highest values) and shorter distances away from the center of the map to reach the sill are interpreted as being more heterogenous than sites with a smaller sill and longer distance to reach away from the center of the map to reach the sill (Legleiter 2014a). In addition to visualizing the dispersion variance and integral range, variogram maps show anisotropy (i.e. higher total sill and/or range in one of the directions). Geometric anisotropy is defined by a constant sill, but differing ranges depending on direction, while zonal anisotropy is characterized 
by different sills depending on direction being reached at the same range (Isaaks and Srivastava 1989).

The relative heterogeneity of channel morphology for each site was visually determined by considering the one-dimensional streamwise and normal variogram models, and the variogram maps (which visualize the sill, integral range, and dispersion variance for the full two-dimensional variogram model). It is important to consider not only the overall variability in streambed morphology, but also the spatial scale (e.g. range) and direction (streamwise versus across-stream) in which this variability is exhibited because each of these metrics on their own do not necessarily explain heterogeneity (Legleiter 2014b). We predicted that sites with the largest volumes of wood would also have the most heterogenous channel morphology based on variograms. To compare each of the sites and their relative heterogeneity, a combination of the streamwise and normal variogram models, integral range and dispersion variance, and variogram maps were visually evaluated.

As a step towards understanding if other reach and landscape variables (e.g. slope, drainage area, substrates) may be associated with the complexity in channel morphology we applied non-metric multidimensional scaling (NMDS) to the site data. With this, we sought to understand how the river sites group based on a subset of these commonly reported metrics to characterize rivers, and if these groupings followed what we observed for large wood and variogram derived morphological complexity. These metrics included standardized data for channel slope $(\%)$, drainage area $\left(\mathrm{m}^{2}\right)$, substrate heterogeneity $\left(\mathrm{D}_{84} / \mathrm{D}_{50}\right.$; Laub et al. 2012), and mean width to depth ratio.

\subsection{Results}

\subsubsection{Large Woody Material and Substrates}

Total volume of instream large wood was highly variable across sites, ranging from 1.1 $\mathrm{m}^{3}$ (site THM) to $11.2 \mathrm{~m}^{3}$ (site OSR) with an average volume across all sites of $4.0 \pm 3.7$ 
$\mathrm{m}^{3}$ (mean $\pm \mathrm{SD}$ ). When standardized by site area, OSR had the highest relative volume of large wood $\left(0.028 \mathrm{~m}^{3} \mathrm{~m}^{-2}\right)$ of which nearly all was in the form of jams. BEC contained the next largest volume of large wood $0.013 \mathrm{~m}^{3} \mathrm{~m}^{-2}$ with no jams. BTC had a similar relative volume (Table 4.2 ), of which $\sim 17 \%$ of the volume was in jams. NBR, THM, and WBS had the lowest relative volumes of large wood (range: $0.004-0.005 \mathrm{~m}^{3} \mathrm{~m}^{-2}$ ) and NBR was the only site of these to contain log jams (Figure 4.3). The number of large wood pieces and jams ranged from 9 to 36 per $100 \mathrm{~m}$ of river length. BEC contained the most pieces of wood, while BTC, NBR and THM contained 35, 15, and 13 pieces, respectively. WBS had 11 pieces of large wood, while OSR had the fewest, but also contained many additional smaller pieces of wood (diameter $<0.1 \mathrm{~m}$ ) in the downstream of the site as a result of due to beaver activity.

Table 4.2. Substrate and large wood in Otter River Water sites.

\begin{tabular}{lccc}
\hline \multicolumn{1}{c}{ Site } & $\begin{array}{c}\text { Pebble Count } \\
\mathrm{D}_{50}(\mathrm{~mm})\end{array}$ & $\begin{array}{c}\text { Pebble Count } \\
\mathrm{D}_{84}(\mathrm{~mm})\end{array}$ & $\begin{array}{c}\text { Large Wood } \\
\text { Standardized } \\
\text { Volume }\left(\mathrm{m}^{3} \mathrm{~m}^{-2}\right)\end{array}$ \\
\hline Beaver (BEC) & 7 & 43 & 0.0128 \\
Bart (BTC) & 21 & 65 & 0.0129 \\
North Branch Bear (NBR) & 31 & 53 & 0.0036 \\
Otter Siding Road (OSR) & 2 & 15 & 0.0283 \\
Thirteen Mile (THM) & 39 & 72 & 0.0043 \\
West Branch Sante (WBS) & 43 & 87 & 0.0054 \\
\hline
\end{tabular}




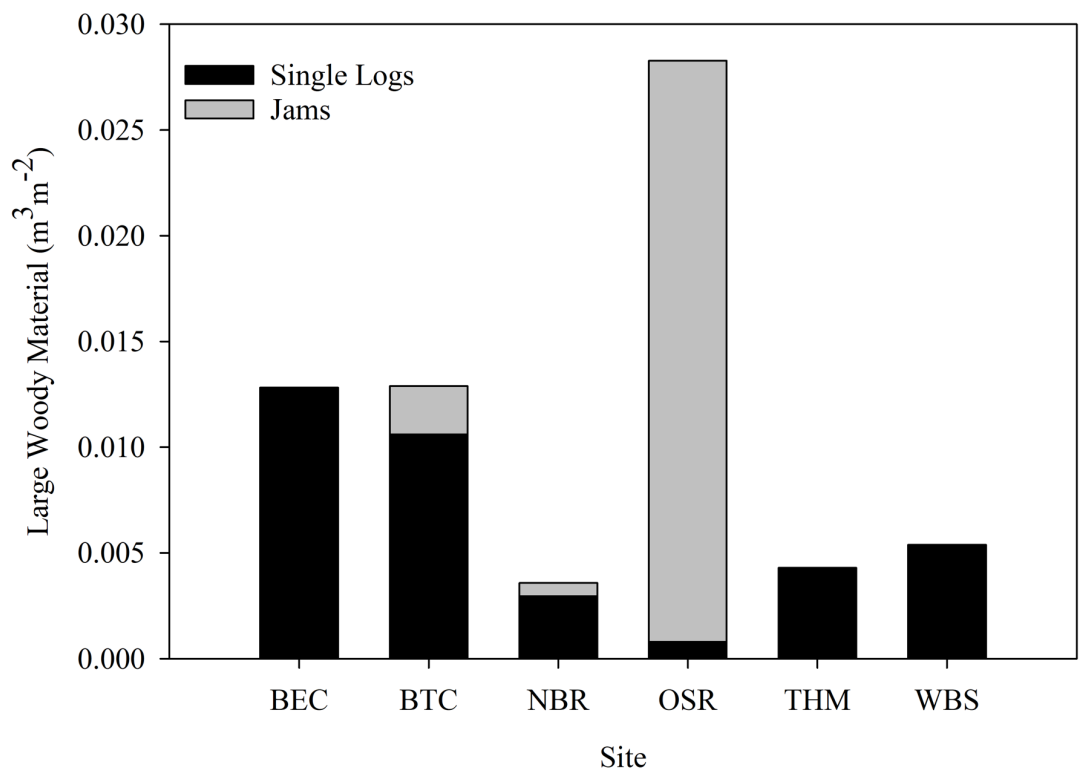

Figure 4.3. Area standardized volume of large woody material in Otter River Watershed sites. Black portion of bars represent volume of individual logs while gray portions represent log jam volume. OSR contained a beaver dam in the lower part of the study reach, which is why the majority of large wood in this site was classified as a jam. This site also had much additional smaller (diameter $>0.1 \mathrm{~m}$ ) wood that was not quantified.

Median substrate size $\left(\mathrm{D}_{50}\right)$ based on pebble counts ranged from sand $(2 \mathrm{~mm})$ in OSR to coarse gravel $(43 \mathrm{~mm}$ ) in WBS (Table 4.2). BEC was the only other site with a relatively small $\mathrm{D}_{50}$ at $7 \mathrm{~mm}$, while the remaining sites were all $>20 \mathrm{~mm}$. The $84^{\text {th }}$ percentile $\left(\mathrm{D}_{84}\right)$, which represents one standard deviation above the mean, ranged from $15 \mathrm{~mm}$ in OSR to $87 \mathrm{~mm}$ in WBS (Table 4.2). The remaining sites all had $\mathrm{D}_{84}$ values $>40 \mathrm{~mm}$.

\subsubsection{Geostatistical Results}

The variance in the data (i.e. sills) and spatial scale that it occurs over (i.e. range) in the streamwise and across stream directions varied among the study sites. In the streamwise direction, the two sites with the lowest total sills (i.e. combination of all nested model partial sills) also had the shortest ranges (Table 4.3; Figure 4.4). Of the six tributaries, BEC and BTC had total sills of 0.56 and 0.48 , and ranges of 1.21 and 1.31 channel widths, respectively. WBS had the highest sill (1.09) indicating that the greatest variance in morphology data occurred in WBS, and was $\sim 2 \mathrm{x}$ that of BEC and BTC. OSR had the longest range (5.29 stream widths), meaning that point-to-point data are related over 
longer distances than any other site, and were related for $>4 \mathrm{x}$ longer distances compared to the sites with the shortest ranges (i.e. BEC and BTC). In the cross channel (normal) direction, all the streams had total sills between 0.41-0.78, except for the WBS, which was the highest at 1.42 (Table 4.3; Figure 4.5). Similarly, ranges for five of the streams were between $0.65-1.08$ channel widths, while the WBS range was 1.82 channel widths.

Table 4.3. Total sill $\left(\sigma^{2}\right)$ and range (channel widths) from streamwise (S) and cross channel (n) model variograms of Otter River Watershed tributaries. Variogram data derived from channel morphology survey using a total station.

\begin{tabular}{l|c|c|c|c}
\hline \multirow{2}{*}{\multicolumn{1}{c|}{ Site }} & \multicolumn{2}{|c|}{ Total Sill $\left(\sigma^{2}\right)$} & \multicolumn{2}{c}{ Range (channel widths) } \\
\cline { 2 - 5 } & $\mathrm{S}$ & $\mathrm{n}$ & $\mathrm{S}$ & $\mathrm{n}$ \\
\hline Beaver (BEC) & 0.48 & 0.41 & 1.31 & 0.65 \\
Bart (BTC) & 0.56 & 0.53 & 1.21 & 0.78 \\
North Branch Bear (NBR) & 0.72 & 0.64 & 1.84 & 1.00 \\
Otter Siding Road (OSR) & 0.77 & 0.78 & 5.29 & 1.08 \\
Thirteen Mile (THM) & 0.93 & 0.62 & 3.78 & 0.93 \\
West Branch Sante (WBS) & 1.09 & 1.42 & 3.69 & 1.82 \\
\hline
\end{tabular}



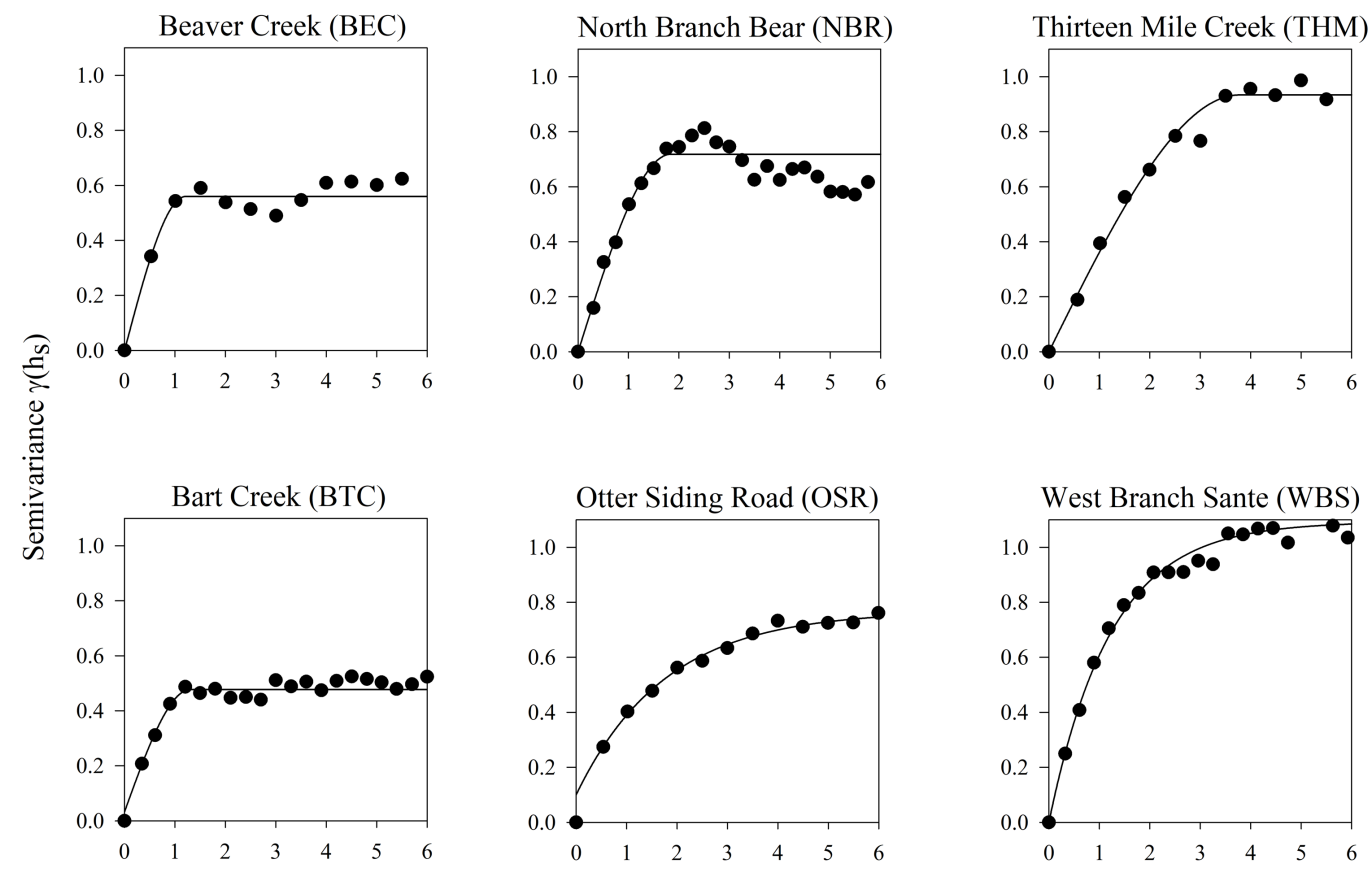

Streamwise Lag Distance (channel widths)

Figure 4.4. Streamwise variograms for Otter River Watershed sites derived from channel bed morphology data from total station surveys. The y-axis represents semivariance values while the $\mathrm{x}$-axis is the lag distance between measurements in the streamwise (i.e. longitudinal) direction. The black points in each graph represent the empirical variogram while the black line represents the model variogram. Nugget effects (i.e. a value $>0$ at zero lag distance) were observed in Otter Siding Road (OSR) and Bart Creek (BTC). 

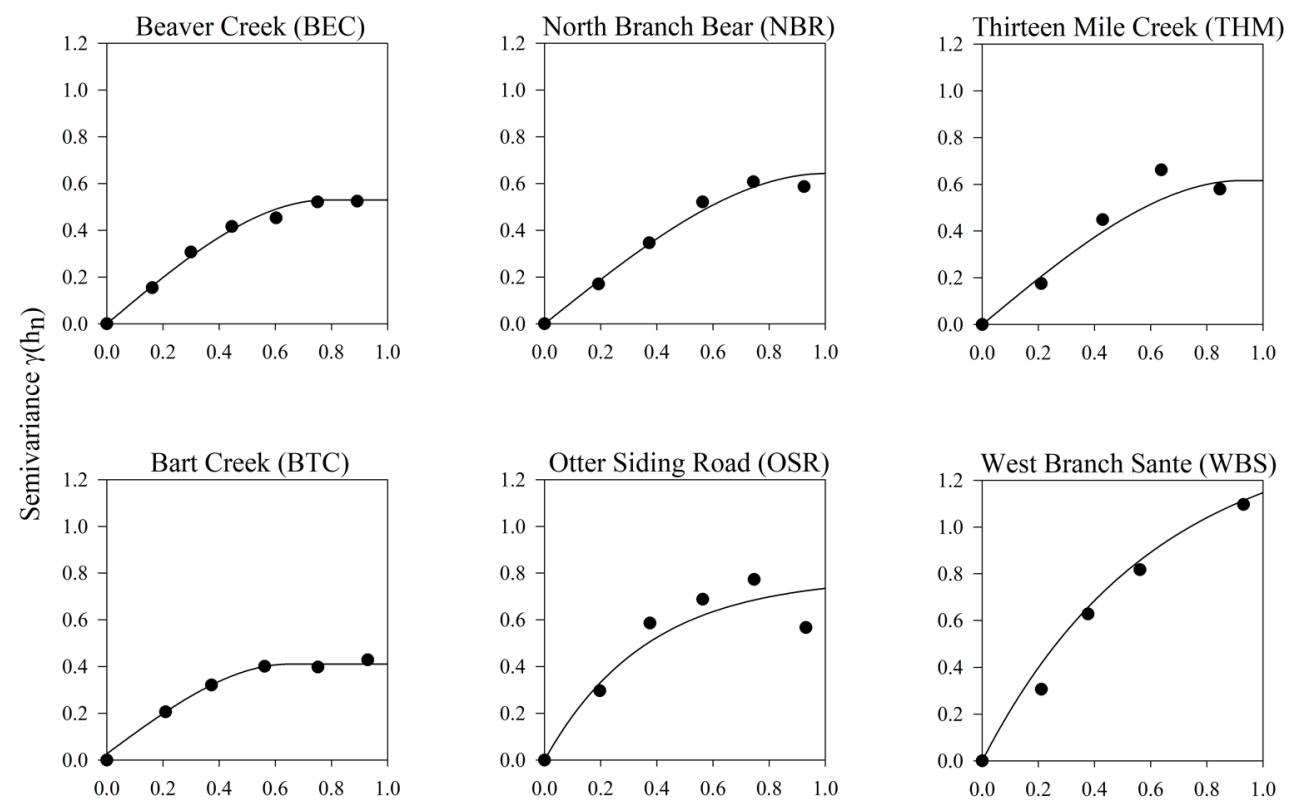

Normal Lag Distance (channel widths)

Figure 4.5. Normal (across stream) variograms for Otter River Watershed sites derived from channel morphology data from total station surveys. The y-axis represents semivariance values while the $\mathrm{x}$-axis is the lag distance between measurements in the normal or across the channel (i.e. bank to bank) direction. The black points in each graph represent the empirical variogram while the black line represents the model variogram. A nugget effects (i.e. a value $>0$ at zero lag distance) was observed in Bart Creek (BTC). 
The combined results from the streamwise and normal variograms, and the variogram maps indicate that the complexity in channel morphology of some of these sites may be similar. The streamwise variograms from the six sites behaved as three groups based on their total sills: (1) BEC and BTC, (2) NBR and OSR, and (3) THM and WBS (Figure 4.4), and these groupings were also represented in the variogram maps (Figure 4.6). Nugget effects in the streamwise variograms were observed for BTC and OSR, which had partial sills of 0.03 and 0.10 , respectively. Based on the total sill, integral range, and dispersion variance for the streamwise, normal, and full anisotropic variogram models (Figure 4.7) and the variogram maps (Figure 4.6) all of the streams appear to have varying degrees geometric anisotropy (i.e. higher range in one of the directions), while BTC and OSR were the only sites that had similar sill values for the streamwise and normal directions. Absolute differences in streamwise and normal sills ranged from 0.010.33 (Table 4.3). BTC and OSR streamwise and normal total sill did differ, but the magnitudes were low (0.03 and 0.01, respectively), suggesting the predominant anisotropy at these sites was geometric and that variance in data occurs over shorter distances across than along the channel (i.e. reaching the same sill at shorter distances across the channel than along the channel). The direction with the highest total sill also varied among sites. Total sills higher in the streamwise direction, meaning with variance in this longitudinal direction, occurred for BEC, BTC, NBR, and THM, while OSR and WBS each had a higher total sill in the normal direction (i.e. across the channel). In the streamwise direction, dispersion variance was highest for WBS (0.77) and lowest in BTC (0.42). For the normal direction, dispersion variance was also highest for WBS (0.46) and OSR (0.36), and lowest in BTC, NBR, THM, and BEC which ranged from 0.23-0.24. 
Beaver Creek (BEC)

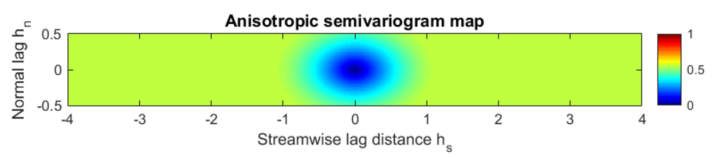

North Branch Bear (NBR)

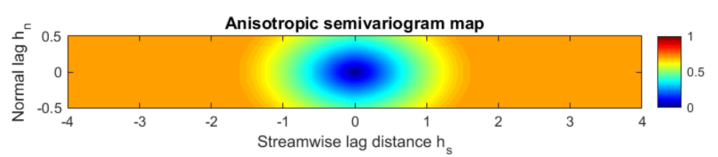

Thirteenmile Creek (THM)

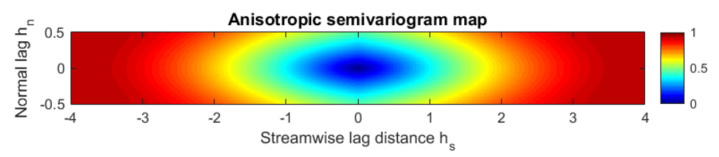

Bart Creek (BTC)

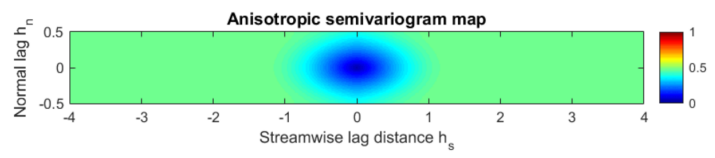

Otter Siding Road (OSR)

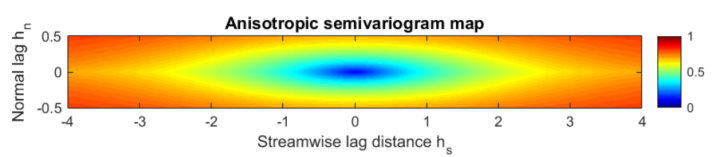

West Branch Sante (WBS)

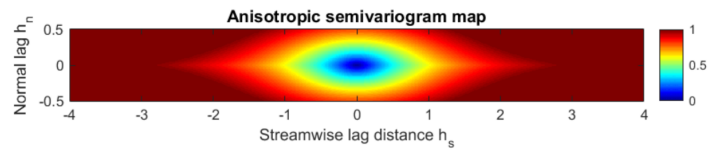

Figure 4.6. Variogram maps for Otter River Watershed sites illustrate how variogram values change as the lag distance increases in the streamwise (S) and normal (n) or across stream directions. Colors represent semivariance, with the cooler colors (e.g. blue) in the center represent low semivariance while the warmer colors (e.g. red) are higher variogram values and the highest values representing the sills for each site.
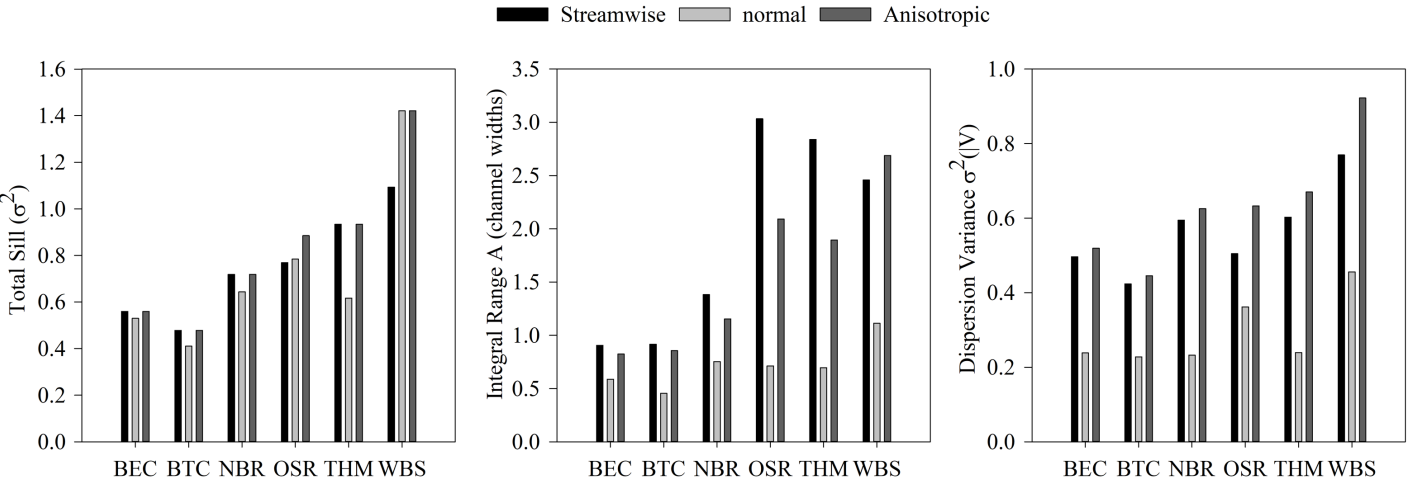

Figure 4.7. Total sill, integral range and dispersion variance for the one-dimensional streamwise and across stream directions, and the full two-dimensional anisotropic variogram for each study site in the Otter River Watershed. The total sill represents the overall variance observed in the data, while the integral range represents the change in topography. Finally, dispersion variance represents the spatial heterogeneity within a defined area (e.g. the 1 stream width $x 8$ stream width area of the variogram maps in Figure 4.6).

Integral range $\mathrm{A}$ in the streamwise direction $\left(\mathrm{A}_{\mathrm{s}}\right)$ was highest for OSR at 3.0 channel widths (Figure 4.7), indicating this site had the highest spatial auto-correlation in channel bed morphology in the streamwise direction. THM and WBS had the next highest 
Integral Ranges at $\sim 2.8$ and 2.5 , respectively. NBR had an integral range of 1.4 channel widths, and $\mathrm{BEC}$ and $\mathrm{BTC}$ were both $<1$ channel width, meaning these sites have the lowest autocorrelation in channel morphology.

Based on the variogram metrics and variogram maps, WBS and THM were the most heterogenous channels due to having the highest total sills and dispersion variances, respectively (Figure 4.7). However, it should be noted that for THM, some of these variables were similar to lower heterogeneity sites (e.g. the streamwise dispersion variance was similar to that of NBR). The next highest heterogeneity was observed in NBR and OSR. Although OSR had a slightly higher total sill than NBR, indicating greater variance in the data, its range was much longer in the streamwise direction, at $>5$ channel widths versus $<2$ channel widths for NBR. This difference can be conceptualized by looking at the variogram maps as elevation plots (Figure 4.6).

WSB and THM had the biggest difference between in minimum and maximum variogram values (i.e. total sill) based on variogram maps. Although these sites did not have the shortest ranges, the combination of total sill, integral range, and dispersion variance indicates these sites had the most complex channel bed morphology. NBR and OSR had similar total sill values but the gradient moving away from the center of the OSR variogram map was more gradual than for NBR, indicating that there was a greater distance across which the variability was correlated. Finally, the sites with the least heterogenous morphologies were BEC and BTC. These sites had the shortest ranges, which alone indicate reaching dissimilarity at a short distance. However, these sites also had the lowest variance in channel morphology based on variogram value reached at the sill (Figure 4.7). For BEC and BTC, this was akin to a very shallow minimum or low with short and steep gradients moving away from the center, while for example, the variogram maps for WBS and THM each had much deeper minimum with more longer and more gradual gradients moving away from the center (Figure 4.6). 


\subsubsection{Non-metric Multidimensional Scaling Results}

As a further step toward understanding the differences between these study sites in terms of their physical characteristics, we applied an NMDS to a metric of substrate heterogeneity ( $\mathrm{D}_{84} / \mathrm{D}_{50}$ percentile from pebble counts), channel slope, catchment area, and width/depth ratio. Compared with groupings based on the variogram maps, we observed a different grouping of sites based on these four physical metrics, with THM, BTC, and NBR having similarities based on the ordination (Figure 4.8). However, these sites differed in complexity from one another, with relatively low complexity in BTC, moderate complexity in NBR, and high complexity in THM channel morphology based on the variograms. As with the variogram results, large wood volume does not appear to relate to this NMDS grouping as these three sites had low to intermediate amounts of wood (Table 4.2). The remaining sites did not appear to group based on the results of the ordination. The differences in the variogram results and the NMDS groupings indicate that some other landscape or environmental factor is likely driving the complexity in channel morphology that we observed. 


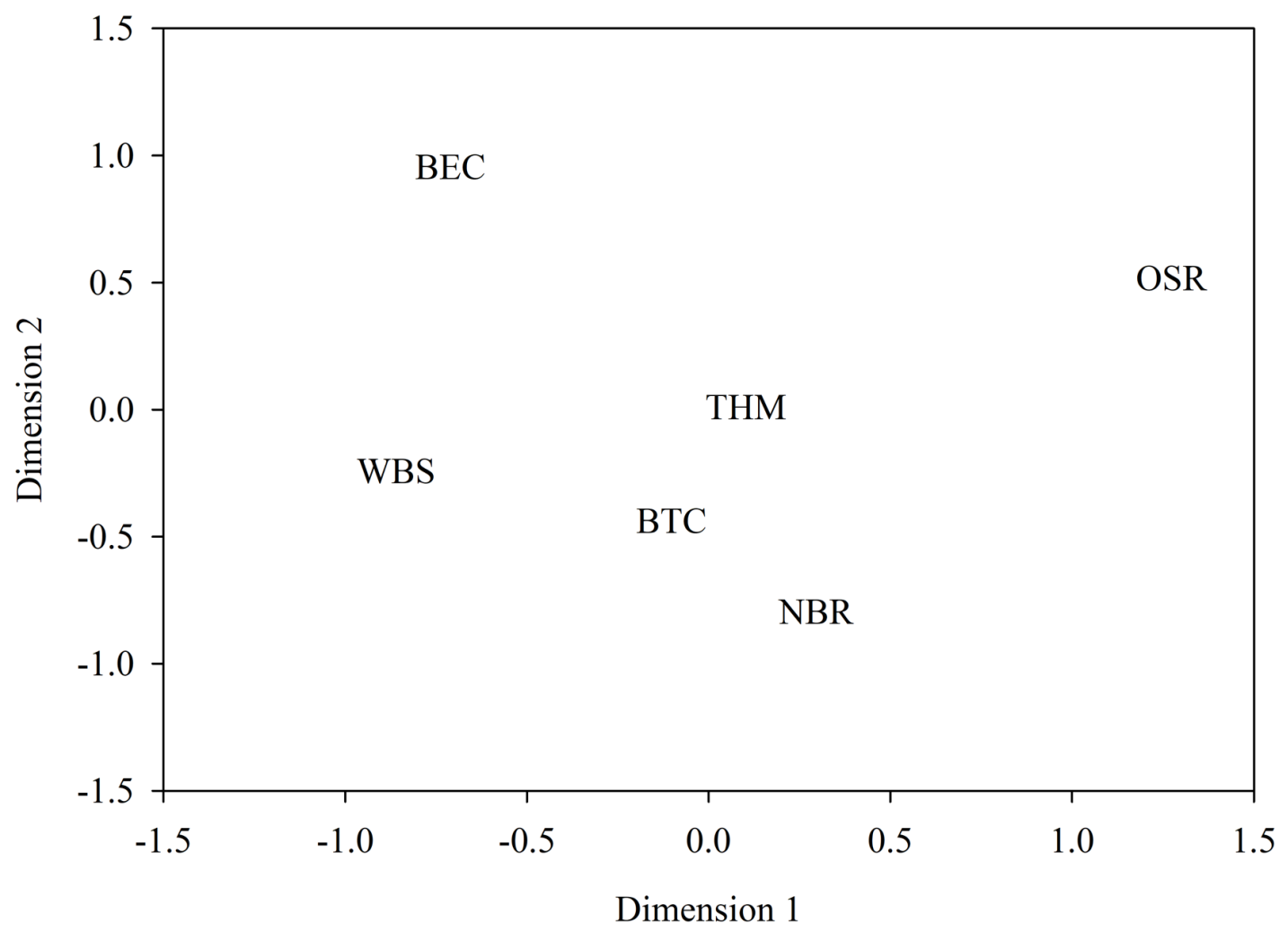

Figure 4.8. Non-metric multidimensional scaling (NMDS) of substrate heterogeneity $\left(\mathrm{D}_{84} / \mathrm{D}_{50}\right)$, channel slope, catchment area, and average width/depth ratio for the six Otter River Watershed sites.

\subsection{Discussion}

The selectively logged forested rivers in this study did have large (8-fold) differences in the volume of large wood and the spatial complexity in stream channel morphology based on variograms, however we did not detect relationships between these in-channels features that we expected. We found the six study sites grouped into three different categories of morphological heterogeneity (Figure 4.6 and Figure 4.7). In terms of large wood volume, OSR was somewhat of an anomaly at nearly twice as much wood as the next most abundant sites (Figure 4.3). BEC and BTC contained a similar relative volume of wood, and the same occurred among NBR, THM, and WBS (Figure 4.3). In contrast to how these sites grouped based on relative volume of wood, this pattern was not reflected in the channel morphology features in Figure 4.6. 
The lack of a clear association between the amount of large instream wood and channel complexity based on either relative downstream or normal channel morphology may be the result of not enough wood in these sites to substantially influence channel structure. While the methods we used estimated the volume of $\log$ jams, it is likely that the actual volume of wood (e.g., in OSR) was overestimated because the method used to estimate $\log$ jam volume does not account for their porosity (Manners et al. 2007). Yet, the absolute amount of instream wood was relatively low compared to the western US, even in the stream site with the highest volume per unit area (OSR). In unmanaged and managed forest streams across four geomorphic regions in Northern California Benda and Bigelow (2014) used a similar criterion for defining large wood (diameter and length $\geq 0.1 \mathrm{~m}$ and $1.5 \mathrm{~m}$, respectively) and they observed volumes ranging from 0.0013-0.1059 $\mathrm{m}^{3} \mathrm{~m}^{-2}$, similar to the range we observed (Table 4.2) and 35\% of pools identified were formed by wood. However, six of their nine site groupings had mean large wood diameters $>2 \mathrm{x}$ what we observed in the Otter River Watershed (Benda and Bigelow 2014). Benda and Bigelow (2012), along with Martin (2001) and Ralph et al. (1994) suggest an important factor in the function of large wood is its diameter. Martin (2001) observed $>50 \%$ of pools associated with large wood in managed forested streams along the southern coast of Alaska, with as much as $39 \%$ of that wood $>60 \mathrm{~cm}$ in diameter. Elsewhere, data from 245 stream segments in Washington state revealed that large wood with a diameter $>50 \mathrm{~cm}$ made up $>20 \%$ of all wood found in a majority of streams, and for many unharvested streams more than half the wood measured had a diameter of $>50$ $\mathrm{cm}$ (Ralph et al. 1994). In addition, some of these sites were comprised of $\sim 50 \%$ pools by area (Ralph et al. 1994). In comparison, mean large wood diameters among our sites ranged from $14 \pm 5 \mathrm{~cm}$ to $25 \pm 12 \mathrm{~cm}$, with only one site (BEC) containing wood $>50 \mathrm{~cm}$ in diameter, which comprised $\sim 3 \%$ of the wood counted.

Our study sites in the Otter River Watershed have a history of being actively logged (VanDusen et al. 2005), which likely contributed to the smaller diameters of large wood encountered. The size and abundance of large wood in the Otter River Watershed likely 
reflects a combination of the historical and contemporary logging practices of the region, as logging has been associated with a reduction in the loading and diameter of wood in rivers (Ralph et al. 1994). Results from a separate study in this part of the western Upper Peninsula, Michigan showed only 14\% of large wood associated with pools and a mean large wood diameter of $18 \mathrm{~cm}$ (Cordova et al. 2007). Our sites and those from Cordova et al. (2007) in the Western Upper Peninsula also have relatively low volumes of wood compared to streams from the Pacific Northwest of North America and the large wood present is often smaller. The largest diameter wood we encountered was $66 \mathrm{~cm}$ and the mean diameter was $19 \pm 9 \mathrm{~cm}$.. In contrast, wood in the Pacific Northwest can have larger mean diameters (e.g. 22-85 cm; Beechie and Sibley 1997, Benda and Bigelow 2014) with some wood $\geq 2 \mathrm{~m}$ in diameter (Andrus et al. 1988, Abbe and Montgomery 2003).

Although an association between channel bottom morphology and large wood was not evident, our results provide important data on what conditions exist in these selectively logged forests. Understanding changes in channel morphology is often a goal of monitoring (e.g Chapter 3), and it has been argued that only using CGU classification to quantify or monitor channel morphology may not be appropriate (Poole et al. 1997). This is in part because criteria and determination of these classifications can be somewhat arbitrary, for example, the edge of a pool can be gradual so the boundary is difficult to define (Poole et al. 1997). Using separate streamwise and normal variogram models to describe stream channel complexity as developed by Legleiter (2014a) and applied here acts as a suitable alternative because approaches such as quantifying the number of CGUs or measuring gross channel dimensions (e.g. mean width and depth) do not provide enough information to characterize the underlying spatial structure in channel morphology. Even though these methods are suitable characterizing stream channel complexity, Legleiter (2014b) concluded that multiple variogram metrics (e.g. dispersion variance, integral range) as well as the anisotrophic variogram models may need to be considered to fully understand the differences when comparing among stream channels. Legleiter (2014b) recommends that this approach may be best suited for monitoring within stream temporal changes, particularly in response to restoration. There are 
limitations to using variogram for characterizing stream channel complexity. First, they require surveying equipment (e.g. total station), which can be cost prohibitive. More importantly, not all stream researchers or managers may be familiar with variograms and because the interpretation of these data is not as straightforward as evaluating, for example, the differences in mean values, a deeper understanding of geostatistical techniques such as variograms may be needed. Likewise, understanding or being able to conceptualize differences in variance structures, as well as relating these structures to more intuitive metrics such as the initial topographic survey data (e.g. Figure 4.9) is valuable to their interpretation.
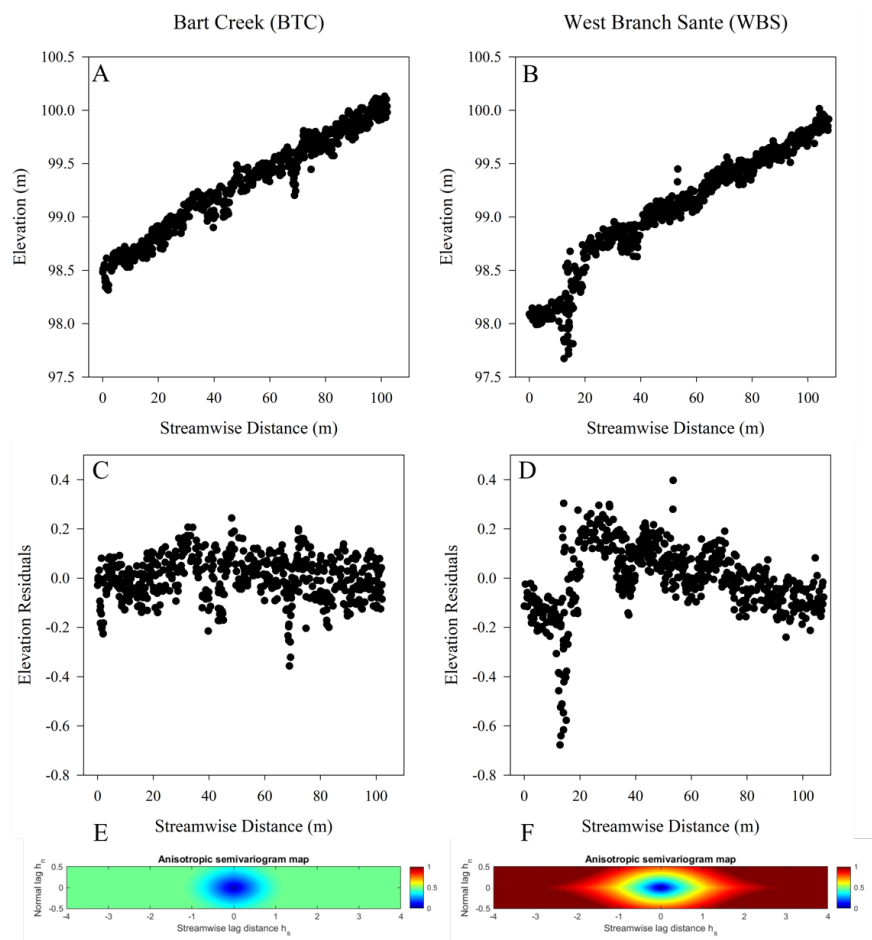

Figure 4.9: Topographic survey data and variogram maps for Bart Creek (BTC) and West Branch Sante (WBS) sites in the Otter River Watershed, MI. Longitudinal change in elevation is shown in A and B, while residuals from detrended elevation data are shown in $\mathrm{C}$ and $\mathrm{D}$. These residuals were used in the variogram analysis to produce the variogram maps (E, F). Based on variograms, Bart Creek was a low heterogeneity site (E) while West Branch Sante was a high heterogeneity site (F).

Finally, there is no software or software packages that will perform these steps of variogram assessment needed to apply the methods outlined by Legleiter (2014a) without needing troubleshooting, meaning a substantial understanding of coding (e.g. Matlab) is 
required. Despite the complexities in using this approach to evaluate channel morphology, we have shown that sites in the Otter River Watershed differ in their morphological complexity, and that wood volume does not appear to relate to complexity. The spatial complexity quantified in this study may be related to important instream processes such as the movement and arrangement of sediment as well as habitat heterogeneity for instream biota (Legleiter 2014b). Maintaining or improving habitat is often a goal of management and restoration, and that these methods could be used to reveal important relationships between the spatial structure of streambeds and instream habitat (e.g. heterogeneity; Wohl 2016) . Due to the significance of channel morphology for fluvial ecosystems, these data are important for understanding what morphological conditions exist among streams in this selectively forested watershed. 


\subsection{References}

Abbe, T. B., and D. R. Montgomery. 1996. Large woody debris jams, channel hydraulics, and habitat formation in large rivers. Regulated Rivers: Research and Management 12: 201-221.

Abbe, T. B., and D. R. Montgomery. 2003. Patterns and processes of wood debris accumulation in the Queets river basin, Washington. Geomorphology 51: 81-107.

Andrus, C. W., B. A. Long, and H. A. Froehlich. 1988. Woody debris and its contribution to pool formation in a coastal stream 50 years after logging. Can. J. Fish. Aquat. Sci. 45: 2080-2086.

Beechie, T. J., and T. H. Sibley. 1997. Relationships between channel characteristics, woody debris, and fish habitat in northwestern Washington streams. Transactions of the American Fisheries Society 126: 217-229.

Beisel, J., P. Usseglio-Polatera, and J Moreteau. 2000. The spatial heterogeneity of a river bottom: a key factor determining macroinvertebrate communities. Hydrobiologia 422/423: 163-171

Benda, L., and P. Bigelow. 2014. On the patterns and processes of wood in northern California streams. Geomorphology 209:79-97.

Bilby, R. E. 1984. Removal of wood debris may affect stream channel stability. Journal of Forestry 82: 609-613.

Boyero, L. 2003. The quantification of local substrate heterogeneity in streams and its significance for macroinvertebrate assemblages. Hydrobiologia 499: 161-168.

Brooks, A. P, P. C. Gehrke, J. D. Jansen, and T. B. Abbe. 2004. Experimental reintroduction of woody debris on the Williams river, NSW: geomorphic and ecological responses. River Research and Applications 20: 513-536.

Brown, B. L. 2003. Spatial heterogeneity reduces temporal variability in stream insect communities. Ecology Letters 6: 316-325.

Buffington, J. M., T. E. Lisle, R. D. Woodsmith, and S. Hilton. 2002. Controls on the size and occurance of pools in coarse-grained forest rivers. River Research and Applications 18:507-531.

Buffington, J. M., and D. Tonina. 2009. Hyporheic exchange in mountain river II: effects 
of channel morphology on mechanics, scales, and rates of exchange. Geography Compass 3/3: 1038-1062.

Burgess, A. F. 2008. Macroinvertebrate Communities, Organic Matter, and Physical Habitat Conditions Across Headwater Streams of the Otter River, In Michigan's Upper Peninsula. Michigan Technological University.

Chappell, A., G. L. Heritage, I. C. Fuller, A. R. G. Large, and D. J. Milan. 2003.

Geostatistical analysis of ground-survey elevation data to elucidate spatial and temporal river channel change. Earth Surface Processes and Landforms 28: 349370.

Chiverton, A., J. Hannaford, I. Holman, R. Corstanje, C. Prudhomme, J. Bloomfield, and T. M. Hess. 2015. Which catchment characteristics control the temporal dependence structure of daily river flow? Hydrological Processes 29: 1356-1369.

Collins, B. D., D. M. Montgomery, K. L. Fetherston, and T. B. Abbe. 2012. The floodplain large-wood cycle hypothesis: a mechanism for the physical and biotic structuring of temperate forested alluvial valleys in the North Pacific coastal ecoregion. Geomorphology 139-140: 460-470.

Cooper, S. D., L. Barmuta, O. Sarnelle, K. Kratz, and S. Diehl. 1997. Quantifying spatial heterogeneity in streams. Journal of the North American Benthological Society 16(1):174-188.

Cordova, J. M., E. J. Rosi-Marshall, A. M. Yamamuro, and G. A. Lamberti. 2007. Quantity, controls and function of large woody debris in midwestern USA streams. River Research and Applications. 23: 21-33.

David, G. C. L., C. J. Legleiter, E. Wohl, and S. E. Yochum. 2013. Characterizing spatial variability in velocity and turbulence intensity using 3-D acoustic doppler velocimeter data in a plane-bed reach of East St. Louis Creek, Colorado, USA. Geomorphology 183: 28-44.

Davidson, S. L., and B. C. Eton. 2013. Modeling channel morphodynamic response to variations in large wood: implications for stream rehabilitation in degraded watersheds. Geomorphology 202: 59-73.

Deutsch, J. L. 2015. Experimental Variogram Tolerance Parameters. In J. L. Deutsch 
(Ed.), Geostatistics Lessons. Retrieved from http://www.geostatisticslessons.com/lessons/variogramparameters

Diez, J. R., S. Larranaga, A. Elosegi, and J. Pozo. 2000. Effect of removal of wood on streambed stability and organic matter retention. J. N. Am. Benthol. Soc. 19(4): 621632.

Faustini, J. M., J. A. Jones. 2003. Influence of large woody debris on channel morphology and dynamics in steep, boulder-rich mountain streams, western Cascades, Oregon. Geomorphology 51:187-205.

Frissell, C. A., W. J. Liss, C. E. Warren, and M. D. Hurley. 1986. A hierarchical framework for stream habitat assessment classification: viewing streams in a watershed context. Environmental Management 10(2): 199-214.

Ganio, L. M., C. E. Torgersen, and R. E. Gresswell. 2005. A geostatistical approach for describing spatial patterns in stream networks. Front Ecol Environ 3(3): 138-144.

Garrigues, S., D. Allard, F. Baret, M. Weiss. 2006. Quantifying spatial heterogeneity at the landscape scale using variogram models. Remote Sensing of Environment 103: $81-96$.

Gerhard, M., and M. Reich. 2000. Restoration of streams with large wood: effects of accumulated and built-in wood on channel morphology, habitat diversity, and aquatic fauna. Internat. Rev. Hydrobiol 85(1): 123-137.

Gooseff, M. N., R. O. Hall Jr., J. L. Tank. 2007. Relating transient storage to channel complexity in streams of varying land use in Jackson Hole, Wyoming. Water Resour. Res 43. W01417.

Goovaerts, P. 1997. Geostatistics for natural resources evaluation. Oxford University Press, New York.

Gurnell, A. M., and R. Sweet. 1998. The distribution of large woody debris accumulations and pools in relation to woodland stream management in a small, low-gradient stream. Earth Surface Processes and Landforms 23: 1101-1121.

Gurnell, A. M., H. Piegay, F. J. Swanson, and S. V. Gregory. 2002. Large wood and fluvial processes. Freshwater Biology 47: 601-619.

Hood, G. A., and S. E. Bayley. 2008. Beaver (Castor canadensis) mitigate the effects of 
climate on the area of open water in boreal wetlands in western Canada. Biological Conservation 141: 556-567.

Isaaks, E. H. and R. M. Srivastava. 1989. Applied Geostatistics. Oxford University Press Kaufmann, P. R., and J. M. Faustini. 2012. Simple measures of channel habitat complexity predict transient hydraulic storage in streams. Hydrobiologia 685: 69-95.

Keller, E. A., and F. J. Swanson. 1979. Effects of large organic material on channel form and fluvial processes. Earth Surface Processes and Landforms 4: 361-380.

Leatherberry, E. C., and J. S. Spencer, Jr. 1996. Michigan forest statistics, 1993. USDA Forest Service Resources Bulletin NC-170.

Legleiter, C. J. 2014a. A geostatistical framework for quantifying the reach-scale spatial structure of river morphology: 1. Variogram models, related metrics, and relation to channel form. Geomorphology 205(4): 65-84.

Legleiter, C. J. 2014b. A geostatistical framework for quantifying the reach-scale spatial structure of river morphology: 2. Application to restored and natural channels. Geomorphology 205(4): 85-101.

Legleiter, C. J., and P. C. Kyriakidis. 2006. Forward and inverse transformations between Cartesian and channel-fitted coordinate systems for meandering rivers. Mathematical Geology 38(8): 927-958.

Legleiter, C. J., and P. C. Kyriakidis. 2008. Spatial prediction of river channel topography by kriging. Earth Surface Processes and Landforms 33(6): 841-867.

Manners, R. B., M. W. Doyle, and M. J. Small. 2007. Structure and hydraulics of natural woody debris jams. Water Resources Reseach 43. W06432.

Martin, D. J. 2001. The influence of geomorphic factors and geographic region on large woody debris loading and fish habitat in Alaska coastal streams. North American Journal of Fisheries Management 21:429-440.

MI-DNR (Michigan Department of Natural Resources). 2018. Michigan forestry best management practices for soil and water quality. Michigan Department of Natural Resources, Lansing, MI.

Montgomery, D. R., J. M. Buffington, R. D. Smith, K. M. Schmidt, and G. Pess. 1995. Pool spacing in forest channels. Water Resources Research 31(4): 1097-1105. 
Oliver, M. A., and R. Webster. 2015. Basic steps in geostatistics: the variogram and kriging. Springer Briefs in Agriculture. Springer Science + Business Media, New York.

Palmer, M. A., C. C. Hakenkamp, and K. Nelson-Baker. 1997. Ecological heterogeneity in streams: why variance matters. J. N. Am. Benthol. Soc. 16(1):189-202.

Palmer, M. A., C. S. Swan. K. Nelson, P. Silver, and R. Alvestad. 2000. Streambed landscapes: evidence that stream invertebrates respond to the type and spatial arrangement of patches. Landscape Ecology 15: 563-576.

Palmer, M. A., H. L. Menninger, and E. Burnhardt. 2010. River restoration, habitat heterogeneity and biodiversity: a failure of theory or practice? Freshwater Biology 55: 205-222.

Poole, G. C., C. A. Frissell, and S. A. Ralph. 1997. In-stream habitat unit classification: inadequacies for monitoring and some consequences for management. Journal of the American Water Resources Association 33(4): 879-896.

Ralph, S. C., G. C. Poole, L. L. Conquest, and R. J. Naiman. 1994. Stream channel morphology and woody debris in logged and unlogged basins of western Washington. Can. J. Fish. Aquat. Sci. 51: 37-51.

Rathbun, S. L. 1998. Spatial modeling in irregularly shaped regions: Kriging estuaries. Environmetrics 9(2): 109-129.

Robison, E. G., and R. L. Beschta. 1990. Coarse woody debris and channel morphology interactions for undisturbed streams in southeast Alaska, U.S.A. Earth Surface Processes and Landforms 15: 149-156.

Roni, P., K. Hanson, and T. Beechie. 2008. Global review of the physical and biological effectiveness of stream habitat rehabilitation techniques. North American Journal of Fisheries Management 28: 856-890.

Roni, P., T. Beechie, G. Pess, and K. Hanson. 2015. Wood placement in river restoration: fact, fiction, and future direction. Can. J. Fish. Aquat. Sci. 72: 466-478.

Schwenner, C. 1991. Soil survey of Houghton County area, Michigan. USDA Soil Conservation Service, Washington, D.C.

Sheldon, F., and M. C. Thoms. 2006. In-channel geomorphic complexity: the key to the 
dynamics of organic matter in large dryland rivers? Geomorphology 77: 270-285.

USDA-NRCS (United States Department of Agriculture Natural Resource Conservation Service). 2008. Otter river rapid watershed assessment resource profile and assessment matrix. $30 \mathrm{pp}$.

VanDusen, P. J., C. J F. Huckins, D. J. Flaspohler. 2005. Associations among selection logging history, brook trout, macroinvertebrates, and habitat in northern Michigan headwater streams. Transactions of the American Fisheries Society 134: 762-774.

Verry, E. S., and C. A. Dolloff. 2000. The challenge of managing for healthy riparian areas. Pages 1-22 in E. S. Verry, J. W. Hornbeck, and C. A. Dolloff, editors. Riparian management in forests of the continental eastern United States. Lewis Publishers, Washington, D.C.

Wentworth, C. K. 1922. A scale of grade and class for clastic sediments. The Journal of Geology 30(5): 377-392.

Wohl, E. 2011. Threshold-induced complex behavior of wood in mountain streams. Geology 39(6): 587-590.

Wohl, E. 2014. A legacy of absence: wood removal in US rivers. Progress in Physical Geography 38(5): 637-663.

Wohl, E. 2016. Spatial heterogeneity as a component of river geomorphic complexity. Progress in Physical Geography 40(4): 598-615.

Wohl, E. 2017. Bridging the gaps: An overview of wood across time and space in diverse rivers. Geomorphology 279: 3-26.

Wolman, M. G. 1954. A method of sampling coarse river-bed material. Transactions of the American Geophysical Union 35(6): 951-956. 